Florida International University

FIU Digital Commons

$11-5-2020$

\title{
The Moderating Effects of Neuroticism and Psychological Contract Incongruence on the Relationship Between Perceived Organizational Support, Perceived Supervisor Support, and Affective Commitment
}

Gail M. Hansen

Florida International University, gmhansen@fiu.edu

Follow this and additional works at: https://digitalcommons.fiu.edu/etd

Part of the Adult and Continuing Education Commons, Organizational Behavior and Theory Commons, and the Training and Development Commons

\section{Recommended Citation}

Hansen, Gail M., "The Moderating Effects of Neuroticism and Psychological Contract Incongruence on the Relationship Between Perceived Organizational Support, Perceived Supervisor Support, and Affective Commitment" (2020). FIU Electronic Theses and Dissertations. 4577.

https://digitalcommons.fiu.edu/etd/4577

This work is brought to you for free and open access by the University Graduate School at FIU Digital Commons. It has been accepted for inclusion in FIU Electronic Theses and Dissertations by an authorized administrator of FIU Digital Commons. For more information, please contact dcc@fiu.edu. 


\section{FLORIDA INTERNATIONAL UNIVERSITY}

Miami, Florida

THE MODERATING EFFECTS OF NEUROTICISM AND PSYCHOLOGICAL CONTRACT INCONGRUENCE ON THE RELATIONSHIP BETWEEN PERCEIVED ORGANIZATIONAL SUPPORT, PERCEIVED SUPERVISOR SUPPORT, AND AFFECTIVE COMMITMENT

A dissertation submitted in partial fulfillment of the requirements for the degree of DOCTOR OF EDUCATION in ADULT EDUCATION AND HUMAN RESOURCE DEVELOPMENT by

Gail Maureen Hansen 
To: Dean Michael R. Heithaus

College of Arts, Sciences and Education

This dissertation, written by Gail Maureen Hansen, and entitled The Moderating Effects of Neuroticism and Psychological Contract Incongruence on the Relationship between Perceived Organizational Support, Perceived Supervisor Support, and Affective Commitment, having been approved in respect to style and intellectual content, is referred to you for judgment.

We have read this dissertation and recommend that it be approved.

Haiying Long

Judith Bernier

Jina Hyejin Bang

Thomas G. Reio, Major Professor

Date of Defense: November 5, 2020

The dissertation of Gail Maureen Hansen is approved.

Dean Michael R. Heithaus College of Arts, Sciences and Education

Andrés G. Gil Vice President for Research and Economic Development And Dean of the University Graduate School

Florida International University, 2020 
(C) Copyright 2020 by Gail Maureen Hansen

All rights reserved. 


\section{DEDICATION}

I dedicate this dissertation to my family: Bill, my husband of 45 years, our grown children, Alan (and his wife Kristin), Jenna, and Alexander, our grandchildren Amelia, Catherine, Erik, future family, and future grandchildren. My love for you fills my heart with joy and pride. By completing a doctorate now, though my life is full, and my career has been rewarding and successful without one, my hope is that this dedication will inspire you to keep creating your own possibilities. Pursue them with optimism and perseverance, at any age. Enjoy the journey.

An additional dedication goes to Dr. Joanne Sanders-Reio, my dear committee member watching from Heaven. 


\section{ACKNOWLEDGMENTS}

To my committee chair: Thank you, Dr. Reio. You first encouraged me to take a class, just to see how I liked it. Then, you encouraged me to enroll in the program. Then, each semester, for five years, you encouraged me to keep going. The world has changed several times in the past years, most profoundly with the loss of Joanne. Throughout the journey, your encouragement kept me putting one foot in front of the other to move forward. This achievement would not have been possible without your support and encouragement.

To my committee members: Thank you for helping me accomplish the mission of a completed dissertation. Thank you, Dr. Long, for believing in me, for sharing your wealth of knowledge, patience, and ability to know when I was freaking myself out.

To the LEAP graduates who participated in the study, thank you for your valuable contribution and for the ways you embody leadership at FIU.

To my Division of Human Resources colleagues, thank you for being a wonderful group of professionals who make working at FIU such a pleasure.

To my team of TAM colleagues, thank you for being such talented and dedicated people. You make me so proud to work alongside each of you. You encouraged me throughout this journey, with admirable toleration, wisdom, and humor.

To my fellow students, thank you for enriching my experience. Salma, you somehow magically appeared every time I was lost.

To El pagnier Hudson, Senior Vice President of Human Resources and Vice Provost of Diversity, Equity, and Inclusion, thank you for your unwavering support and the incredible benefit FIU provides for education and professional development leave. 


\begin{abstract}
OF THE DISSERTATION
THE MODERATING EFFECTS OF NEUROTICISM AND PSYCHOLOGICAL CONTRACT INCONGRUENCE ON THE RELATIONSHIP BETWEEN PERCEIVED

ORGANIZATIONAL SUPPORT, PERCEIVED SUPERVISOR SUPPORT, AND

AFFECTIVE COMMITMENT
\end{abstract}

by

Gail Maureen Hansen

Florida International University, 2020

Miami, Florida

Professor Thomas G. Reio, Major Professor

The nonexperimental study $(N=279)$ investigated the moderating effect of the trait neuroticism and psychological contract incongruence on perceptions about the organization, supervisor, and level of affective commitment. Using Qualtrics, a survey battery was administered to supervisors who had completed leadership training at a single institution of higher education located in southern Florida, USA.

The findings of the present study provided new insights into the neuroticism scale items, suggesting that depression might be a hidden factor in more than half of the population. Another finding demonstrated that few individuals attribute a psychological contract breach to an honest misunderstanding. Nearly half of identified breaches were attributed to intentional reneging. These findings, from a population with positive, significant levels of POS, PSS, and AC, suggest that supervisors and organizations recognize that employees develop unspoken psychological contracts. Providing training for supervisors to improve two-way communication may mitigate unspoken expectations. 


\section{TABLE OF CONTENTS}

CHAPTER

PAGE

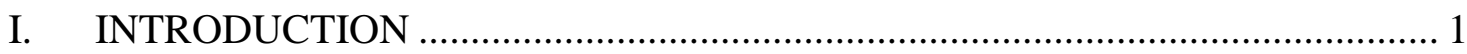

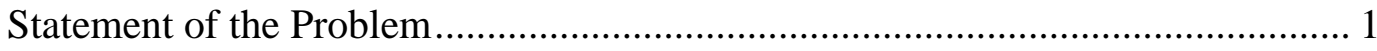

Moderating Effects.......................................................................................... 4

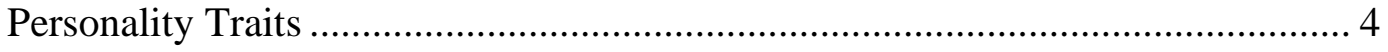

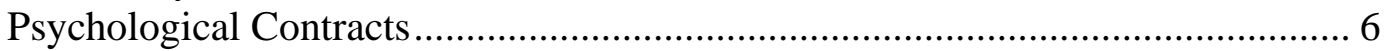

Background to the Problem ............................................................................... 7

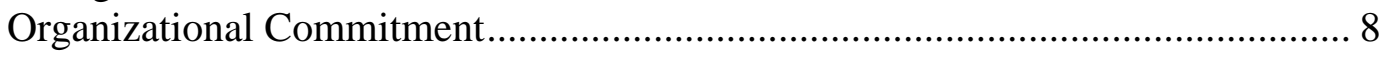

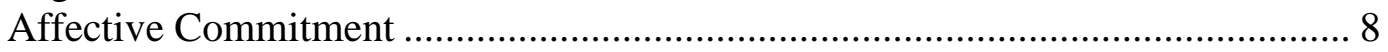

Perceived Organizational Support …………................................................... 9

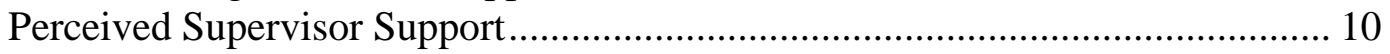

Foundational Constructs …………………................................................. 10

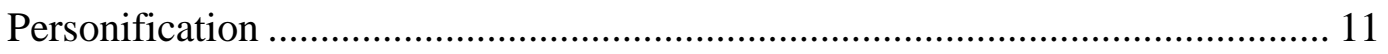

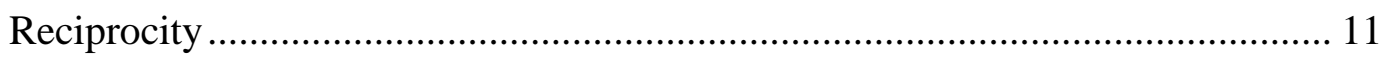

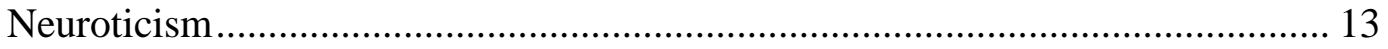

Psychological Contract Incongruence................................................................ 14

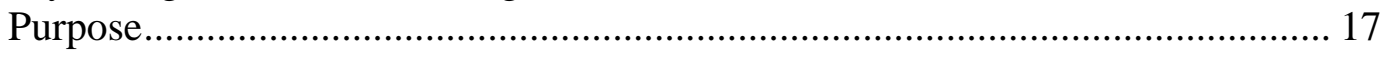

Research Questions and Hypotheses ............................................................ 17

Theoretical Framework .............................................................................. 18

Moderating Variable: Personality Trait Neuroticism .......................................... 20

Moderating Variable: Psychological Contract Incongruence ................................ 20

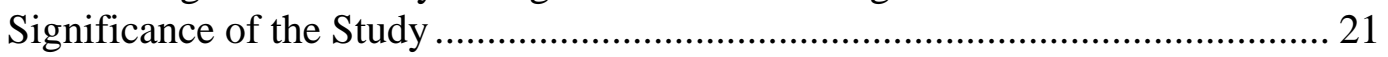

Definition of Key Terms ............................................................................. 24

Assumptions and Delimitations of the Study..................................................... 26

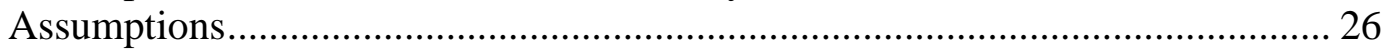

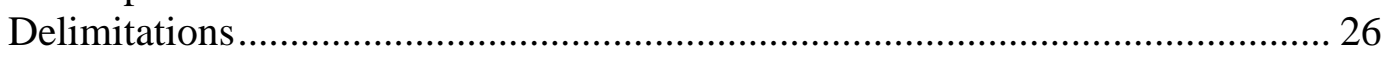

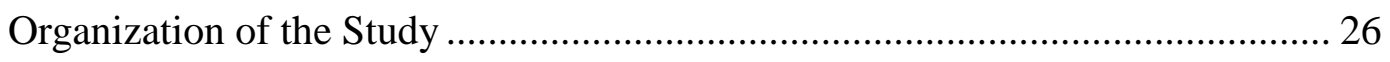

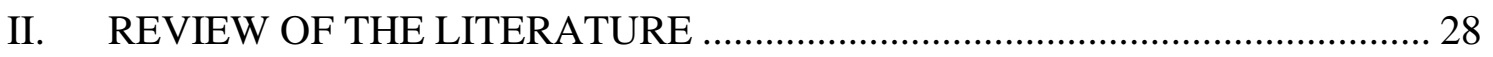

Organizational Commitment....................................................................... 28

Social Exchange Models and Metrics ................................................................. 29

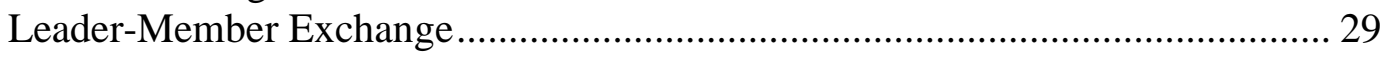

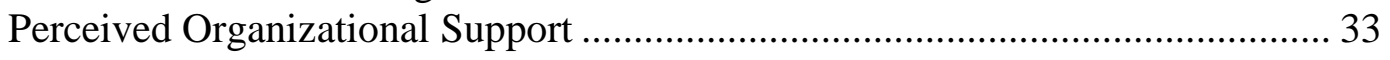

Perceived Supervisory Support........................................................................ 40

Moderating Factors ………………............................................................ 42

Big Five Personality Traits .......................................................................... 42

Measuring Personality Traits .............................................................................. 43

Neuroticism as a Moderator................................................................................. 47

Psychological Contract Incongruence.................................................................. 47

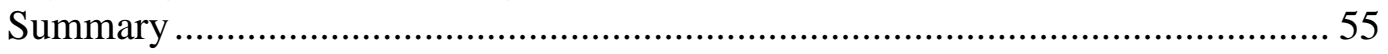

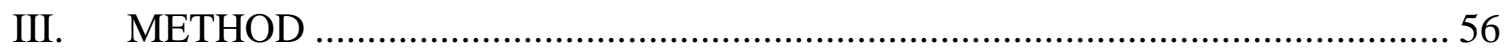

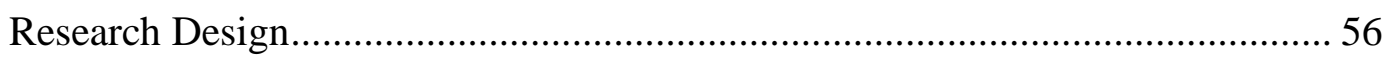


Survey Target Population ........................................................................... 56

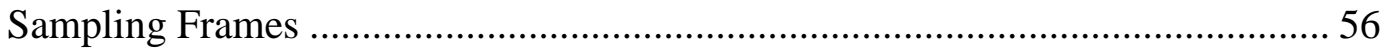

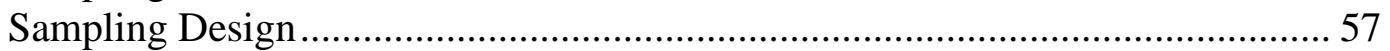

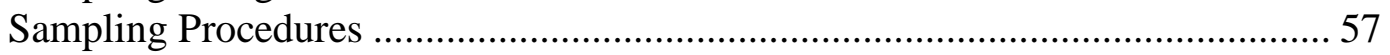

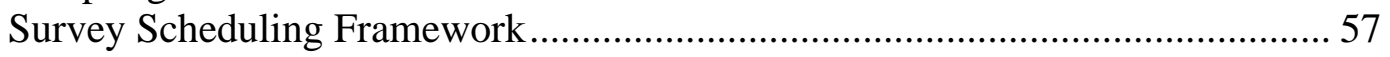

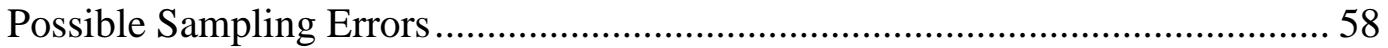

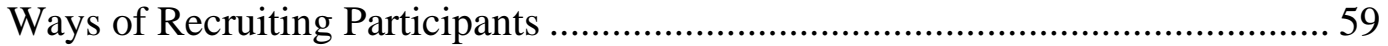

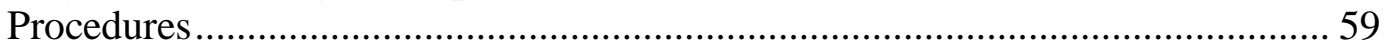

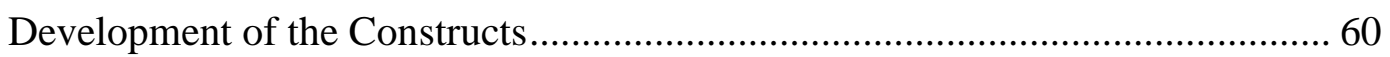

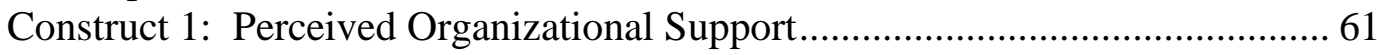

Construct 2: Perceived Supervisor Support .......................................................... 62

Construct 2(a) Adapted Perceived Supervisor Support ....................................... 62

Construct 3: Affective Commitment....................................................................... 63

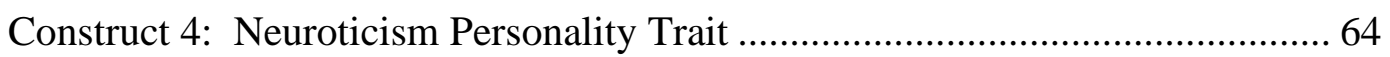

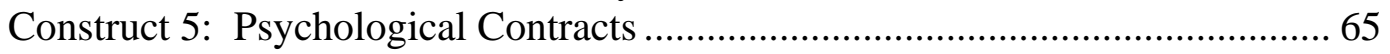

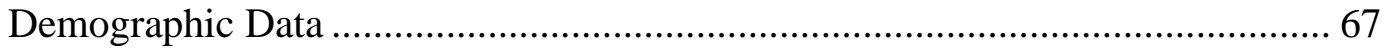

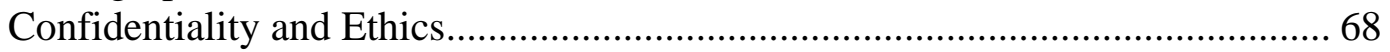

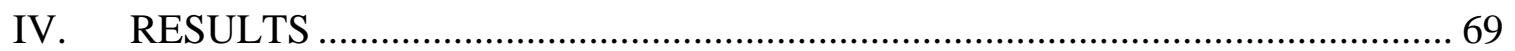

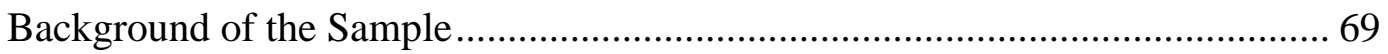

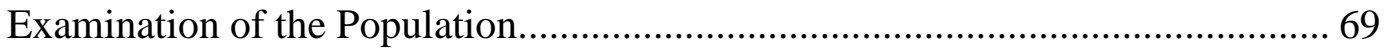

Examination of Questionnaire Items ............................................................. 72

Descriptive Statistics and Scale Reliability ..................................................... 76

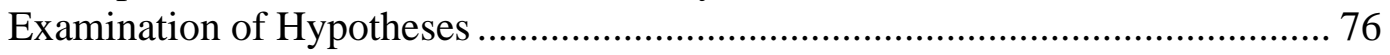

Testing the Research Hypotheses ...................................................................... 78

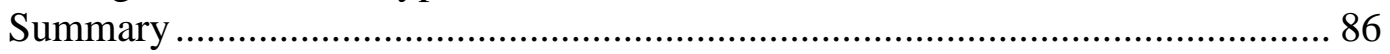

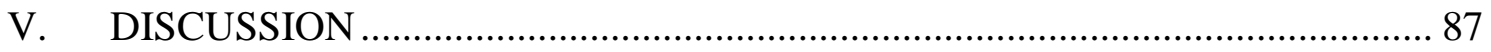

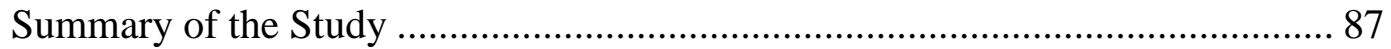

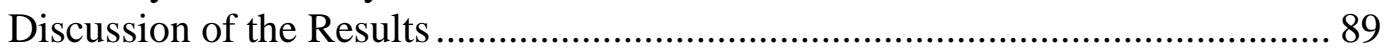

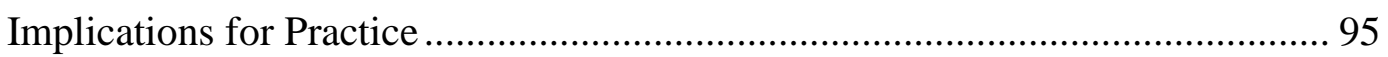

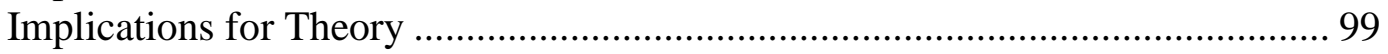

Limitations and Recommendations for Future Research.................................... 101

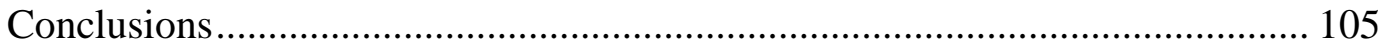

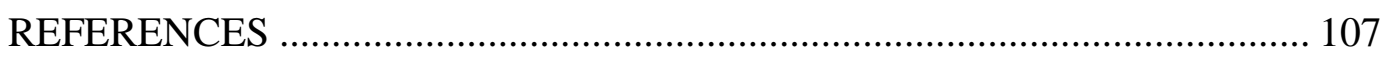

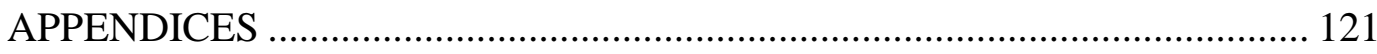

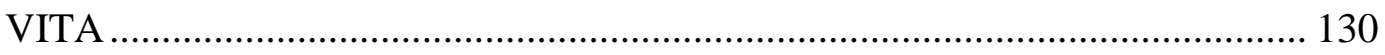




\section{LIST OF TABLES}

TABLE

PAGE

1. Organizational Commitment Questionnaire (OCQ) ...................... 35

2. SPOS 36 Questions in Comparison to OCQ 15 Questions ................. 36

3. Survey of Perceived Supervisory Support (SPSS) 16 Questions .......... 41

4. Correlations among Measures of EPQ-BV and EPQR-S $(N=290) \ldots \ldots \ldots \quad 45$

5. EPQ-BV Items - Extraversion and Neuroticism .................... 45

6. BFI-2-S Negative Emotionality (Neuroticism) ....................... 46

7. Transactional and Relational Contract Perspectives .................... 49

8. $\quad$ SPOS Items Adapted by Coyle-Shapiro and Conway (2005) .............. 53

9. Employee Perceived Employer Obligation Items ...................... 54

10. Constructs and Related Surveys .................................. 61

11. Summary of Adapted SPOS and Adapted SPSS Items ................. 63

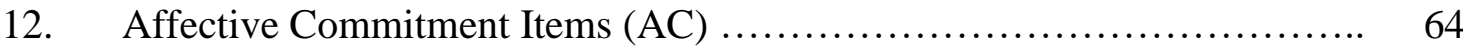

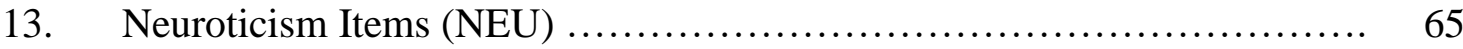

14. Psychological Contract Breach and Attribution Items ................... 67

15. Demographic Questions ......................................... 68

16. Frequency Table of Demographic Variables ........................... 71

17. ANOVA Ethnicity ........................................... 72

18. Item Mean/Standard Deviations of Questionnaire Items ............... 75

19. Scale Reliability Scores, Means/SD of Scales, Skewness, and Kurtosis .... 76

20. Pearson Correlation Coefficients among Variables .................... 79

21. Bivariate and Partial Correlations of Predictors with AC ................ 80

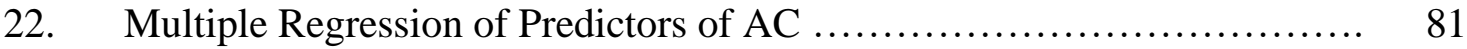




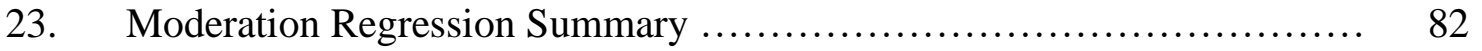

24. Gender and Ethnicity of Reporting Tendency for Depression ............ 92

25. Gender and Ethnicity of Population Reporting Contract Renege .......... 94 


\section{LIST OF FIGURES}

FIGURE

PAGE

1. Conceptual model of the links between perceived organizational support and affective commitment, as moderated by the personality trait of neuroticism and psychological contract incongruence ..................................

2. Conceptual model of the links between perceived supervisor support and affective commitment, as moderated by the personality trait of neuroticism and psychological contract incongruence

3. Moderating Effect of Neuroticism Between POS and AC .................. 83

4. Moderating Effect of Neuroticism Between PSS and AC .................... 84

5. Moderating Effect of Psychological Contract Incongruence (POS and AC ..... 85

6. Moderating Effect of Psychological Contract Incongruence (PSS and AC .... 86

7. Pearson correlations among POS, PSS, and AC $\ldots \ldots \ldots \ldots \ldots \ldots \ldots \ldots \ldots \ldots \ldots \ldots$ 


\section{CHAPTER I}

\section{INTRODUCTION}

The present research explores whether hidden employee factors might be linked to employee feelings of commitment to their employer. Chapter I begins with identifying the background of the problem, the problem statement, the purpose of the study, research questions and hypotheses, and conceptual framework. Chapter I also discusses the significance of the study, delimitations, and definitions of terms. Finally, the chapter closes with the presentation of an organizational support model that will guide the research study.

\section{Statement of the Problem}

An organization's workforce is comprised of individuals with a wide range of personality traits (Costa \& McCrae, 1987), holding a broad array of expectations about their employer. Reflecting such individual differences, employee viewpoints and expectations are, essentially, in the eyes of each beholder. Given these individual factors, do the differences have effects on an employee's perceptions about and loyalty to an employer?

The organizational commitment (OC) field of study seeks to understand the mechanisms that influence the quality and durability of employee-employer relationships. There are three main types of organizational commitment (affective, normative, continuance (Mowday, Porter, \& Steers, 1982). Affective commitment (AC) is the type of organizational commitment described as an emotional bond an employee feels for the organization; that is, a psychological attachment of an employee to the employer (Allen \& Meyer, 1990; Mowday et al., 1982; O’Reilly \& Chatman, 1986). Normative 
commitment $(\mathrm{NC})$, on the other hand, reflects feelings of employee obligation to remain with the employer, and continuance commitment (CC) is associated with an employee's belief that the cost of leaving the employer would be too great (Meyer, Stanley, Jackson, McInnis, Maltin \& Sheppard, 2012).

Although studies support a relationship between the obligation-based NC and positive workforce outcomes, the association of $\mathrm{AC}$ with positive workforce outcomes is greater than that of NC (Meyer \& Parfyonova, 2010). Empirical evidence finds CC to have either a negative or null relationship with positive outcomes such as job performance and organizational citizenship behavior (Meyer et al., 2002). For the present research, AC is examined because empirical studies demonstrate its strong association with important organizational outcomes, e.g., job performance and organizational citizenship behavior (Meyer \& Allen, 1991, 1997).

Further, a significant body of research explores the formation of AC by studying employee perceptions of organizational support (POS) (Conway, 2012; Cotterell, Eisenberger \& Speicher, 1992; Coyle-Shapiro, 2002; Eisenberger, 2001; Eisenberger, Cotterell \& Marvel, 1987; Rousseau, 1989). There is a positive link with POS because of to its clear role in an employee's development of AC, and the association with desirable workplace outcomes such as employee job performance, retention, employee engagement, and prosocial behavior (Eisenberger, Stinglhamber, Vandenberghe, Sucharski \& Rhoades, 2002; Kurtessis, Eisenberger, Ford, Buffardi, Stewart \& Adis, 2017; O’Reilly \& Chatman, 1986).

Within the framework of POS studies, researchers have also explored perceived supervisor support (PSS) as a related and potentially more direct indicator of perceived 
support. Kottke \& Sharafinski (1988) adapted Eisenberger's (1986) POS items to replace the word "organization" with "supervisor," reporting the loading factors of both versions as nearly identical (Kottke \& Sharafinski, 1988, p. 1078). Since the introduction of PSS, numerous studies measuring both POS and PSS have been conducted to explore antecedents and consequences of POS, and to establish PSS as an important and distinct variant of POS. More than a dozen studies provide empirical results clearly showing positive relationships among POS, PSS, and affective commitment (Eisenberger et al., 2002; Eisenberger, Schloss, Karagonlar, Gonzalez-Morales, Wickham \& Buffardi, 2014; Rhoades, Eisenberger \& Armeli, 2001; Shanock \& Eisenberger, 2006; Yoon \& Thye, 2002).

Because of the strong associations with positive employee behaviors and organizational outcomes, understanding how employees perceive both organizational and supervisory support, and develop feelings of affective commitment to their organization are enduring and increasingly important areas of study by scholars in human resource development (HRD), organizational development (OD), and workplace psychology. The literature includes numerous studies of the relationships between POS, PSS, and AC, exploring their distinctions, directionality, causality, similarities of antecedents and consequences (Biggs, Brough \& Barbour, 2014; Buchanan, 1974; Eisenberger et al., 1986; Eisenberger, Fasolo \& Davis-LaMastro, 1990; Klein, Becker \& Meyer, 2012; Kurtessis et al, 2017; Meyer, Becker \& Van Dick, 2006; Rhodes, Eisenberger \& Arneli, 2001; Shore \& Tetrick, 1991; Shore \& Wayne, 1993; Shuck, Reio \& Rocco, 2011). An abundance of evidence supports the critical role of POS in the development of AC. 


\section{Moderating Effects}

Studies have also examined moderating effects of a wide range of factors on the relationships among POS, PSS and AC. Examples of employee perceptions tested as moderators of AC include: perception of organizational competence (POC) (Kim, Eisenberger \& Baik, 2016), the quality of leader-member exchange relationship (LMX) with the supervisor Liden \& Maslyn, 1998), job autonomy (Armeli, Eisenberger, Fasolo \& Lynch, 1998), perceived supervisor prestige (Smidtx, Pruyn \& van Riel, 2001), and trust (Eisenberger et al., 2014; Kim, Eisenberger, \& Baik, 2016).

Eisenberger, Cotterell \& Marvel (1987) examined an intriguing moderating factor, reciprocation wariness. Reciprocation wariness has been described in studies as an individual's feeling of distrust, fear of being exploited in an exchange, tendency towards weakened interpersonal relationships, and generally lower expectations of a fair reciprocal exchange (Cotterell \& Eisenberger, 1992; Cottrell \& Marvel, 1987; Shore, Bommer, Rao \& Seo, 2009). These studies of moderating negative employee perceptions have implications for further research to test whether negativity associated with reciprocity wariness might instead, or also, be indicative of personality traits or psychological contracts.

\section{Personality Traits}

To study workforce dynamics, scholars and HRD professionals must consider the role of individual differences in personality traits. Using the framework of personality trait theory, scholars have developed empirical data to support definition of the five most common personality traits, referred to as the five-factor model or the Big Five. The Big Five personality traits are Openness, Conscientiousness, Extraversion, Agreeableness, 
and Neuroticism (Barrick \& Mount, 1991; Barrick, Mount, \& Gupta, 2003; Barrick, Parks, \& Mount, 2005; Costa \& McCrae, 1995; Judge \& Zapata, 2015).

Studies have suggested that personality traits have the potential to moderate the relationships among research variables. For example, Bowling \& Eschleman (2010) explored the moderating effect of Big Five personality traits on workplace stressors and negative behaviors such as sabotage, theft, and absenteeism. The study found that the personality traits of conscientiousness and agreeableness dampened the relationship between work stressors and counterproductive work behaviors (CWB). Additionally, the study determined that a personality trait they called negative affectivity, abbreviated as NA, strengthened the relationship between work stressors and CWBs. Bowling \& Eschleman (2010) defined the trait NA as the negative emotions experienced as a result of work stressors, and described the similarity of NA to the personality trait of neuroticism as defined by Watson \& Clark (1984).

The personality trait of neuroticism is examined independently of the other four traits in the Big Five because it is the trait associated with the dampening of an individual's feelings of well-being (Judge \& Bono, 2001). Judge \& Bono (2001) identified a tendency for individuals with high levels of neuroticism to self-select into negative situations and then view the outcomes through the lens of negativity (Judge \& Bono, 2001). A study by Van Hiel, De Cremer \& Stouton (2008) found that, of the Big Five traits, neuroticism alone demonstrated a significant moderating effect with procedural fairness, $F(1,167)=4.00, p<.05, n^{2}=.02$ (Van Hiel et al., 2008, p. 532). Informed by Van Hiel et al.'s (2008) study, Ohana (2016) selected neuroticism, also 
excluding the other four traits, in a study of moderating effects on the relationship between affective commitment, voice, and citizenship behaviors.

A deeper exploration of the moderating effects of high levels of neuroticism is particularly relevant because research clearly shows the association of low levels of the trait with employee perceptions of well-being and positive organizational experiences (Allen \& Meyer, 1990; Eysenck, S.B, Eysenck, H.J. \& Barrett, 1985; Judge, Heller \& Mount, 2002; Ozer \& Benet-Martinez, 2006; Panaccio \& Vandenberghe (2012).

\section{Psychological Contracts}

Rousseau (1998) explains that "a psychological contract is an individual perception," and cautions researchers to clearly differentiate psychological contracts from the broader concept of expectations (Rousseau \& Tijoriwala, 1998, p. 680). The researchers explain the value of studying psychological contracts instead of general expectations in that perceived contract violations engender more intense emotional reactions than do generally unmet expectations (Rousseau, 1989,1998; Robinson, 1996).

Psychological contract theory, within the social exchange framework, describes tacit employee-employer expectations of a fair exchange of work for something of value to the employee (Aselage \& Eisenberger, 2003; Coyle-Shapiro \& Kessler, 2000; Rousseau, 1998, 2011). When a psychological contract is formed by an employee, there are two potential outcomes: psychological contract fulfillment or breach, representing opposite ends of an employee's perceptions of whether the employer fulfilled expectations or not (Zhao et al., 2007). When these contractual expectations are unspoken, there is an increased risk of employee-employer exchange misunderstandings; additionally, the degree of congruence or incongruence of employee-employer 
expectations contributes to an employee's perception of being valued by the employer (Eisenberger et al., 2002).

The present study examines two moderator variables associated with negativity. The negative emotions of unmet psychological contracts and the negative interpretations associated with neuroticism offer promising research variables for the present study. There is a gap in the literature for empirical data regarding how an employee's personality and psychological contract exchange expectations might increase or dampen the relationships between POS and PSS and AC.

By examining each of these two moderating variables, the present study will contribute to the field of HRD through (a) enrichment of organizational support theory, (b) empirical findings for use by scholars in new research, (c) practical information that would bridge a gap in the literature, and (d) provide insight into how management might adapt organizational policies and practices to provide a supportive environment for all employees and to cultivate psychological contract congruence to encourage greater organizational commitment.

\section{Background to the Problem}

To provide background to the study, the following sections will begin with an overview of organizational commitment, followed by a discussion of affective commitment, the present study's dependent variable. I then explain the independent variables, perceived organizational support and perceived supervisor support, and discuss the foundational mechanisms through which employees develop perceptions. Finally, this section describes the two moderating variables examined in the present study: the 
personality trait of neuroticism and the phenomenon of psychological contract incongruence.

\section{Organizational Commitment}

Mowday, Porter \& Steers (1979) developed the Organizational Commitment Questionnaire (OCQ) as a scale to measure organizational commitment. Studies supported the relationship of mutually beneficial exchange with increased affective commitment of employees and positive employer perceptions (Buchanan, 1974; Steers, 1977; Cook \& Wall, 1980; Hrebiniak, 1974). Studies using the OCQ indicated that higher scores in affective attachment "reflect an unwillingness to leave the organization, in spite of inducements to do so," resulting in reduced employee withdrawal behavior (Meyer \& Allen, 1984, p.3; Mowday et al., 1979).

As OC studies examined factors in the formation of commitment, Meyer \& Allen (1991) posited three forms of commitment: continuance, normative, and affective. Continuance commitment (CC) is described as an employee's perceived financial need and belief that the cost of leaving an employer to be prohibitive. Normative commitment (NC) represents feelings of obligation to remain with an employer. Affective commitment (AC) describes emotional bonds or psychological attachment an employee feels for an organization (Meyer \& Allen, 1991; O’Reilly \& Chatman, 1986).

\section{Affective Commitment}

Studies clearly associate AC, the dependent variable in this research, with employees' feelings of belonging and identification with their organization (Mowday et al., 1979; Porter, Steers, Mowday \& Boulian, 1974). Employers increasingly rely upon HRD-related practices to build AC and reduce employee withdrawal behaviors 
(Eisenberger \& Stinglhamber, 2011; Shuck, Twyford, Reio \& Shuck, 2014). Mercurio (2015) reported an intensification of organizational calls for HRD practices to enhance AC. Researchers also suggest that organizations increasingly view low AC as a strategic threat to their workforce stability and growth potential, and organizations look to HRD scholars and professionals for programs and interventions to increase AC (Clothier, Felusiak \& Pemberton-Jones, 2015: Mercurio, 2015).

\section{Perceived Organizational Support}

Perceived organizational support is the first independent variable of the present study. As described previously, Mowday et al.’s (1979) OCQ measured employee feelings about an organization. Eisenberger, Huntington, Hutchison \& Sowa (1986) proposed a new scale to measure employee perceptions about the level of support they received from the organization, hypothesizing that employees who felt supported would, in turn, develop positive feelings about the organization, and, further, that resulting improvements would occur in work behaviors.

Eisenberger et al., (1986) developed the Survey of Perceived Organizational Support (SPOS), a scale for measurement of employee perceptions. A meta-analysis of organizational support theory by Kurtessis et al. (2017) identified 496 papers, containing 558 studies using the SPOS. The meta-analysis reported that organizational support theory (OST) was an effective framework for studying antecedents of POS, e.g., leadership, employee-organizational context, human resource practices, and working conditions; OST is also an effective model for studying the consequences of POS, e.g., employee's orientation towards the organization and work, employee performance, and well-being (Kurtessis et al., 2017). 


\section{Perceived Supervisor Support}

The second independent variable in the present study is perceived supervisor support (PSS). As with POS, employees develop beliefs about their organization; with PSS, employees view supervisors as agents of the organization, experiencing the employee-employer exchange relationship through the supervisor. Studies establish that POS is influenced by the employee's perception of their supervisor's support through HRD practices and treatments, e.g., performance evaluations, pay increases, professional development opportunities, and feedback (Eisenberger et al, 2002; Kottke \& Sharafinski, 1988; Rhoades et al, 2001; Shanock \& Eisenberger, 2006; Stinglhamber \& Vandenberghe, 2003). Research supports the positive relationship between PSS and work performance and negative relationship with turnover (Eisenberger et al., 2002).

\section{Foundational Constructs}

Within the social exchange theoretical framework, there are multiple lenses through which researchers explore affective commitment, perceived organizational support, and perceived supervisor support. It is important to understand two foundational constructs underlying employee-employer exchanges and perceptions: personification and reciprocity. Each of these constructs is relevant to the present study of the relationship between perceived organizational support, perceived supervisor support, and affective commitment. In particular, the construct of personification is foundational for considering the moderating variable of neuroticism. The construct of reciprocity is foundational for considering the moderating variable of psychological contract incongruence. 


\section{Personification}

A construct used to better understand employee-employer perceptions and expectations is the phenomenon of personification. Personification occurs when an employee projects, or attributes, human traits (e.g., personality traits) and anthropomorphic qualities to the organizations, e.g., referring to their employers as good or bad, caring or cold (Eisenberger et al., 1986). Levinson (1965) (as cited in Levinson (2009) suggested that employees may develop these personifications through observations of three elements in their organization: the actions of its people, its policies, processes, and traditions, and its use of power (Levinson, 2009). The present study seeks to better understand the possible moderating effect of neuroticism to the employee's perceptions of support and development of commitment. As described earlier, the trait of neuroticism is associated with the tendency to perceive situations and workplace outcomes through a negative lens (Judge \& Bono, 2001).

Reciprocity

The concept of reciprocity appears throughout commitment literature as a central concept underlying mutual expectations held by employees and employers (Blau, 1964; Conway, 2012; Cotterell, Eisenberger \& Speicher, 1992; Coyle-Shapiro, 2002;

Eisenberger, 2001; Eisenberger, Cotterell \& Marvel, 1987; Rousseau, 1989). These mutual expectations may be consistent between the employee and employer, or they may be incongruent.

To clarify and codify these expectations, some organizations document them formally using HRD systems and practices, e.g., job descriptions, performance appraisals, employment contracts, or collective bargaining agreements (Eisenberger \& Stinglhamber, 
2011). However, employee-employer expectations are often undocumented; in fact, it is not uncommon for these expectations to remain as unspoken assumptions, forming psychological contracts (Aselage \& Eisenberger, 2003). The congruence of expectations between employees and employers, through the norm of reciprocity, contributes to employees' perceptions of whether they are valued as people and workers by their organization values (Eisenberger \& Stinglhamber, 2011).

The concept of reciprocity is evident throughout history, across cultures (Eisenberger \& Stinglhamber, 2011). Reciprocity, or quid pro quo, is the expectation of some form of repayment in an exchange between people (Gouldner, 1960). The norm of reciprocity also has deep philosophical roots. Scottish economist and philosopher Adam Smith published The Theory of Moral Sentiments (1759), in which he compared two virtues: Justice and Beneficence. Even Smith's (1759) description of two virtues clearly attributes of human traits of justice and beneficence, suggesting an early reflection on both the economic and emotional aspects of reciprocity. Reciprocity continues to serve as a cornerstone of organizational commitment research. For example, Gouldner's (1960) research summarized the norm of reciprocity to be that people will (and should) help those who have helped them.

The importance of an exchange having mutual benefits between the parties was illustrated by Blau's (1964) observation that, when an employer uses power in ways perceived as unfair, workers may join forces and retaliate, reinforcing Smith's (1759) prognostication. Blau (1964) also noted that, when employees bond together, their combined power can destabilize an organization. The U.S. history of labor organization and collective bargaining further validates the power of a workforce united in opposition 
of perceived injustices (Carrell \& Heavrin, 2008). The relevance of reciprocity to perceptions of inequities is essential to the present study's exploration of psychological contract incongruence as a moderating variable.

\section{Neuroticism}

Neuroticism is the personality trait selected for the present study. Judge \& Bono (2001) define neuroticism as a dampening of an individual's feelings of well-being, and the tendency for individuals with high levels of the neuroticism trait to self-select into negative situations and then experience the outcomes through a negative lens (Judge \& Bono, 2001). In contrast, other studies describe individuals with low levels of the neuroticism trait in terms of emotional stability, associating low levels of neuroticism with tendencies to seek positive environments and handles stress with more equanimity (Eysenck, 1990).

Researchers have found that employees high in neuroticism demonstrate a tendency to engage in either unsatisfying or stressful situations, perhaps mediating job satisfaction (Judge, Heller, \& Mount, 2002). Studies of neuroticism have found employees who report low levels of well-being also measure high in the trait of neuroticism (Ozer, \& Benet-Martinez, 2006). Panaccio \& Vandenberghe (2012) suggested that those high in the neuroticism trait tend to exhibit counterproductive work behavior (CWB), such as conflicting with coworkers and supervisors and being more socially isolated within the organization. Other studies have defined employee commitment as the psychological attachment of employees to their employers (Allen \& Meyer, 1990; O'Reilly \& Chatman, 1986). On the basis of the associations of neuroticism with employee perceptions of well-being and positive organizational experiences, the 
study intends to explore whether high levels of neuroticism have a moderating effect on the relationship between perceived organizational support and affective organizational commitment. It will also explore whether employees high in the trait of neuroticism tend to attribute breaches of psychological contracts to incongruence and not to reneging. Psychological Contract Incongruence

The present study explores a second moderating variable, psychological contract incongruence. Through the additional social exchange theory known as psychological contract theory, the present study will explore whether employees high in the trait of neuroticism tend to perceive more unintentional breaches than fulfillments of psychological contracts.

As previously discussed, the norm of reciprocity is an underlying mechanism in the formation of employee and employer expectations, thus forming psychological contracts (Aselage \& Eisenberger, 2003). When expectations are unspoken, there is an increased risk of employee-employer exchange misunderstandings (Eisenberger, 2011). The degree of congruence or incongruence of expectations between employees and employers contributes to employees' perceptions of how valued they are by their employer (Eisenberger, 2011).

Zhao (2007) explained psychological contract fulfillment (PCF) and psychological contract breach (PCB) to represent opposite ends of an employee's perceptions of whether the employer fulfilled expectations or not (Zhao et al., 2007). Conway \& Coyle-Shapiro (2012) studied six reciprocal relationships among psychological contract fulfillment, POS, and employee performance, and reported positive relationships in five. Morrison \& Robinson (1997) explored the factors 
underlying a psychological contract violation and introduced a conceptual model of how an employee considers an unmet expectation. Contract breaches are distinguished as either reneging, disruption, or incongruence. Reneging is defined as an unwillingness to fulfill a known expectation; disruption is explained as the emergence of circumstances that prevent the fulfillment of the obligation; incongruence represents a failure to fulfill an unknown expectation (Morrison \& Robinson, 1997).

Some researchers examined incongruence by measuring employee and employer responses to specific examples of contracts, or inducements. Inducements were defined in three categories of benefits identified as valued by employees yet not typically specified in employment contracts: (a) commitments to employees such as guaranteed job security, salary increases, and opportunities to voice their opinions, (b) career growth pathways and development through training, and (c) performance rewards such as special recognition or a spot bonus (Porter, Pearce, Tripoli \& Lewis, 1998). Studies to measure differences in perception between the employee and employer offer the benefits of quantifying incongruence yet present challenges such as determining who should respond on behalf of the organization and what inducements should be measured. Overall, Porter et al. (1998) found that employees expect significantly more inducements than employers knew were offered.

To focus on the individual employee's perception, the present study incorporates Morrison's (1998) organizing framework for measuring psychological contracts and approaching the more elusive incongruence. The only possible source for information regarding a psychological contract is the individual who formed the perception (Morrison, 1998). Numerous studies have measured employee perceptions through the 
lens of perceived organizational support (POS), and identified POS elements that serve as general indicators of psychological contract fulfillment (Barksdale \& Shore, 1997; Guzzo \& Berman, 1995).

Researchers have called for additional studies of employers taking steps to understand the employees' views of psychological contracts, suggesting that recognition of incongruence could inform any needed clarifications or even alterations of the terms (Conway \& Coyle-Shapiro, 2012). Morrison (1998) suggests enriching the POS assessment with items measuring perceived promises fulfilled or violated and discern whether the employee perceives the breach to be a clear breaking of a promise or could be attributed to a misunderstanding (Morrison \& Tijoriwala. 1998).

A study of these relationships will contribute to the literature and to the HRD field through enrichment of organizational support theory and fill a knowledge gap in the degree to which perceived organizational support and organizational commitment are associated. Further, empirical findings related to the moderating effects of individual traits and psychological contract incongruence on the on the relationship between perceived support and organizational commitment may fill gaps in our empirical knowledge. In addition, the research could provide insight into how management might adapt organizational policies and practices to provide a more supportive environment for all employees and cultivate psychological contract congruence to encourage greater organizational commitment. 


\section{Purpose}

Inasmuch as we need to advance social exchange theory and increase our understandings about how POS, PSS, and AC are linked, the purpose of this empirical research is to examine the relationship between POS, PSS, and AC and investigate the possible moderating effects of (a) neuroticism and (b) psychological contract incongruence between an employee and employer. It may be that each of the two moderating variables dampen the relationship between POS, PSS, and AC, but this has not been investigated sufficiently.

\section{Research Questions and Hypotheses}

There are three questions guiding this study: (a) What is the relationship between perceived organizational support, perceived supervisor support, neuroticism, psychological contract incongruence, and affective commitment? (b) Does neuroticism moderate the relationships between POS, PSS, and AC? (c) Does psychological contract incongruence moderate the relationship between POS, PSS, and AC?

To explore these research questions, three hypotheses will be tested.

Research question 1: What is the relationship between perceived organizational support, perceived supervisor support, neuroticism, psychological contract incongruence, and affective commitment?

$\mathrm{H}_{1}$ : Perceived organizational support, perceived supervisor support, neuroticism, psychological contract incongruence, and affective commitment are significantly related. Research question 2: Does neuroticism moderate the relationship between POS, PSS, and $\mathrm{AC}$ ? 
$\mathrm{H}_{2}$ : Neuroticism will significantly moderate the relationship between POS and AC and PSS and AC, such that the relationships will be weakened.

Research question 3: Does psychological contract incongruence moderate the relationship between POS, PSS, and AC?

$\mathrm{H}_{3}$ : Psychological contract incongruence will significantly moderate the relationship between POS and AC and PSS and AC, such that the relationships will be weakened.

\section{Theoretical Framework}

The social exchange theoretical framework provides an overarching construct for multiple theories used to explore employee-employer relationships and exchanges (Cropanzano \& Mitchell, 2005). Social exchange theory was described by Blau (1964) as the exchange of work performed by an employee, with an expectation of receiving something in return from the employer. To incorporate the exchange theories underlying the independent, dependent, and moderating variables, several exchange theories were examined: organizational commitment theory, organizational support theory, personality trait theory, and psychological contract theory.

Early scholars describe organizational commitment theory in terms of employees' feelings of belonging and identification with their organization (Mowday, Steers, \& Porter, 1979; Porter, Steers, Mowday \& Boulian, 1974).

Eisenberger et al. (1986) hypothesized that employees' perceptions would test the exchange theory of organizational commitment in a new way. The SPOS was developed to measure employee perceptions (Eisenberger et al., 1986) and the instrument is widely used to the present day (Kurtessis et al., 2017). A related study adapted items from the SPOS to create a Survey of Perceived Supervisor Support (SPSS; Kottke \& Sharafinski, 
1988). Empirical results suggest that the supervisor may be perceived as an agent of the organization and is the primary other party in the exchange relationship (Dysvik, 2012; Eisenberger et al., 2002; Guchait, Cho, Seonghee \& Meurs, 2015; Kottke \& Sharafinski, 1988; Shanock \& Eisenberger, 2006; Shoss, Eisenberger, Restubog, Simon, Zagenczyk, 2013). Employee-employer exchange relationship items in the present study are informed by the SPOS (Eisenberger et al., 1989) and the SPSS (Kottke \& Sharafinski, 1988).

Additional studies of POS, PSS, and AC evolved the lens of organizational support theory (OST), which discusses the emotional bonds and feelings of loyalty that employees develop for their organization (Eisenberger et al., 1986; Rhoades, Eisenberger, \& Arneli, 2001; Shore \& Shore, 1995). Though POS and AC are related, empirical results clearly show they are distinct constructs (Eisenberger, Fasolo, \& Davis-LaMastro, 1990; Shore \& Tetrick, 1991; Shore \& Wayne, 1993; Wayne, Shore, \& Liden, 1997).

The present study follows the recommendation of Shanock \& Eisenberger (2006) for exploring POS and PSS "using six items from the short form of the Survey of Perceived Organizational Support (Items 1, 4, 9, 20, 23, and 27; factor loadings from .71 to .84; Eisenberger et al., 1986)" (Shanock \& Eisenberger, 2006, p. 691). To measure perceived supervisor support, the present study follows the recommendation of Shanock \& Eisenberger (2006) to "use the same six items used to assess POS, as modified by using the word supervisor in place of the word organization" (Shanock \& Eisenberger, 2006, p. 691). All items measuring POS and PSS use a 7-point Likert scale, consistent with Eisenberger et al. (2002). 
The following sections discuss the theoretical frameworks relevant to this study's moderating variables: the personality trait neuroticism and psychological contract incongruence.

\section{Moderating Variable: Personality Trait Neuroticism}

In the present study, the first of the factors tested the moderating effects of the personality trait neuroticism. The hypotheses exploring neuroticism are guided by personality trait theory (Eysenck, S.B. \& Eysenck, H.J., 1964), and the five-factor personality trait framework as tested by Panaccio \& Vandenberghe's (2012) to explore relationships between the Big Five and organizational commitment. The theoretical lens of personality traits can help to better understand whether an employee's commitment to an employer is dampened by an individual's propensity to attribute negative intentions or to perceive an exchange to be lacking (Erdheim, Wang \& Zickar, 2006).

\section{Moderating Variable: Psychological Contract Incongruence}

Another lens in the social exchange spectrum is psychological contract theory, a construct for studying the beliefs formed by an individual about an anticipated exchange (Conway et al., 2012; Coyle-Shapiro, Pereira, Doden \& Chang, 2019; Eckerd, Hill, Boyer, Donahue \& Ward, 2013; Guchait et al, 2015; Harrington \& Lee, 2014; Jafri, 2014; Robinson, 1996; Rousseau, 1989). Conway \& Coyle-Shapiro (2012) describe psychological contract theory as a framework to understand often unspoken expectations held by both employees and employers in an exchange relationship, viewing employee commitment as transactional in nature and based primarily on factors such as pay and opportunities for promotion (Etzioni, 1961; Gould, 1979; March \& Simon, 1958). 
While strongly related to organizational support theory, psychological contract theory recognizes a distinct construct, measuring a different form of exchange (Aselage \& Eisenberger, 2003; Coyle-Shapiro \& Kessler, 2000). Aselage \& Eisenberger (2003) describe organizational support theory as the overall favorable treatment of employees and psychological contract theory in terms of promises made to a specific employee. For example, if employees are offered a generally available benefit such as a training program for supervisors, its availability illustrates organizational support. However, if an employee asks to attend that training program, the supervisor's response, whether it's a vague comment about considering the request, or a clear approval, creates a psychological contract (Aselage \& Eisenberger, 2003).

Psychological contract theory is the most appropriate framework for testing psychological contract incongruence, the perceived differences between the employee and employer of the terms of the psychological contract. Items selected for the present study are informed by Robinson \& Morrison (2000) and Lester, Turnley, Bloodgood \& Bolino (2002). In summary, the present study builds upon the broad framework of social exchange theories and employs multiple constructs.

\section{Significance of the Study}

The present study advances Eisenberger's (2011) organizational support theory by exploring whether two hidden factors moderate how an employee thinks about their employer and supervisor, and whether they strengthen or dampen loyalty to the organization. The study hypothesizes that both neuroticism and psychological contract incongruence will dampen the relationship between organizational support, supervisor support, and affective commitment. Looking closely at interactions of the two 
independent variables and two moderators might offer new insights to underlying mechanisms in the employee-employer exchange relationship.

The conceptual models in the present study in Figure 1 and Figure 2 suggest a potential framework and scale for studies of other AC-related dependent variables such as job satisfaction, employee engagement, retention, and performance management. While the present study focuses on AC, future research is suggested to explore these moderating variables on the other types of organizational commitment, normative and continuance.

There are also practical reasons to study the possible effects of neuroticism and incongruence of psychological contracts. From an HRD practitioner's standpoint, recognizing that hidden factors may moderate employee perceptions may offer new insights into organizational practices (Panaccio \& Vandenberghe, 2012). Panaccio \& Vandenberghe (2012) suggested that organizations be willing to adapt programs in ways that can appeal to varying levels of personality traits and recommended HRD professionals design systems and processes with personality differences in mind. For example, Panaccio \& Vandenberghe (2012) noted that individuals having a high level of neuroticism might benefit from coaching and reassurance by supervisors to offer them a more positive perspective in the workplace. 


\section{Figure 1.}

Conceptual model of the links between perceived organizational support and affective commitment, as moderated by the personality trait of neuroticism and psychological contract incongruence.
Independent
Moderating
Dependent
Variables
Variables
Variable

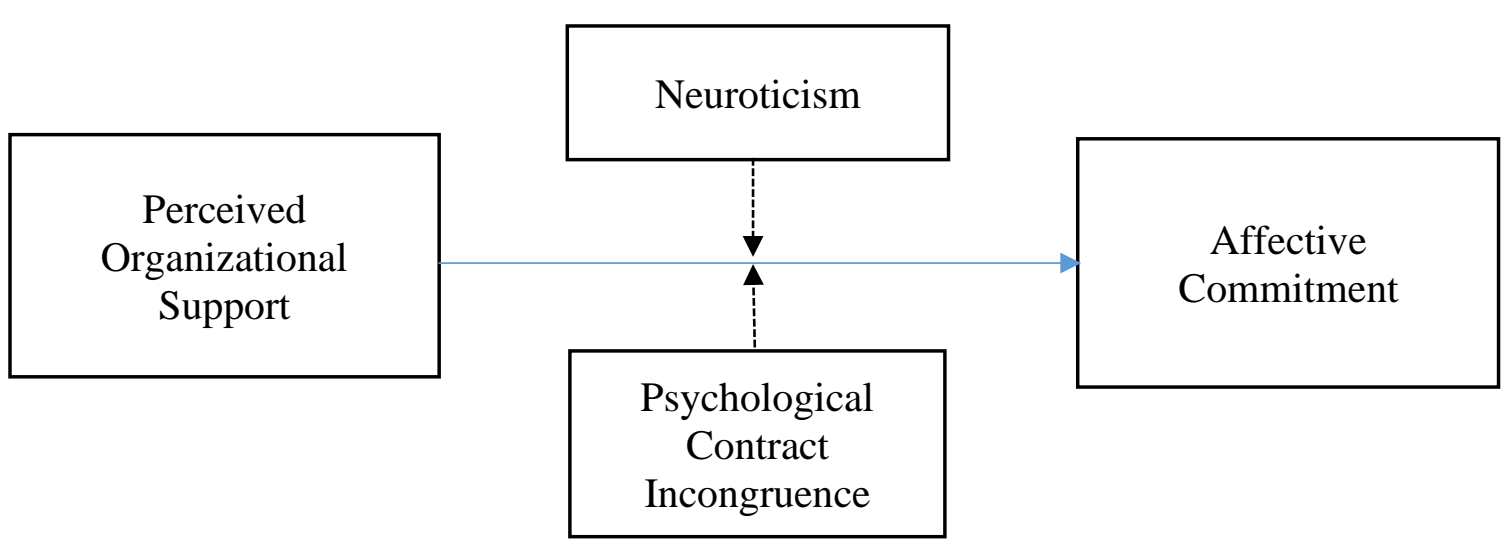

Figure 2.

Conceptual model of the links between perceived supervisor support and affective commitment, as moderated by the personality trait of neuroticism and psychological contract incongruence.

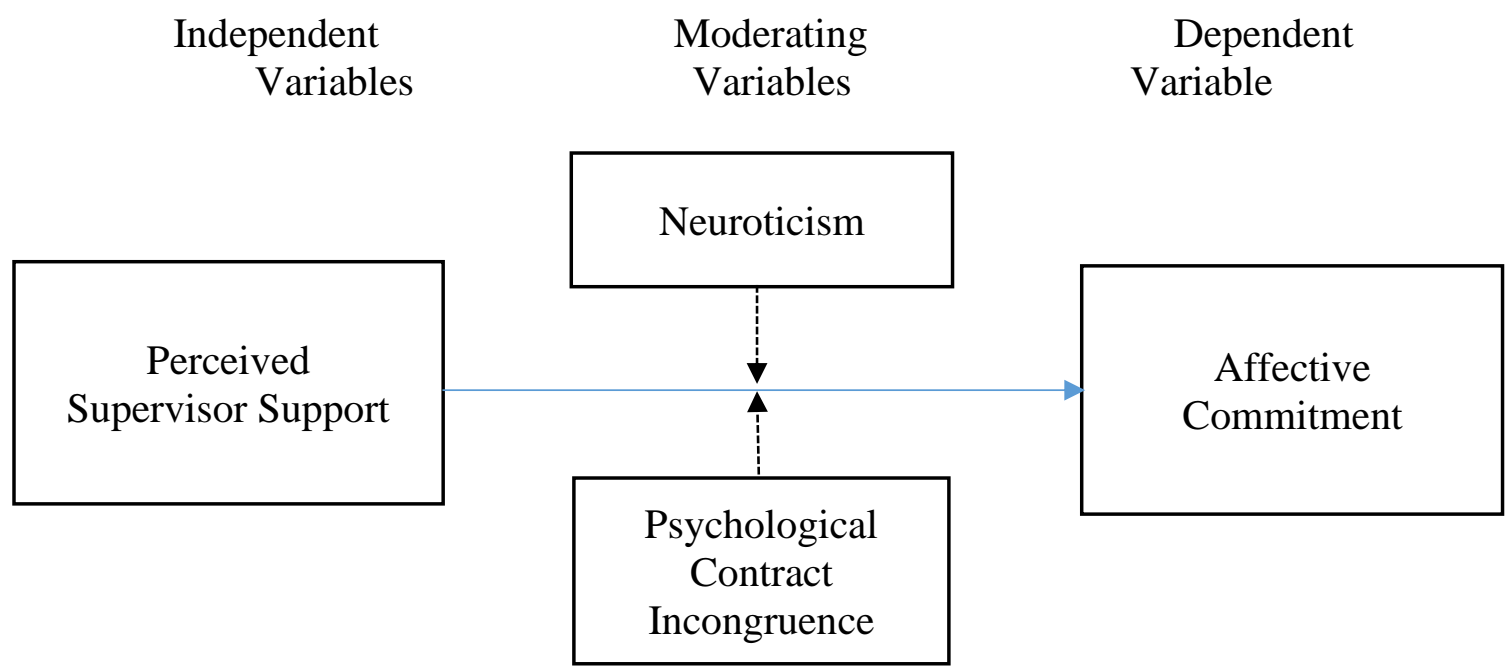




\section{Definition of Key Terms}

Affective Commitment: One of three forms of commitment, affective commitment describes an emotional bond with an organization (Eisenberger \& Stinglhamber, 2011).

Big Five: This phrase is used to describe five primary personality traits considered to be primary: Extraversion, Emotional Stability, Agreeableness, Conscientiousness, and Openness to Experience (Barrick \& Mount, 1991).

Emotional stability: This phrase the negative expression of the trait of Emotional Stability is defined as neuroticism (Barrick \& Mount, 1991; Costa \& McCrae, 1995).

Expectations: In the context of this study, this term represents an employee's general views about the job and does not reflect a clearly define exchange in the individual's cognition and is distinctly different than a psychological contract (Rousseau, 1998).

Leader-member exchange (LMX): This phrase is used to describe the perceptions developed by employees about their supervisor and organization through a transactional or economic lens (Graen \& Uhl-Bien, 1995; Wayne, Shore \& Liden, 1997; Wayne et al., 2002).

Neuroticism: This term is defined as "diminished subjective well-being because neurotic individuals are more likely to choose situations in which they experience negative affect" (Judge \& Bono, 2001, p. 84). The term neuroticism is utilized by researchers to represent the converse of the trait Emotional Stability (Eysenck, Eysenck \& Barrett, 1985).

Negative emotionality: Some researchers adopt the term negative emotionality in lieu of using the term neuroticism because of its connotation with psychiatric illness 
(Harkness, Tellegen \& Waller, 1995, p. 185; John, Naumann \& Soto., 2008; Soto \& John, 2017, p. 120).

Norm of reciprocity: This phrase "holds that people should help those who help them and, therefore, those whom you have helped have an obligation to help you" (Gouldner, 1960, p.173).

Perceived organizational support: This phrase is used to describe the perceptions developed by employees regarding their employer through a relational or emotionalbased lens. "Employees tend to ascribe humanlike characteristics to the organization" and develop beliefs about their organization "as if it were a powerful individual with a personality and motives that influence the favorableness of its orientation towards them" (Eisenberger \& Stinglhamber, 2011, p. 41).

Perceived supervisor support: This phrase is used to describe the perceptions developed by employees regarding their direct supervisor as the primary "agent" of the organization, and studies of perceived supervisor support provide the supervisor-level perceptions within the broader organizational support framework (Kottke \& Sharafinski, 1988).

Psychological contract: This term is used to describe the relationship and mutual unspoken expectations between employees and supervisors (Argyris, 1960; CoyleShapiro \& Kessler, 2000). The two categories of psychological contracts are transactional and relational (MacNeil, 1985).

Psychological contract incongruence: This phrase refers to the result of the "different views on the content of a psychological contract and the degree to which each party has fulfilled the mutual obligations of the exchange" (Coyle-Shapiro, 2000, p. 905). 
Reciprocation wariness: This phrase refers to an individual's fear of being exploited in a social exchange. A person considered high-wary tends to interpret actions of others to be manipulative (Cottrell \& Eisenberger, 1992).

Social exchange: This term was defined by Blau (1964) as the exchange of work performed by an employee, with an expectation of receiving something in return from the employer. The social exchange theoretical framework provides an overarching construct for multiple theories used to explore employee-employer relationships and exchanges (Cropanzano \& Mitchell, 2005).

\section{Assumptions and Delimitations of the Study}

There were several assumptions and delimitations in this study.

\section{Assumptions}

The assumptions are: (a) participants in the study will be full-time, benefitsearning employees; (b) participants will have a work e-mail address; (c) participants in my study may include employees covered by a collective bargaining agreement; and (d) participants in the survey will respond honestly.

\section{Delimitations}

Although it would be ideal to study all the administrative and staff employees in institutions of higher education, the scope of this research will be focused only upon administrative and staff employees at a single public institution of higher education located in southern Florida, USA.

\section{Organization of the Study}

Chapter I provided the background to the study, formulated the problem statement, and described the purpose and theoretical framework. The significance of the 
study was described, key terms were defined, and assumptions and delimitations of the study were discussed.

Chapter II reviews literature studied in support of this dissertation. Chapter III discusses the method selected for use in this study. Chapter IV preents the findings of the study. Chapter V discusses the results and concludes with implications for theory, research, and practice. 


\section{CHAPTER II}

\section{REVIEW OF THE LITERATURE}

This chapter is comprised of four major sections. The first section revisits the topics of organizational commitment and affective commitment and discusses relevant studies or points of view discovered in the literature. The second section addresses social exchange theory's foundational element of reciprocity, and reviews studies that illustrate three relevant exchange theory lenses: (a) leader-member exchange (LMX), (b) perceived organizational support (POS), and an associated study introducing perceived supervisory support (PSS) as an important aspect of POS, and (c) psychological contract theory. The third section examines literature on the moderating factors of the study, the psychological trait neuroticism and the effects of psychological contract incongruence. The chapter concludes with a summary of the literature and discussion of its relevance to the study.

\section{Organizational Commitment}

Commitment is a relationship phenomenon in which a person feels a sense of a willing bond to a person, group, or organization (Eisenberger \& Stinglhamber, 2011). As described in Chapter 1, organizational commitment has been defined in three forms, which Meyer \& Allen (1991) suggest are components of commitment rather than types: affective, normative, and continuance. Affective commitment (AC) describes the emotional bond an employee feels for the organization. Normative commitment (NC) represents feelings of obligation to remain with the employer. Continuance commitment (CC) relates to the employee's need to maintain the job, and the perceived cost of leaving the organization to be prohibitive. 


\section{Social Exchange Models and Metrics}

Using the social exchange theory (SET) framework, researchers have enriched the social exchange theory through the development of numerous related theories and concepts. A review of key studies portrays SET as a study of power.

Studies of the dynamics of power emerged in the late 1950s, with the broad purpose of exploring the relationship between employees and the employer (Blau, 1964; Etzioni, 1961; Gould, 1979; March \& Simon, 1958; Mowday, Porter, \& Steers, 1982). Blau's (1964) seminal book Exchange and Power in Social Life explains social exchange as the power exerted by one person in exchange for goods or services from another. In the workplace, the social exchange occurs between the employer and employees. Blau noted that, while an employer has the power to coerce employees who rely on wages, an employer's power is diminished when the employee has other employment options, or if the employee no longer values or needs what the employer offered. Reciprocity in the employee-employer relationship is an underlying mechanism across the literature on LMX, POS, and PSS.

\section{Leader-Member Exchange}

As noted earlier, studies of the role of reciprocity in employee-supervisor relationships bifurcated into branches focusing on either the transactional or relational aspects of the relationship. The transactional or economic view of the employeesupervisor relationship was developed in concept as LMX (Eisenberger \& Stinglhamber, 2011; Graen \& Uhl-Bien, 1995; Wayne, Shore \& Liden, 1997; Wayne et al., 2002). Leader-Member Exchange (LMX) (Graen \& Scandura, 1987) focuses upon the transactional exchanges between and employee and direct supervisor and is associated 
with leadership domains. Graen \& Uhl-Bien (1995) published a summary of the evolution of LMX across a 25-year period, tracking its four progressive stages of development and incorporating three domains of leadership. The three domains of leadership are leader-based, relationship-based, and follower-based. Each domain defines leadership from a different point of view, with LMX representing the relationship-based model. For example, leadership itself is described in terms of trust, mutual respect, and a reciprocal relationship between both parties (Graen \& Uhl-Bien, 1995).

Of the four stages of LMX development as a theoretical concept, the first stage was Vertical Dyad Linkage (VDL). VDL focused primarily on the quality of the supervisor-employee dyad. In the early studies' findings, researchers found significant variation in the perceptions of followers about their leader (Graen \& Uhl-Bien, 1995). Subsequent studies (Dansereau et al, 1975; Graen \& Cashman, 1975; Vecchio, 1984) established that many managerial processes in an organization occur within dyad relationships. These studies also determined that managers differentiated relationships with subordinates, prompting the next stage of the theory to develop (Graen \& Uhl-Bien, 1995). In the second stage of studies, the name shifted to LMX, and researchers began to evaluate characteristics of the LMX relationship between the leader and member (Graen, Novak, \& Sommerkamp, 1982). The third wave of studies focused essentially on improving the effectiveness of managers working with each subordinate, building partnerships with direct reports. Longitudinal studies explored the effects of manager training on the quality of relationships between managers and all subordinates (Graen, Novak \& Sommerkamp, 1982; Graen, Scandura \& Graen, 1987; Graen, Scandura \& Graen., 1986). Development of the managers was described as leadership-making, and 
the training described relationship-building as beginning as strangers, then advancing to become acquaintances, and finally achieving a mutually reciprocal mature relationship (Graen \& Uhl-Bien, 1995). The fourth stage of LMX began in the late 1990s, with the focus expanding the scale of the LMX concepts beyond the manager level to the organizational level, illustrating the ongoing development and expansion of LMX across the first 25 years.

Wayne et al. (1997) questioned whether LMX and POS are distinct concepts, or whether the two literatures should be integrated. Testing seven hypotheses, the study obtained responses to questionnaires from 570 employees, and also collected data from 289 of the employees' supervisors. The questionnaires measured developmental experiences, promotions, organizational tenure, liking, expectations, POS, LMX, AC, intentions to quit, performance ratings, organizational citizenship behavior (OCB), and favor doing. Following are the hypotheses tested in the Wayne et al. (1997) study:

Hypothesis 1: Numbers of developmental experiences and promotions will be positively related to perceived organizational support.

Hypothesis 2: Leader liking and expectations of an employee will be positively related to leader-member exchange quality.

Hypothesis 3: There will be a positive, reciprocal relationship between leader-member exchange and perceived organizational support.

Hypothesis 4: Perceived organizational support will be positively related to performance ratings and organizational citizenship behavior.

Hypothesis 5: Leader-member exchange will be positively related to performance ratings and organizational citizenship behavior. 
Hypothesis 6: Perceived organizational support will be positively related to affective commitment and negatively related to intentions to quit.

Hypothesis 7: Leader-member exchange will be positively related to the member's doing favors for the leader (Wayne et al., 1997, p. 88-92).

Wayne et al.’s (1997) findings that are particularly relevant to the study are summarized as follows: (a) the researchers noted that LMX is based on personalities of the people in the leader-member relationship; (b) the direct supervisor is the primary determinant of employee behavior; (c) the leader's perceptions of liking and expectations are potential antecedents of LMX; (d) both POS and LMX were related to a number of employee attitudes and behavior. In the study's discussion, the researchers further reinforced that supervisors are instrumental as agents of the organization's resources, e.g., pay, bonuses, career advancement, and developmental opportunities (Wayne, Shore \& Liden, 1997). In summary, Wayne et al. (1997) found that each construct, LMX, POS, and PSS, offers unique insights into the quality of an employee's relationship on transactional factors with LMX, and on emotional-based factors, with POS and PSS. The next sections will discuss seminal studies on the two types of emotional based exchange relationships referenced above: POS, between employees and the organization, and PSS, between employees and their supervisors as primary agents of the organization. Three studies were selected for in-depth review because they explained, in detail, the rationale for the questionnaire items of two surveys identified for use in the study: Survey of Perceived Organizational Support (SPOS) and Survey of Perceived Supervisor Support (SPSS). 


\section{Perceived Organizational Support}

Nearly forty years after his seminal study on perceived organizational support (POS), Eisenberger (2011) recounted the mid-1980s origin of using organizational support theory as a framework to learn how employees develop perceptions and feelings of commitment (Eisenberger \& Stinglhamber, 2011). He described how discussions with his students had sparked the concept of exploring affective commitment through the employee's point of view. Eisenberger et al. (1986) hypothesized that perceived organizational support would increase employees' job efforts, positive orientation towards the employer, and affective commitment and attachment to the organization. Through this new lens of POS, the researchers sought to analyze empirical data to test the hypothesis that employees who felt positively valued by their employer, in turn, would feel positively about the organization, and, further, that there would be resulting improvements in work behaviors.

In their seminal study, Eisenberger et al. (1986) formulated a questionnaire to examine the core assumption that an organization's personification emerged from an employee's perceptions about the organization, and its members, which control the employee's finances and job satisfaction. Employees perceive their organization in a manner similar to how people describe their relationships with people.

Referring to Blau's (1964) social exchange framework, and before Graen \& Scandura (1987) introduced leader-member exchange (LMX), Eisenberger et al. (1986) hypothesized that organizational perceptions would be influenced by a wide range of processes or signals such as compensation, career opportunities, and rewards and recognition. An earlier study by Brinberg (1982) had determined that employees perceive 
expressions of organizational values through such means as policies and procedures; employees interpreted that the provision of such documents to employees demonstrated that the organization cared about the employees' well-being (Brinberg \& Castell, 1982, as cited in Eisenberger et al. 1986).

The researchers took special note of studies utilizing the Organizational Commitment Questionnaire (OCQ; Table 1) which focused on the perceptions by employees of organizations and the criticality of quid pro quo as the mutually beneficial dynamic based upon increased affective commitment of employees with positive employer perceptions (Buchanan, 1974; Cook \& Wall, 1980; Hrebiniak, 1974; Patchen, 1960; Steers, 1977). 
Table 1.

Organizational Commitment Questionnaire (OCQ)

Listed below are a series of statements that represent possible feelings that individuals might have about the company or organization for which they work. With respect to your own feelings about the particular organization for which you are now working, (company name), please indicate the degree of your agreement or disagreement with each statement by checking one of the seven alternatives below each statement*

1. I am willing to put in a great deal of work beyond that normally expected in order to help this organization to be successful.

2. I talk up this organization to friends as a great organization to work for.

3. I feel very little loyalty to this organization. (R)

4. I would take almost any type of assignment in order to keep working for this organization.

5. I find that my values and the organization's values are very similar.

6. I am proud to tell others that I am part of this organization.

7. I could just as well be working for another organization as long as the type of work was similar. (R)

8. This organization really inspires the very best of me in the way of job performance.

9. It would take very little change in circumstances to cause me to leave this organization. (R)

10. I am extremely glad that I chose this organization to work for over others I was considering at the time I joined.

11. There's not too much to be gained by sticking with this organization indefinitely. (R)

12. Often, I find it difficult to agree with this organization's policies on important matters relating to its employees. (R)

13. I really care about the fate of this organization.

14. For me this is the best of all possible organizations for which to work.

15. Deciding to work for this organization was a definite mistake on my part. (R)

*Responses to each item are measured on a 7-point scale with scale point anchors labeled: (1) strongly disagree; (2) moderately disagree; (3) slightly disagree; (4) neither agree nor disagree; (5) slightly agree; (6) moderately agree; (7) strongly agree. An "R" denotes a negatively phrased and reverse scored item.

Mowday, Porter \& Steers (1979)

Eisenberger et al. (1986) reviewed the factors and objectives of questions used in

the OCQ by Mowday et al. (1979), and then developed a scale to measure perceived

organizational support. The 36 questions in the original Survey of Perceived

Organizational Support (SPOS) were framed from the employee's point of view to

explore the factors measured by the OCQ. 
Both sets of questions are provided for comparison and contrast of their

viewpoints, with suggested factor alignment (Table 2). The SPOS questions are broader

ranging and designed to elicit personifications of the organization; the OCQ questions,

developed by Mowday et al. (1979), asked how the employee felt about working for the

organization.

Table 2.

SPOS 36 Questions in Comparison to OCQ 15 Questions

\begin{tabular}{|c|c|}
\hline SPOS & OCQ \\
\hline $\begin{array}{l}\text { 1. The organization values my contribution to its } \\
\text { well-being }\end{array}$ & I really care about the fate of this organization \\
\hline $\begin{array}{l}\text { 2. If the organization could hire someone to } \\
\text { replace me at a lower salary it would do so (R) }\end{array}$ & I feel very little loyalty to this organization (R) \\
\hline $\begin{array}{l}\text { 3. The organization fails to appreciate any extra } \\
\text { effort from me (R) }\end{array}$ & $\begin{array}{l}\text { I am willing to put in a great deal of effort } \\
\text { beyond that normally expected in order to help } \\
\text { this organization be successful. }\end{array}$ \\
\hline $\begin{array}{l}\text { 4. The organization strongly considers my goals } \\
\text { and values }\end{array}$ & $\begin{array}{l}\text { I find that my values and the organization's } \\
\text { values are very similar. }\end{array}$ \\
\hline $\begin{array}{l}\text { 5. The organization would understand a long } \\
\text { absence due to illness }\end{array}$ & \\
\hline $\begin{array}{l}\text { 6. The organization would ignore any complaint } \\
\text { from me }(\mathrm{R})\end{array}$ & \\
\hline $\begin{array}{l}\text { 7. The organization disregards my best interests } \\
\text { when it makes decisions that affect me (R) }\end{array}$ & $\begin{array}{l}\text { Often, I find it difficult to agree with this } \\
\text { organization's policies on important matters } \\
\text { relating to its employees (R) }\end{array}$ \\
\hline $\begin{array}{l}\text { 8. Help is available from the organization when I } \\
\text { have a problem }\end{array}$ & \\
\hline $\begin{array}{l}\text { 9. The organization really cares about my well- } \\
\text { being }\end{array}$ & $\begin{array}{l}\text { I am extremely glad that I chose this } \\
\text { organization to work for over others I was } \\
\text { considering at the time I joined. }\end{array}$ \\
\hline \multicolumn{2}{|l|}{$\begin{array}{l}\text { 10. The organization is willing to extend itself in } \\
\text { order to help me perform my job to the best of } \\
\text { my ability }\end{array}$} \\
\hline \multicolumn{2}{|l|}{$\begin{array}{l}\text { 11. The organization would fail to understand my } \\
\text { absence due to a personal problem (R) }\end{array}$} \\
\hline \multicolumn{2}{|l|}{$\begin{array}{l}\text { 12. If the organization found a more efficient way to } \\
\text { get my job done, they would replace me }(\mathrm{R})\end{array}$} \\
\hline \multicolumn{2}{|l|}{$\begin{array}{l}\text { 13. The organization would forgive an honest } \\
\text { mistake on my part }\end{array}$} \\
\hline $\begin{array}{l}\text { 14. It would only take a small decrease in my } \\
\text { performance for the organization to want to } \\
\text { replace me (R) }\end{array}$ & $\begin{array}{l}\text { It would take very little change in my present } \\
\text { circumstances to cause me to leave this } \\
\text { organization (R) }\end{array}$ \\
\hline $\begin{array}{l}\text { 15. The organization feels there is little to be gained } \\
\text { by employing me for the rest of my career }(\mathrm{R})\end{array}$ & $\begin{array}{l}\text { There's not too much to be gained by sticking } \\
\text { with this organization indefinitely. (R) }\end{array}$ \\
\hline $\begin{array}{l}\text { 16. The organization provides me little opportunity } \\
\text { to move up the ranks }\end{array}$ & \\
\hline
\end{tabular}


17. Even if I did the best job possible, the organization would fail to notice $(\mathrm{R})$

18. The organization would grant a reasonable request for a change in working conditions

19. If I were laid off, the organization would prefer to hire somebody new rather than take me back (R)

20. The organization is willing to help me when I need a special favor

21. The organization cares about my general I talk up this organization to my friends as a satisfaction at work great organization to work for

22. If given the opportunity, the organization would Deciding to work for this organization was a take advantage of me $(\mathrm{R})$ definite mistake on my part (R)

23. The organization shows a lot of concern for me For me this is the best of all possible organizations for which to work

24. If I decided to quit, the organization would try to persuade me to stay

25. The organization cares about my opinions

26. The organization feels hiring me was a definite mistake

27. The organization takes pride in my accomplishments

I am proud to tell others that I am part of this organization.

28. The organization cares more about making a profit than about me (R)

29. The organization would understand if I was unable to finish a task on time

30. If the organization earned a better profit, it would consider increasing my salary

31. The organization feels that anyone could I could just as well be working for a different perform my job as well as I do (R) organization as long as the type of work was similar. (R)

32. The organization is unconcerned about paying me what I deserve (R)

33. The organization wants to give me the best possible job for which I am qualified.

34. If my job were eliminated, the organization would prefer to lay me off than transfer me to another job (R)

35. The organization tries to make my job as interesting as possible

I would accept almost any type of job assignment in order to keep working for this organization.

This organization really inspires the very best in me in the way of job performance

36. My supervisors are proud that I am part of this organization

In both scales, responses to each item are measured on a 7-point scale with scale point anchors labeled:

(1) strongly disagree; (2) moderately disagree; (3) slightly disagree; (4) neither agree nor disagree; (5) slightly agree; (6) moderately agree; (7) strongly agree. An " $\mathrm{R}$ " denotes a negatively phrased and reverse-scored item.

SPOS, Eisenberger et al., 1986; OCQ, Mowday et al., 1979

In the two-part 1986 study, Eisenberger et al. used the questionnaire to test the

hypotheses that: 
a. Employees form global beliefs concerning the extent to which the organization values their contributions and cares about their well-being;

b. Such perceived organizational support reduces absenteeism; and

c. The strength of the relation between perceived organizational support and absenteeism is greater for employees with a strong exchange ideology than those with a weak exchange ideology. (Eisenberger et al., 1986).

Both studies are discussed in the following sections to summarize the development of the seminal survey, the research method, and the descriptive statistics of the results.

\section{Study 1: Globality of Perceived Organizational Support}

The researchers constructed 36 "commitment statements" believed to be indicators of how employees might expect beneficial or harmful actions by the organization relative to them in different situations, using a 7-point Likert scale $(1=$ strongly disagree, 7 = strongly agree). The first study tested the theory that employees "personified" organizations, and attributed actions and policies of the organization as if it were a person with either benevolent or malicious intent (Eisenberger et al., 1986)

The 36-question SPOS survey was administered to nine companies and returned by a total of 361 respondents. The factor loadings indicate the Perceived Support factor loaded higher than a possible second factor on all thirty-six statements. The reliability analysis results had a reliability coefficient (Cronbach's alpha) of .97, with item-total correlations ranging from .42 to .83 . The mean and median item-total correlations were .67 and .66 , respectively. Findings supported that employees developed global beliefs about the extent to which they feel the employer values their work and cares about them as people. 
Guided by factor loadings, Eisenberger et al. (1986) selected the subset of sixteen survey items identified with asterisks in Table 3. These comprise the most utilized items, and are referred to in literature as the short version. When researchers selected different items for surveys, the studies indicate item numbers used by the numbering in the original 36-item survey.

Study 2: Effects of Perceived Organizational Support and Exchange Ideology on Absenteeism

Eisenberger et al. (1986) conducted a second study to test the prediction that the effects of POS would have a positive correlation with the employee's strength of exchange ideology. He developed questions to probe whether employees would increase or decrease their work effort based on how they felt the organization treated them.

The second study was administered to 97 private high school teachers, and the attendance and absentee data was obtained for each participant for the purpose of determining whether greater perceived organizational support would result in greater attendance. The results supported all three hypotheses that employees form global beliefs about the organization, that POS has strong positive relationships between the employee's work effort and increased attendance and the strength of the employee's exchange ideology (Eisenberger et al, 1986). Since 1986, the SPOS has been extensively studied, enhanced, recognized as a valid construct, and remains today the standard scale used in studies of organizational support perceptions.

A meta-analysis of organizational support theory by Kurtessis et al. (2017) identified 496 papers, containing 558 studies using the SPOS. The meta-analysis did not include studies that combined the POS questionnaire with other measures, such as PSS or 
employee engagement. The meta-analysis reported that organizational support theory (OST) was an effective framework for studying antecedents of POS, e.g., leadership, employee-organizational context, human resource practices, and working conditions; OST is also an effective model for studying the consequences of POS, e.g., employee's orientation towards the organization and work, employee performance, and well-being (Kurtessis et al., 2017).

\section{Perceived Supervisory Support}

Within two years of the development of the POS questionnaire, Kottke and Sharafinski (1988) suggested adapting the questions to measure employees' perceptions of their direct supervisor's support. The researchers sought to develop questions that might offer additional insights to the concept of reciprocity in the organizational context. The researchers described anecdotal reports that employees differentiate between support from the organization and support from their manager. The researchers sought to understand both perceptions and noted the value of having additional empirical data regarding perceptions of support at two levels. Kottke and Sharafinski (1988) also cited a study by Greller and Herold (1975) that reported the supervisor to be the most relied upon source of work-related information by employees.

Kottke and Sharafinski (1988) developed the Survey of Perceived Supervisor Support (SPSS), replacing the word "organization" with "supervisor," in 16 items as shown in Table 3. The questionnaire used a slightly different sequence in the items from that used in the Survey of Perceived Organizational Support (SPOS). Both questionnaires were administered to 216 municipal government employees. The factor analysis demonstrated was deemed to be almost identical (Kottke \& Sharafinski, 1988). 
Table 3.

Survey of Perceived Supervisory Support (SPSS) 16 Questions

1. My supervisor values my contributions to the well-being of our department.

2. If my supervisor could hire someone to replace me at a lower salary, he/she would do so. (R)

3. My supervisor appreciates extra effort from me.

4. My supervisor strongly considers my goals and values.

5. My supervisor wants to know if I have any complaints.

6. My supervisor takes my best interests into account when he/she makes decisions that affect me.

7. Help is available from my supervisor when I have a problem

8. My supervisor really cares about my well-being.

9. If I did the best job possible, my supervisor would be sure to notice.

10. My supervisor is willing to help me when I need a special favor.

11. My supervisor cares about my general satisfaction at work.

12. If given the opportunity my supervisor would take advantage of me. (R)

13. My supervisor shows a lot of concern for me.

14. My supervisor cares about my opinions.

15. My supervisor takes pride in my accomplishments.

16. My supervisor tries to make my job as interesting as possible

Responses to each item are measured on a 7-point scale with scale point anchors labeled: (1) strongly disagree; (2) moderately disagree; (3) slightly disagree; (4) neither agree nor disagree; (5) slightly agree; (6) moderately agree; (7) strongly agree. An " $R$ " denotes a negatively phrased and reverse-scored item.

Note: Kottke \& Sharafinski, 1988, adapted from SPOS (Eisenberger et al., 1986)

Comparing the two scores, Kottke and Sharafinski reported a $t$-test $(t=6.58, p<$ $.001)$ "revealed that the employees reported more support from supervisors (PSS Mn $[s i c]-50.8)$ than from the organization as a whole (POS $M n[s i c]=66.04)$ " and they urged additional studies to validate findings and to study outcome variables (p. 1079).

Numerous studies using both questionnaires have been conducted for more than three decades to explore antecedents and consequences of POS, and to establish PSS as an important and distinct variant of POS. Within twelve years of the introduction of PSS, Eisenberger et al. (p. 565) described more than a dozen studies had found positive relationships of POS, PSS, and employee retention, including studies by Eisenberger himself (Eisenberger et al., 2002; Eisenberger, Schloss, Karagonlar, et al., 2014; ; 
Rhoades, Eisenberger \& Armeli, 2001; Shanock \& Eisenberger, 2006; Yoon \& Thye, 2002).

Shanock et al., (2006) suggested future research explore whether supervisors' dispositions (i.e., personality traits) would affect the relationship between supervisors' POS and subordinates' PSS. The following two sections will discuss one such trait and the phenomenon of psychological contract expectations as they might relate to the relationship between POS and PSS for both supervisors and subordinates.

$$
\text { Moderating Factors }
$$

\section{Big Five Personality Traits}

Personality traits have been a subject of prolific research for more than 50 years. A significant body of literature addresses personality traits, which are grouped into common categories known as the Big Five (Barrick \& Mount, 1991, 1993; Barrick, Mount \& Gupta, 2003; Barrick, Parks \& Mount, 2005; Costa \& McCrae, 1995; Judge \& Zapata, 2015). The traits are defined as: Extraversion, Emotional Stability, Agreeableness, Conscientiousness, and Openness to Experience. The traits are often defined in terms of positive attributes; however, each trait also has its converse, negative attributes. For example, the negative expression of the trait of Emotional Stability is defined as neuroticism (Barrick \& Mount, 1991; Costa \& McCrae, 1995).

Judge \& Bono (2001) conducted a meta-analysis of the relationships of four core self-evaluation traits, self-esteem, self-efficacy, locus of control, and emotional stability with job satisfaction and job performance, and found the trait of neuroticism to be related to lower perceived well-being. They reported that individuals with a higher level of the neuroticism trait are more likely to participate in situations in which they experience 
negative results. The researchers challenged the validity of neuroticism, citing the hypothesis by Barrick and Mount (1991) that emotional stability would be predictive of job performance, yet Barrick \& Mount reported the relationship to be very weak ( $p=$ .08). In a subsequent study, Judge \& Bono (2001) then argued that the measures used by Barrick \& Mount (1991) had not been validated as a measure of emotional stability, and that measure of neuroticism would require careful design and validation. The section that follows, measuring personality traits, describes studies that found significant validity and reliability of measures of personality traits in general, and questions pertaining to neuroticism in particular.

\section{Measuring Personality Traits}

Of the Big Five personality traits described earlier in this chapter, Eysenck (1990) considered three to be "supertraits" and therefore essential measures of personality differences: Extraversion, Neuroticism, and Psychoticism. Since the 1950's, researchers have labored to develop questionnaires measuring these traits (Eysenck, H.J., 1952, 1958; Eysenck, S.B. \& Eysenck, H.J.,1964, 1975; Francis, Brown, \& Philipchalk, 1992). The number and wording of items in questionnaires were adapted and distilled over time as hypotheses evolved. Eysenck \& Eysenck (1964) designed the Maudsley Personality Inventory, which would serve as the basis of the 12-item questionnaire published as the Eysenck Personality Inventory (1964). For the next decade, researchers added questions to measure Psychoticism, and subsequently added more questions to detect Lying. As these additions increased the length of the questionnaire, the number of questions also increased the time researchers needed to administer and analyze the surveys. Beginning in 1975, researchers began to adapt shorter versions. 
Nearly 30 years after the introduction of the Eysenck Personality Inventory (Eysenck \& Eysenck, 1964), two versions of a revised questionnaire were published in the same year: Eysenck (1992) introduced the Eysenck Personality QuestionnaireRevised (EPQR-S), with 48-items measuring Extraversion and Neuroticism, and Francis et al., (1992) published the 24-question Eysenck Personality Questionnaire Revised Abbreviated (EPQR-A).

Sato (2005) cited Forrest et al., (2000) as finding the EPQR-A, because it was even briefer than the 48-item EPQR-S, to be very useful. However, Sato (2005) expressed dissatisfaction with the reliability coefficients of the measures, particularly the scales measuring Psychoticism and Lies (Sato, 2005).

Leveraging the stronger reliability coefficients of the EPQR-S, Sato (2005) further adapted that 48-item questionnaire to design the 24-item Eysenck Personality Questionnaire - Brief Version (EPQ-BV). Sato's adaptation was primarily accomplished by retaining the Extraversion and Neuroticism scales, and removing the 12 Psychoticism and Lie scales, with alphas of .80, .78, 59, and .73, respectively. Sato's (2005) EPQ-BV questionnaire returned a coefficient alpha of .92 for the Extraversion scale, and a coefficient alpha of 90 for the Neuroticism scale in the EPQ-BV. Table 4 displays the results of the correlation analyses. 
Table 4.

Correlations among Measures of EPQ-BV and EPQR $-S(N=290)$

Variable

1

2

3

1. Extraversion EPQ-BV

2. Neuroticism EPQ-BV

3. Extraversion EPQR-S

1.00

$-.25 *$

$.89 * \quad-.29 *$

4. Neuroticism EPQR-S

1.00

$-.25^{*}$

$.88^{*}$

1.00

$-.25 *$

1.00

Note. EPQ-BV - Eysenck Personality Questionnaire-Brief Version; EPQR-S = Eysenck Personality Questionnaire Revised-Short form.

$* p<.001$.

Table 5 lists all items in the EPQ-BV (Sato, 2005), and indicates the two domains.

Table 5 .

EPQ-BV Items - Extraversion and Neuroticism

\begin{tabular}{|l|l|}
\hline \multicolumn{1}{|c|}{ Extraversion } & \multicolumn{1}{|c|}{ Neuroticism } \\
\hline Are you a talkative person? & Does your mood often go up and down? \\
Are you rather lively? & Do you ever feel miserable for no reason? \\
Do you enjoy meeting new people? & Are you an irritable person? \\
Can you usually let yourself go and enjoy & Are your feelings easily hurt? \\
yourself at a lively party? & Do you often feel "fed-up"? \\
Do you usually take the initiative in making & Would you call yourself a nervous person? \\
new friends? & Are you a worrier? \\
Can you easily get some life into a rather & Would you call yourself tense or "highly- \\
dull party? & strung"? \\
Do you tend to keep in the background on & Do you worry too long after an embarrassing \\
social occasions? (R) & experience? \\
Do you like mixing with people? & Do you suffer from nerves? \\
Do you like to have plenty of action and & Do you often feel lonely? \\
excitement around you? & Are you often troubled about feelings of guilt? \\
Are you mostly quiet when you are with & \\
other people? (R) & \\
Do other people think of you as being very & \\
lively? & \\
Can you get a party going? & \\
\hline
\end{tabular}

Sato (2005)

Note. Items with an "(R)" are reverse scored.

With an aim to develop a new scale that provides a more descriptive framework

for trait studies, Soto \& John (2017) developed a 60-item Big Five Inventory-2 (BFI-2)

containing 15 nested facets. At the domain level, the scales showed alpha reliabilities of, 
“.82 for Extraversion, .38 for Agreeableness, .88 for Conscientiousness, .91 for Negative Emotionality, and .84 for Open-Mindedness" (p. 123). The domain of negative emotionality (neuroticism) is comprised of 3 facets: anxiety, depression, and emotional volatility. Data from two groups, internet-based participants $(N=1,000)$ and student validation sample $(N=470)$ showed loadings: anxiety $(.89 / .88)$, emotional volatility (.86/.83), and depression (.73/.67) (Soto \& John, 2017, p. 124.)

Within months of publishing the BFI-2, the researchers published additional studies of two abbreviated forms, the short 30-item BFI-2-S, and the extremely short 15item BFI-2-XS. The purpose was to test their reliability and validity against the fulllength BFI-2 (Rammstedt, Danner, Soto \& John, 2018; Soto \& John, 2017b). The researchers found domain-level correlations for the BFI-2 and the BFI-2-S were almost identical, however they noted a decreased facet-level internal validity with the BFI-2-XS.

To prevent respondent fatigue, yet achieve desired levels of validity and reliability, the present study uses Soto's (2017) BFI-2-S scale "Negative Emotionality" (neuroticism) items: 9, 14R, 19R, 24R, 29 (Soto et al., 2017b, p. 79-80). Table 6 illustrates the items selected for the present study. The BFI-2-S will provide similarity in format to the other variables measured in the present study. Items use a 5-point Likert scale, ranging from 1 (disagree strongly) to 5 (agree strongly).

Table 6.

BFI-2-S Negative Emotionality (Neuroticism)

\begin{tabular}{|l|l|}
\hline 9 & I am someone who tends to feel depressed, blue. \\
\hline $14 \mathrm{R}$ & I am someone who is emotionally stable, not easily upset.(R) \\
\hline $19 \mathrm{R}$ & I am someone who is relaxed, handles stress well.(R) \\
\hline $24 \mathrm{R}$ & I am someone who feels secure, comfortable with self.(R) \\
\hline 29 & I am someone who is temperamental, gets emotional easily. \\
\hline
\end{tabular}

Soto \& John, 2017; Note. Items with an "(R)" are reverse scored. 


\section{Neuroticism as a Moderator}

Neuroticism was selected as a moderator in the study to focus its role in the relationship between POS and AC. Cable \& Judge (1994) reported that personalities defined in the Big Five moderated the effectiveness of HRD practices, particularly in areas related to pay. Individuals high in neuroticism are described as emotionally unstable and prone to self-reported anxiety, nervousness, and insecurity (Barrick \& Mount, 1991). Kampkotter (2017) wanted to investigate the moderating effects of personality traits on the relationship between performance assessments and job satisfaction. He hypothesized that higher levels of the neuroticism trait and would have a positive relationship with increased distrust of the performance appraisal process, increased fear of repercussions, and decreased job satisfaction. The findings supported his hypotheses. Bowling \& Eschleman (2010) studied the moderating effects of neuroticism on negative affect and stress. Their findings suggest that individuals high in neuroticism tend to be more sensitive to negative events, less skilled at coping, and even inhibited from savoring positive events (Bowling \& Eschleman, 2010). In the literature, Neuroticism has been found to be a moderator, sometimes significantly so, between other factors (Gunthert, Cohen, \& Armeli, 1999; Suls \& Martin, 2005; Watson \& Hubbard, 1996 as cited by Bowling \& Eschleman, 2010).

Psychological Contract Incongruence

A seminal study by Coyle-Shapiro \& Kessler (2000) published a comprehensive analysis of employee-employer relationships through the lens of the psychological contract. Designed to examine the mutuality of exchanges between the employee and employer, the researchers sought to advance the knowledge regarding the effects of 
change on the employee-employer relationship, and to explore predictive factors resulting from change. They focused on whether the perceptions and expectations of obligations were consistent and reciprocal. The study also investigated the consequences of perceived contract fulfillment (or breach) on perceived organizational support.

The foundational concept for psychological contracts, established in a study by Argyris (1960), is that management of employees by a supervisor represents a psychological work contract. Subsequent studies by Levinson (1962) (as cited in Rousseau \& Tijoriwala (1998) and Schein (1965) introduced the term psychological contract and explained the formation of employer-employee expectations. Coyle-Shapiro \& Kessler (2000) recognized that employees and supervisors might interpret the contents of a psychological contract differently. The researchers noted that the employee and supervisor might also disagree on whether either party has fulfilled their expected obligations in the exchange (Coyle-Shapiro \& Kessler, 2000).

In organizational support studies in the 1960s, as referenced earlier in this chapter, there were two viewpoints regarding perceptions of organizational support: economic or emotional. In parallel, the psychological contract studies in the 1960s and 1970s put forth two similar definitions of contract types: transactional or relational. These definitions utilized categories of contracts as defined by MacNeil (1985). Shore \& Tetrick (1994) introduced the psychological contract as a framework for understanding the employeeemployer relationship.

Coyle-Shapiro \& Kessler (2000) developed examples of transactional contracts which are linked to pay and benefits as shown in the first column of Table 7. Alternatively, other researchers focused on relational contracts which are associated with 
more intangible benefits derived from the supervisor-employee relationship; examples of relational benefits are shown in the second column of Table 7, adapted from Kottke \& Sharafinski's (1988) SPSS questionnaire items.

Table 7.

Transactional and Relational Contract Perspectives

\begin{tabular}{|ll|}
\hline \multicolumn{1}{|c|}{ Transactional } & \multicolumn{1}{c|}{ Relational } \\
\hline Coyle-Shapiro \& Kessler (2000) & Kottke \& Sharafinski (1988) \\
\hline Salary & Supervisor provides regular schedules \\
\hline Employee Benefits & $\begin{array}{l}\text { Supervisor encourages workplace health program } \\
\text { attendance }\end{array}$ \\
\hline Promotional Opportunities & Supervisor provides coaching and feedback \\
\hline Bonus & Supervisor expresses appreciation \\
\hline Merit Increase & Supervisor recommends increase due to performance \\
\hline Pension & $\begin{array}{l}\text { Supervisor encourages employees to plan for } \\
\text { retirement }\end{array}$ \\
\hline Vacation & $\begin{array}{l}\text { Supervisor supports employees' need to recharge and } \\
\text { take earned vacation }\end{array}$ \\
\hline Sick Pay & $\begin{array}{l}\text { Supervisor expresses support for employees' recovery } \\
\text { and health }\end{array}$ \\
\hline
\end{tabular}

Kottke \& Sharafinski (1988); Coyle-Shapiro \& Kessler (2000)

A key study by Morrison \& Robinson (1997) defined three types of contract breach: (a) reneging, when a contract is willfully broken, (b) disruption, when an unexpected environmental or economic problem prevents the employer from keeping a promise, and (c) incongruence, when the two parties have different perceptions about a contract or the extent it was fulfilled. Morrison et al. (1997) identified incongruence as a more subtle exchange condition that might lead to a perception of an unmet obligation. Multiple causes of incongruence were suggested in the Morrison et al. model of how psychological contract violation occurs, defining violation as the employee's negative emotional reaction to a perceived contract breach. Violation is generally a reaction to a breach thought to be willful reneging. A number of potential incongruence antecedents are identified in the model. For example, (a) an overall difference in worldview, defined as 
divergent schemata such as cultural differences or different practices in organizational locations, (b) complexity and ambiguity, reflecting the challenges of congruent expectations which are unspoken promises, not fully defined by either party, or the terms of the contract may have dimmed over time, and (c) communication, or the lack thereof, is an antecedent of incongruence, for example, when a new employee does not have a realistic job preview, has not had interaction with a new supervisor, or does not understand an incentive plan (Morrison \& Robinson, 1997). Coyle-Shapiro \& Kessler (2000) noted the importance of understanding whether a perceived contract failure is the result reneging or incongruence because of the associated effects on the employee. Lester, Turnley, Bloodgood \& Bolino (2001), building upon the Morrison et al. (1997) model of how violation occurs, hypothesized that, when a breach is perceived, the employee will seek information to explain what happened and why. If the explanation points to an intentional disregard of the promise, the employee will attribute it to reneging, and the employee might perceive that intentional harm was done by the employer. If the breach is explained by circumstances that prevented the employer from fulfilling a promise, the employee might attribute the breach to disruption, and not attribute the breach to ill will. If the breach is thought to be "an honest misunderstanding regarding the terms or conditions of the employment relationship," the employee may attribute the breach to incongruence (Lester, Turnley, Bloodgood \& Bolino, 2001, p. 43).

Based upon Lester et al.'s (2001) study, in order to examine the moderating effect of psychological contract incongruence, this study developed an item to tease out the attribution of contract breach. While in many studies, both POS and PC are used as a measure of psychological contract breach, studies have noted the less obvious condition 
leading to a perception of an unmet promise. Rousseau \& Tijoriwala (1998) describe evaluation-oriented measures of psychological contract as those eliciting participant judgements about their personal experience in relation to a psychological contract, because "fulfillment is a matter of degree" (Rousseau \& Tijoriwala, 1998, p. 691). Several studies have employed Perceived Organizational Support (POS) (Eisenberger et al., 1986) to measure psychological contract fulfillment (Guzzo \& Berman, 1995; Barksdale \& Renn, 1997; Barksdale \& Shore, 1997), however Rousseau et al. (1998) suggest that POS does not explicitly associate organizational support with promises. To more explicitly measure a contract violation, Lester et al. (2002) suggest directly asking about overall mutual understanding and fulfillment of expectations to distinguish between intentional reneging and unintentional incongruence; their study of attribution of psychological contract breach informed the response choices offered for the item in the study (Lester, Turnley, Bloodgood \& Bolino, 2002).

The inherent challenges of measuring incongruence have evolved into different theoretical constructs. Irving and Meyer (1999) describe the inherent measurement problems with each approach. Because a psychological contract requires two parties, one research approach is to measure the differences between perceptions of employeesupervisor dyads. Another approach measures the difference in expectations and perceptions of fulfillments over time.

As of 2000, Coyle-Shapiro \& Kessler argued that there was a lack of evidence of connections between psychological contracts and perceived organizational support, despite its intuitive logic. In a subsequent study by Coyle-Shapiro \& Kessler (2002) reciprocity was examined through the lens of psychological contracts, furthering the 
knowledge regarding contract congruence or incongruence, and its effects on both parties' views of the contract's failure or satisfaction. Contrary to Coyle-Shapiro \& Kessler's (2000) view that there was insufficient empirical evidence of the connections between psychological contracts and POS, researchers continued to develop empirical evidence.

By 2003, Aselage and Eisenberger not only described observed connections this time, they went so far as to suggest the theoretical integration of perceived organizational support and psychological contracts. The researchers examined the similarities and differences between organizational support theory and psychological contract theory and found evidence that each theory identified key processes in the other theory that influenced relationships (Aselage \& Eisenberger, 2003).

A study by Coyle-Shapiro \& Conway (2005) studied relationships between POS and Psychological Contract Fulfillment. Their study pointed out how POS and psychological contracts are distinct, with POS measuring only individual perceptions, regardless of what was expected or promised; psychological contracts theory explores the congruence or incongruence of what was promised and what was delivered and emphasize the interdependence of the employee and employer (Coyle-Shapiro \& Conway, 2005). The 2005 study is relevant to the present study because it hypothesized that: (a) PC will positively predict POS, and (b) POS will positively predict PC. The study further explored the mechanisms through which employees changing perceptions of psychological contracts as a result of their fulfillment and the subsequent positive relationship on organizational citizenship behavior. This study provides insights and methods that are relevant to the research questions of the study. For the measures of POS, 
the researchers used the seven items with the highest factor loadings from Eisenberger et al. (1986) POS scale. Table 8 includes the POS survey items adapted by Coyle-Shapiro \& Coyle (2005), in which the word "organization" was replaced with "employer" for the purpose of consistency with items measuring psychological contracts (p.777).

Table 8 .

SPOS Items Adapted by Coyle-Shapiro and Conway (2005)

1. My employer cares about my well-being.

2. My employer values my contributions to its well-being.

3. My employer cares about my opinions.

4. My employer considers my goals and values.

5. My employer cares about my general satisfaction at work.

6. My employer is willing to help me when I need a special favor.

7. My employer shows very little concern for me. (R)

"(R)" indicates a reverse scored item

The researchers also selected 12 items shown in Table 9 measuring psychological contracts based on items commonly used in earlier studies (Robinson, 1996; Rousseau, 1990; Turnley \& Feldman, 1999). All items in the measures utilized a 5-point Likert scale ranging from not at all to a very great extent (Coyle-Shapiro \& Conway, 2005). The study was longitudinal, with up to four measurement occurrences, enabling the examination of the relationship between POS and psychological contracts over time. 
Table 9.

Employee Perceived Employer Obligation Items

1. My employer should provide up to date training and development.

2. My employer should provide the necessary training to do my job well.

3. My employer should support me when I want to learn new skills.

4. My employer should provide me with interesting work.

5. My employer should provide me the opportunity to be involved in decisions that affect me.

6. My employer should give me freedom to do my job well.

7. My employer should provide me with good career prospects.

8. My employer should provide me with fair pay compared to staff doing similar work in other organizations.

9. My employer should provide me with fringe benefits that are fair compared to what staff doing similar work in other organizations get.

10. My employer should provide me with fair pay for the responsibilities in my job.

11. My employer should provide me with pay increases to maintain my standard of living.

12. My employer should provide me with long term job security.

Coyle-Shapiro \& Conway, 2005.

Coyle-Shapiro \& Conway (2005) suggested that decreasing levels of POS may indicate a deteriorating relationship between the employee and employer. In these cases, there is evidence that the employees develop a heightened interest in psychological contracts. Their results also support the necessity of psychological contracts in situations of low POS, indicating lower levels of employee trust that their expectations will be met. The researchers call for additional research to explore the relationship among POS, psychological contracts, and organizational commitment (Coyle-Shapiro \& Conway; 2005).

The preceding sections in the review of literature discussed $\mathrm{OC}, \mathrm{AC}$, the social exchange theoretical framework, and explained the norm of reciprocity as a foundational concept. Next, several studies were described to illustrate two frequently employed frameworks for organizational commitment research: LMX and POS. Additionally, PSS 
was described as a complementary framework to POS, with a narrower focus on the supervisor as an agent of the organization. The review included sections on the moderating factors for the study: neuroticism and psychological contract incongruence. The review addressed the definitions of the factors as well as provided examples of their use in a moderator role in previous research.

\section{Summary}

The research and topics included in the review of literature have informed the development of the study. The intent of the Chapter II was to connect past research questions and findings to the research questions, dependent and independent variables, and environmental factors facing employers. 


\section{CHAPTER III}

\section{METHOD}

Chapter III presents the research design, followed by discussion of the population and sample, instrumentation, and data analyses. The chapter concludes with the summary of the methods presented in this chapter.

\section{Research Design}

The research design was informed by frameworks and theories related to employee-employer relationships. The study employed a nonexperimental design. There are three types of nonexperimental research design: descriptive, explanatory, or predictive (Creswell, 2017). The type is selected depending on the purpose of the study. Because the aim of the study was to predict effects of two moderating variables on the relationship between the dependent and independent variables, a predictive nonexperimental research design was used. Predictive nonexperimental design aims to predict effects of independent variables, using one or more independent variables.

\section{Survey Target Population}

The intended population were full-time, benefits-earning administrative and staff employees who had completed the training Leadership Education Advancement Program (LEAP) at a single institution of higher education located in southern Florida, USA. There were 573 employees in the intended population of the target institution.

\section{Sampling Frames}

1. Full-time, active (not on leave) employees who were employed on or before September 1, 2019.

2. Completed Leadership Education Advancement Program (LEAP). 
3. University email address.

\section{Sampling Design}

Sample size is an important consideration to allow findings to be generalized to the population (Hinkle, Oliver \& Hinkle, 1985). Green (1991) recommended considering the number of variables in the study to estimate sample size, e.g., per variable, the sample have between 5 and 50 participants. The present study has 5 variables, suggesting the minimum sample size should have a minimum of 25 participants and up to 250 (Green, 1991). Using table to determine sample size for desired level of effect and level of power, the recommended sample size is 155 , for a power analysis of . 80 with an effect size of .20 and an alpha of .05 (Hinkle, 2006, p. xxx).

\section{Sampling Procedures}

Employees' names and university email addresses were obtained through a public records request for LEAP graduates meeting the criteria for date of hire, active status (not on leave), full-time, and benefits-earning.

\section{Survey Scheduling Framework}

Once permission was granted by the University Institutional Review Board (permit number IRB-20-0002) for the research to commence, the survey was prepared for administration. Dillman et al.'s (2009) interval-scheduling framework was used to make initial contact, administer the survey, and send follow-up reminders to participants. The types of notifications distributed were: (a) initial invitation from the researcher and the research sponsor, with information about participation being strictly voluntary, and that participants were able to opt out of the study at any point, and an anonymous survey link would be provided to ensure confidentiality (b) pre-notification was sent three days after 
the invitation, (c) three days after the pre-notification invitation, participants received an e-mail with a welcome message, a confidentiality notice, instructions for completing the survey, (d) the survey was sent, (e) a reminder was sent one week after the survey, (f) a reminder was sent two weeks after the survey, $(\mathrm{g})$ a thank you e-mail was sent at the conclusion of the survey (Dillman et al., 2009).

\section{Possible Sampling Errors}

Potential issues with the population and frames included variations in how employees determine their supervisors. For example, in some departments an employee reports to more than one supervisor. The instructions will guide the participant to respond to questions by thinking of the individual they consider to be their primary supervisor. In the event of having no present supervisor, they should consider the previous one.

There were numerous possible challenges with coverage. One example was duplication, because there were individuals in some departments with more than one supervisor, for example Academic Advising and Advancement. The design also considered that, in some cases, supervisors delegate oversight responsibilities to a nonsupervisory individual, such as to an office administrator. To address these supervisor identification challenges, the survey instructions asked participants to think of the person they consider to be their primary supervisor on a day-to-day basis.

The survey design needed to consider the wide range of employee types in the institution and the possibility of an employee being on a leave of absence. To address these challenges, the data request clearly stated the parameters: full-time, benefits-earning employees, active status (not on leave), and latest date of hire was specified to ensure at least six months of employment. These elements were easily filtered systematically 
because employees are assigned to specific pay plans for administrative and staff and the status of being active or on leave is tracked. Each parameter was identifiable through a data element in the human resources information system and was provided as a data file in Excel containing only email addresses and no sensitive information.

\section{Ways of Recruiting Participants}

1. The Division of Human Resources Management Vice President was contacted to discuss the survey purpose, design, and plan to obtain permission.

2. Employees were contacted by email and invited to participate via an online Qualtrics survey link.

\section{Procedures}

A self-report web-based survey system, Qualtrics, was used to collect data for this study. Sauermann \& Roach (2012) note that, since the early adoption of Internet-based surveys by the National Science Foundation and other national and international agencies, scholars have increasingly using Internet-based surveys and electronic communication to expand studies to a broader scale, to offer participants the convenience of choosing when to respond, and to facilitate the collection and export of data for analysis. One of the challenges of web surveys can be lower response rates, often between $10 \%-25 \%$, which can have the effect of diluting the statistical power with a lower than optimal sample size (Sauermann \& Roach, 2012).

The present study used the four guidelines suggested by Dillman et al., (2009) in the Tailored Design Method collection framework. The four guidelines followed in the study were to: (a) have the survey content reviewed by knowledgeable colleagues who are familiar with the study topics and survey design, (b) conduct interviews to evaluate 
cognitive and motivational qualities of the survey's content, providing feedback on factors such as the appropriateness of the items, the order of the items, and the functionality of the process online, (c) conduct a pilot study in which all of the procedures to be used in the study are tested, and (d), complete a final check before implementation, requesting feedback and opinions from an individual who is not involved in the study to confirm that information is not missing.

Development of the Constructs

Building upon foundational studies discussed in Chapter II, items from measures developed in previous research were selected to collect data in five constructs as indicated in Table 10. The selected items for each element of the five constructs will be defined in this section, and any adaptations to be made for the purposes of this study will be described. The constructs are designed to align with the independent variable, dependent variable, and the moderating factors of neuroticism and psychological contract incongruence. 
Table 10.

Constructs and Related Surveys

\begin{tabular}{|c|c|}
\hline Construct & Related Surveys \\
\hline $\begin{array}{l}\text { Perceived } \\
\text { Organizational Support; } \\
\text { Adapted Perceived } \\
\text { Organizational Support }\end{array}$ & $\begin{array}{l}\text { Survey of Perceived Organizational Support (Eisenberger et al., } \\
\text { 1986) } \\
\text { Adapted Survey Perceived Organizational Support (Conway \& } \\
\text { Coyle-Shapiro, 2005) }\end{array}$ \\
\hline $\begin{array}{ll}\text { 2. } & \text { Perceived Supervisor } \\
\text { Support } \\
\text { Adapted Perceived } \\
\text { Supervisor Support }\end{array}$ & $\begin{array}{l}\text { Survey of Perceived Supervisor Support (Kottke \& Sharafinski, } \\
\text { 1988) } \\
\text { Adapted Perceived Supervisor Support (Rhoades, Eisenberger } \\
\text { \& Armeli, 2001) } \\
\text { Adapted Perceived Supervisor Support (Dysvik \& Kuvaas, } \\
\text { 2012) } \\
\text { Adapted Survey Perceived Supervisor Support (Conway \& } \\
\text { Coyle-Shapiro, 2005) }\end{array}$ \\
\hline 3. Affective Commitment & $\begin{array}{l}\text { Affective Commitment Scale (Meyer \& Allen, 1997, with } \\
\text { permission from Sage Publications). Item } 15 \text { is adapted by } \\
\text { Rhoades et al., } 2001 \text { from the Organizational Commitment } \\
\text { Questionnaire (Mowday et al., 1979). }\end{array}$ \\
\hline $\begin{array}{ll}\text { 4. } & \text { Personality Trait } \\
& \text { Neuroticism } \\
\end{array}$ & $\begin{array}{l}\text { BFI2-S (Soto \& Long, 2017) Eysenck Personality } \\
\text { Questionnaire - Brief Version (EPQ-BV) }\end{array}$ \\
\hline $\begin{array}{l}\text { 5. Psychological Contract } \\
\text { Breach } \\
\text { Attribution }\end{array}$ & $\begin{array}{l}\text { Psychological Contract Breach (Robinson \& Morrison, 2000) } \\
\text { Attribution to Reneging, Disruption, or Incongruence (Lester, } \\
\text { Turnley, Bloodgood \& Bolino, 2002) }\end{array}$ \\
\hline
\end{tabular}

\section{Construct 1: Perceived Organizational Support}

As described in Chapter II, Eisenberger et al. (1986) developed the 36-question

Survey of Perceived Organizational Support (SPOS) to test the hypotheses that perceived organizational support would increase employees' job efforts, positive orientation towards the employer, and affective commitment and attachment to the organization. Over time, the number of items on the SPOS have been reduced using the highest loading factors to 16 . The 16 POS questions were adapted to pose the same perception questions at the supervisor level instead of the organizational level. In 2005, Coyle Shapiro \& Conway further reduced the number of items to 7 with the highest loading factors and adapted them to use consistent language when studying the relationships between POS 
and psychological contracts. A summary of the POS, adapted POS, and PSS are shown in Table 11.

\section{Construct 2: Perceived Supervisor Support}

To explore additional insights to the concept of reciprocity, Kottke and Sharafinski (1988) initially adapted the POS items to measure employees' perceptions of their direct supervisor's support and differentiate between support from the organization and support from their manager. The SPSS was adapted by replacing the word "organization" with "supervisor," in 16 items as shown in Table 3 and resequencing the placement of items in comparison to the Survey of Perceived Organizational Support (SPOS).

\section{Construct 2(a) Adapted Perceived Supervisor Support}

For the purposes of the present study, the instrument will utilize four SPSS items adapted by Rhoades et al. (2001) from the SPOS developed by Eisenberger et al. (1986). In Table 11, items 6 from the SPOS and item 12 from the adapted SPSS are stated in negative terms, as indicated by "(R)" to indicate their reversal from the positively stated SPOS and SPSS items. Table 11 lists the combined adapted SPOS and SPSS items used in the present study. 
Table 11.

Summary of Adapted SPOS and Adapted SPSS Items

\begin{tabular}{|l|}
\hline \multicolumn{1}{|c|}{ Statement } \\
\hline My employer cares about my well-being \\
\hline My employer cares about my opinions \\
\hline My employer considers my goals and values \\
\hline My employer cares about my general satisfaction at work \\
\hline My employer is willing to help me when I need a special favor \\
\hline My employer shows very little concern for me (R) \\
\hline My supervisor cares about my opinions \\
\hline My work supervisor really cares about my well-being \\
\hline My supervisor strongly considers my goals and values \\
\hline My supervisor shows very little concern for me (R) \\
\hline
\end{tabular}

"R"- Indicates item reversed

\section{Construct 3: Affective Commitment}

A higher level of affective commitment is positively related to reduced employee withdrawal behaviors such as absenteeism and turnover intent (Allen \& Meyer, 1990; Allen, Shore, \& Griffith, 2003; Harris, 2014; Hom, Lee, Shaw \& Hausknecht 2017; Lu et al., 2016; Mowday, Porter \& Steers, 2013; Porter et al., 1974; Shuck et al., 2014; Tett, 1993). Meyer \& Allen (1990) developed the Affective Commitment Scale (ACS) and reported a .83 correlation with the OCQ (Mowday, Steers \& Porter, 1979). Numerous studies report high reliability (Allen \& Meyer, 1990; Hackett, Bycio \& Hausdorf, 1994; Meyer, Allen \& Gellatly, 1990). Rhoades et al. (2001) conducted 3 studies in which AC was the dependent variable and POS was a mediating factor between various work environment factors, such as supervisor support, organizational justice, and organizational rewards. A factor analysis determined the discriminant validity of POS and $\mathrm{AC}$ constructs at two points in time, after 2 years and after 3 years. The findings report POS and AC are related, yet distinct constructs (Rhoades et al., 2001). 
Affective commitment items selected for the present study are illustrated in Table 12 (Meyer \& Allen, 1997; Rhoades, Eisenberger \& Armeli, 2001).

Table 12.

Summary of Affective Commitment Items

\begin{tabular}{|l|}
\hline \multicolumn{1}{|c|}{ Statement } \\
\hline I feel a strong sense of belonging to my organization \\
\hline I feel personally attached to my work organization \\
\hline I am proud to tell others I work at my organization* \\
\hline Working at my organization has a great deal of personal meaning to me \\
\hline I would be happy to work at my organization until I retire \\
\hline I really feel that problems faced by my organizations are also my problems \\
\hline
\end{tabular}

Construct 4: Neuroticism Personality Trait

Soto \& Long (2017) first developed the BFI - 2, a 60-item survey measuring the Big Five personality trait domains and associated facets. The domain level results showed alpha reliabilities of, “.82 for Extraversion, .38 for Agreeableness, .88 for Conscientiousness, .91 for Negative Emotionality, and .84 for Open-Mindedness” (p. 123). The domain of negative emotionality (neuroticism) is comprised of 3 facets: anxiety, depression, and emotional volatility. Data were collected from two groups, internet-based participants $(N=1,000)$ and a student validation sample $(N=470)$ showed loadings: anxiety (.89/.88), emotional volatility (.86/.83), and depression (.73/.67) (Soto \& John, 2017, p. 124.)

The BFI-2-S, a shorter 30-item form, was found to have almost identical reliability and validity correlations with the BFI-2. The 5 items measuring neuroticism as seen in Table 13 were selected for the present study. 
Table 13.

Summary of Neuroticism Items

\begin{tabular}{|l|}
\hline \multicolumn{1}{|c|}{ Statement } \\
\hline I am someone who tends to feel depressed, blue \\
\hline I am someone who is emotionally stable, not easily upset (R) \\
\hline I am someone who is relaxed, handles stress well (R) \\
\hline I am someone who feels secure, comfortable with self (R) \\
\hline I am someone who is temperamental, gets emotional easily \\
\hline
\end{tabular}

BFI-2-S: Soto \& John, 2017; "R" indicates reversed items

\section{Construct 5: Psychological Contracts}

Psychological contracts are the framework frequently used to study employee reactions to and perceptions about the fulfillment of expected exchanges or benefits received from the supervisor and organization (Coyle-Shapiro \& Kessler, 2003). Items will measure both relational and transactional contracts. Relational contracts refer to an employee's expectation of a non-monetary exchange, e.g., job security, training and development opportunities, and support for personal issues (Harrington \& Lee, 2014; Robinson et al., 1994; cited in Coyle-Shapiro \& Kessler, 2003). Transactional contracts pertain to a monetary exchange or reward given to by a supervisor or the organization, e.g., bonus or promotional salary increase.

Coyle-Shapiro (2003) explains psychological contract breach is measured by the strength of agreement or disagreement with statements about fulfillment of non-monetary and monetary expectations. Morrison \& Robinson (1997) describe incongruence as a difference of perceptions between an employee and an agent of the organization for fulfilling it. Some employees experience strong negative emotional responses to nonfulfillment, viewing a breach as a violation. Morrison et al. (1997) note the importance of understanding of the process through which negative feelings develop upon identification of a contract breach. 
Measuring psychological contracts, their fulfillment, breach, or violation, as well as the attribution of their cause takes many forms and uses and uses a variety of scales. Scholars who have contributed psychological contract measures include Conway \& Briner (2002), Coyle-Shapiro \& Kessler (2002), Freese \& Schalk (2008), Guest \& Conway (2002), Kickul, Lester \& Finkl (2002), Porter, Pearce, Tripoli \& Lewis (1998), Robinson \& Morrison (2000), Robinson \& Rousseau (1994), Rousseau (2000), Tekleab \& Taylor (2003), Thomas \& Anderson (1998), Turnley \& Feldman (1999). A comprehensive analysis by Freese and Schalk (2016) reviewed these scholars' 16 scales used to study psychological contracts, categorizing the scales and providing the items in each. They developed a comprehensive criterion-based analysis of the conceptualizations of content, response scales, and items developed by psychological contract scholars (Freese et al., 2016). To analyze the 16 known psychological contract scales, Freese et al., (2016) applied six questions to each: (a) was the instrument theory-based or inductively developed, (b) did the content assess mutual obligations, (c) were validated psychometric characteristics used, (d) was the measurement was at the item level, (e) was the assessment direct, and (f) did the measurement distinguish contract fulfillment and breach. After these assessments, the researchers offered their findings as they related to different uses for psychological contract studies, providing insights helpful in the selection of two scales for the present study (Freese \& Schalk, 2016).

A five-item psychological contract scale, developed by Robinson \& Morrison (2000), demonstrates an internal consistency reliability of .79. In the interest of aligning measurements with established scales, and to prevent potential survey fatigue using more comprehensive scales, the Robinson et al. (2000) 5-item scale is selected for the present 
study and are reflected in Table 14. To distinguish intentional reneging from

unintentional incongruence, Rousseau \& Tijoriwala (1998) suggest directly asking about overall mutual understanding and fulfillment of expectations, and the Morrison \& Robinson (2000) items align with that recommendation. Additionally, Lester's et al. study of attribution of psychological contract breach informed the three response choices offered for item 28 in the present study as shown in Table 14 (Lester et al., 2002).

Table 14.

\section{Summary of Psychological Contract Breach and Attribution Items}

Almost all of the promises made by my employer during recruitment have been kept so far $(\mathrm{R})$

I feel that my employer has come through in fulfilling the promises made to me when I was hired $(\mathrm{R})$

So far, my employer has done an excellent job of fulfilling its promises to me (R)

I have not received everything promised to me in exchange for my contributions

My employer has broken many of its promises to me even though I've upheld my side of the deal

When I think about a promise not fulfilled by my employer, I believe that: 1)N/A, 2) there was an honest misunderstanding between me and the employer regarding what the organization would provide, 3) a situation beyond my employer's control made it impossible to keep a promise to me, 4) my employer could have kept a promise to me, but it chose not to

\section{Demographic Data}

Participants were asked demographic questions to enable richer analytics of the population by age group, educational achievement, race and ethnicity, gender, income level. Table 15 lists the demographic questions and formats used. 
Table 15.

\begin{tabular}{|c|c|}
\hline Questions & Response Choices \\
\hline What is your age? & $\begin{array}{l}\text { Up to } 20,21-30,31-40,41-50,51-60 \text {, } \\
61+\end{array}$ \\
\hline $\begin{array}{l}\text { With what ethnicity do you most } \\
\text { identify? }\end{array}$ & $\begin{array}{l}\text { American Indian or Alaska Native, } \\
\text { Asian, Black or African American, } \\
\text { Native Hawaiian or Other Pacific } \\
\text { Islander, White }\end{array}$ \\
\hline $\begin{array}{l}\text { With what gender do you most } \\
\text { identify? }\end{array}$ & Female, Male, Other \\
\hline $\begin{array}{l}\text { What is the highest educational } \\
\text { degree achieved? }\end{array}$ & $\begin{array}{l}\text { High School/GED, AA/AS, BA/BS, } \\
\text { MA/MS, PhD/EdD, Other terminal } \\
\text { degree }\end{array}$ \\
\hline
\end{tabular}

\section{Confidentiality and Ethics}

Care was taken to ensure privacy, confidentiality, and to ensure proper

disclosures. Data for the survey were obtained through a public records request which is the process for accessing employee information from a public sector employer under Florida's Sunshine Law under Florida Statute 286.011, Public meetings and records. Even though some survey data in the public sector are subject to public records requests, there is a strong ethical obligation to the employees to protect their identity, as well as to protect the reputation of the institution. The following steps were taken to ensure the utmost protection of privacy and confidentiality throughout data collection, analysis, and storage:

1. The research proposal and employee data request were reviewed by the institution's AVP of Human Resource Information Systems and Compliance.

2. The research proposal and employee data request were reviewed by the Assistant Director of Talent Acquisition and Management. 


\section{CHAPTER IV}

\section{RESULTS}

Chapter IV begins with a description of the sample demographics and their observed associations, followed by an examination of the three hypotheses, and ends with a brief summary. Correlation analysis were conducted to determine the relationship among the variables and moderation analyses were conducted to evaluate the effects of the moderating variables, neuroticism, and psychological contract incongruence, on the relationship between the two independent variables, POS and PSS, and the dependent variable, AC.

\section{Background of the Sample}

Two hundred seventy-nine respondents participated in the study. The sample consisted of past participants of a leadership development program, Leadership Education Advancement Program (LEAP), offered by a single institution of higher education located in southern Florida, USA. The sample population consisted of fulltime, exempt, benefits-earning faculty, and professional staff.

\section{Examination of the Population}

The following section examines the demographics of the population using descriptive statistics, ANOVA, and Tukey HSD multiple comparisons.

\section{Gender}

A frequency analysis of gender indicated that $82.1 \%(n=229)$ was female, $17.6 \%(n=49)$ was male, and .4\% $(n=1)$ identified gender as other.

\section{Ethnicity/Race}


A frequency analysis of ethnicity/race indicated that $1.8 \%(n=5)$ was Asian, 13.3\% ( $n=37)$ was Black or African American, 49.1\% $(n=137)$ was Latin American or Caribbean, $28.3 \%(n=79)$ was White - Non-Hispanic, and 7.5\% $(n=21)$ identified as Other, indicating two or more ethnicities.

Age

A frequency analysis of age level indicated that $1.1 \%(n=3)$ was in the $18-25$ group, $22.2 \%(n=62)$ was in the $26-35$ group, $35.5 \%(n=96)$ was in the 36-45 group, $28.3 \%(n=79)$ was in the $46-55$ group, $13.3 \%(n=37)$ was in the $56-65$ group, and $.7 \%$ $(n=2)$ was in the 66 and over age group.

\section{Highest Level of Education}

A frequency analysis of highest level of education of the sample indicated that $2.5 \%(n=7)$ had a high school diploma or GED equivalent, $2.5 \%(n-7)$ had obtained a two-year associate degree, $19.7 \%(n=55)$ had earned a bachelor's degree, $64.5 \%(n=$ 180) had earned a master's degree, $2.5 \%(n=7)$ had another terminal degree, and $8.2 \%$ $(n=23)$ held a PhD or EdD doctoral degree.

\section{Time with Current Supervisor}

A frequency analysis of the length of time the participant had reported to the current supervisor indicated that $11.5 \%(n=32)$ for $1-11$ months, $22.6 \%(n=3)$ was in the 1-2 year range, $29.4 \%(n=82)$ had reported to the current supervisor for 3-5 years, and $36.6 \%(n=102)$ had worked for the same supervisor for 6 or more years. 


\section{Tenure with Organization}

A frequency analysis of the length of time employed in the organization indicated

that $.7 \%(n=2)$ had been employed for $1-11$ months, $3.9 \%(n=11)$ for $1-2$ years, $14.7 \%$ $(n=41)$ for $3-5$ years, and $80.6 \%(n=225)$ for 6 or more years.

Table 16.

Frequency Table of Demographic Variables

\begin{tabular}{|c|c|c|c|}
\hline Category & Variable & $f$ & Percent \\
\hline \multirow[t]{4}{*}{ Gender } & Female & 229 & 82.1 \\
\hline & Male & 49 & 17.6 \\
\hline & Other & 1 & .4 \\
\hline & Total & 279 & 100.0 \\
\hline \multirow[t]{6}{*}{ Ethnicity } & Asian & 5 & 1.8 \\
\hline & Black/African American & 37 & 13.3 \\
\hline & Latin American or Caribbean & 137 & 49.1 \\
\hline & White & 79 & 28.3 \\
\hline & Other & 21 & 7.5 \\
\hline & Total & 279 & 100.0 \\
\hline \multirow[t]{7}{*}{ Age } & $18-25$ years & 3 & 1.1 \\
\hline & 26-35 years & 62 & 22.2 \\
\hline & $36-45$ years & 96 & 34.4 \\
\hline & $46-55$ years & 79 & 28.3 \\
\hline & $56-65$ years & 37 & 13.3 \\
\hline & $66 \&$ over & 2 & .7 \\
\hline & Total & 279 & 100.00 \\
\hline \multirow{7}{*}{$\begin{array}{l}\text { Highest Level of } \\
\text { Education }\end{array}$} & High school/GED & 7 & 2.5 \\
\hline & Associates (2-year) & 7 & 2.5 \\
\hline & Bachelor's & 55 & 19.7 \\
\hline & Master's & 180 & 64.5 \\
\hline & Other terminal degree & 7 & 2.5 \\
\hline & $\mathrm{PhD} / \mathrm{EdD}$ & 23 & 8.2 \\
\hline & Total & 279 & 100.0 \\
\hline Time with Current & $1-11$ months & 32 & 11.5 \\
\hline \multirow{4}{*}{ Supervisor } & $1-2$ years & 63 & 22.6 \\
\hline & $3-5$ years & 82 & 29.4 \\
\hline & $6 \&$ over & 102 & 36.6 \\
\hline & Total & 279 & 100.0 \\
\hline Tenure with & $1-11$ months & 2 & .7 \\
\hline \multirow[t]{4}{*}{ Organization } & $1-2$ years & 11 & 3.9 \\
\hline & $3-5$ years & 41 & 14.7 \\
\hline & $6 \&$ over & 225 & 80.6 \\
\hline & Total & 279 & 100.0 \\
\hline
\end{tabular}


Using SPSS Version 26 (IBM, 2019) to examine the population, one-way analyses of variance was used to determine the relationship of each demographic variable with affective commitment, the dependent variable of this study (see Table 17) and one variable, ethnicity, had a significant effect $(p=.03)$. Multiple comparisons using Tukey HSD only found a marginally significant difference between Black/African American and Latin American/Caribbean $(p=.05)$. Therefore, it was not necessary to include demographic variables in the moderation analyses.

Table 17.

ANOVA Summary Table of Ethnicity

\begin{tabular}{l|r|r|r|r|r}
\hline AC & $\begin{array}{c}\text { Sum of } \\
\text { Squares }\end{array}$ & df & Mean Square & \multicolumn{1}{c}{ F } & \multicolumn{1}{|c}{ Sig. } \\
\hline & & & & & \\
Between Groups & 155.060 & 4 & 38.765 & 2.642 & .034 \\
\hline Within Groups & 4006.009 & 273 & 14.674 & & \\
\hline Total & 4161.068 & 277 & & & \\
\hline
\end{tabular}

Examination of Questionnaire Items

As discussed in Chapter 3, twenty-six questionnaire items were aggregated to form five scale variables. The discussion of item responses begins with the two independent variables, perceived organizational support (POS), followed by perceived supervisor support (PSS).

\section{Perceived Organizational Support}

The 6 items comprising the variable measuring POS (see Table 18) were based Conway et al. (2005) adaptation of the Eisenberger et al. (1986) scale, scored from 5 (Strongly Agree) to 1(Strongly Disagree). The final item, "My employer shows very little 
concern for me", was reverse scored, with 1 (Strongly Agree) to 5 (Strongly Disagree).

Of the POS items, the item with the highest mean (4.24) stated that the "employer cares about my well-being" and the next highest mean (4.13), the one reverse-scored item, stated that the employer "shows very little concern for me."

Perceived Supervisor Support

The 4 items comprising the PSS scale (see Table 18) consisted of items identical to four in POS, but the word "supervisor" replaced "employer" in this scale (Kottke et al. 1986). Dysvik et al. (2012) suggest the supervisor is viewed as the individual representing the organization in a direct employee-employer relationship. By including corresponding items in both scales, the results provide empirical evidence in which all four PSS items had higher means than the POS counterpart, with differences from .08 to .36 .

\section{Affective Commitment}

Across all scales in the instrument, the 5 items for AC (see Table 18) included the two items with the highest means. All 5 items were rated using the scale from 5 (Strongly Agree) to 1 (Strongly Disagree) and no items were reverse scored in the dependent variable. The highest mean (4.60) is for the item stating, "I am proud to tell others I work at my organization' and the second highest mean (4.41) is for the item, "Working at my organization has a great deal of personal meaning to me." The remaining three items range from 4.20 to 4.28 and indicate positive affective commitment.

\section{Neuroticism}

The 5 items used in the neuroticism scale are based on Soto \& John (2017) and were also scored from 5 (Strongly Agree) to 1 (Strongly Disagree) and three items were 
reverse scored. Table 18 displays the lowest mean (1.43) for the item, "I am someone who is emotionally stable, not easily upset" and the highest mean (1.96) for the item, "I am someone who is temperamental, gets emotional easily." These differences, appearing contradictory, occur between on item using the word "temperamental" and another item using the words "stable" and "not easily upset."

\section{Psychological Contract Incongruence}

The 6 items comprising the PCI aggregated variable were based on Robinson et al. (2000) and Lester et al. (2002). The first 5 items were scored with a 5-level scale from 5 (Strongly Agree) to 1 (Strongly Disagree), with 3 items reverse scored. The final item was scored with a scale beginning at 0 , meaning no psychological contract breach had occurred. All other responses indicated a breach did occur, and the level selected represented the cause of the breach, from 1 to 3, with 3 having the most negative attribution. Results indicated $52.2 \%$ reported no breach had occurred and $47.8 \%$ reported a breach did occur, with $21.3 \%$ indicating "My employer could have fulfilled a known promise but chose not to." Table 18 summarizes the means and standard deviations of the individual items comprising each of the five variables used in the study. 
Table 18.

Item Mean/Standard Deviations of Questionnaire Items

\begin{tabular}{|c|c|c|}
\hline Variable & Definition & Mean $(S D)$ \\
\hline \multirow[t]{6}{*}{ POS } & My employer cares about my well-being & $4.24(.92)$ \\
\hline & My employer cares about my opinions & $3.95(1.04)$ \\
\hline & My employer considers my goals and values & $3.96(.99)$ \\
\hline & My employer is willing to help me when I need a special favor & $3.92(.98)$ \\
\hline & My employer cares about my general satisfaction at work & $3.90(.99)$ \\
\hline & My employer shows very little concern for me (R) & $4.13(1.06)$ \\
\hline \multirow[t]{4}{*}{ PSS } & My supervisor cares about my opinions & $4.31(1.02)$ \\
\hline & My supervisor really cares about my well-being & $4.32(.99)$ \\
\hline & My supervisor strongly considers my goals and /or values & $4.20(1.10$ \\
\hline & My supervisor shows very little concern for me (R) & $4.33(1.10)$ \\
\hline \multirow[t]{5}{*}{$\mathrm{AC}$} & I feel a strong sense of belonging to my organization & $4.24(.97)$ \\
\hline & I feel personally attached to my work organization & $4.20(1.01)$ \\
\hline & I am proud to tell others I work at my organization & $4.60(.74)$ \\
\hline & $\begin{array}{l}\text { Working at my organization has a great deal of personal } \\
\text { meaning to me }\end{array}$ & $4.41(.869)$ \\
\hline & I would be happy to work at my organization until I retire & $4.28(1.00)$ \\
\hline \multirow[t]{5}{*}{ NEU } & I am someone who is emotionally stable, not easily upset (R) & $1.43(.66)$ \\
\hline & I am someone who is relaxed, handles stress well (R) & $1.92(.82)$ \\
\hline & I am someone who tends to feel depressed, blue & $1.86(.99)$ \\
\hline & I am someone who is temperamental, gets emotional easily & $1.96(1.03)$ \\
\hline & I am someone who feels secure, comfortable with self (R) & $1.66(.82)$ \\
\hline \multirow[t]{6}{*}{ PCI } & $\begin{array}{l}\text { Almost all of the promises made by my employer during } \\
\text { recruitment have been kept so far (R) }\end{array}$ & $2.27(1.17)$ \\
\hline & $\begin{array}{l}\text { I feel that my employer has come through in fulfilling the } \\
\text { promises made to me when I was hired }(\mathrm{R})\end{array}$ & $2.11(1.11)$ \\
\hline & $\begin{array}{l}\text { I have not received everything promised tome even though I've } \\
\text { upheld my side of the deal }\end{array}$ & $2.57(1.31)$ \\
\hline & $\begin{array}{l}\text { My employer has broken many of its promises to me even } \\
\text { though I've upheld my side of the deal }\end{array}$ & $2.11(1.21)$ \\
\hline & $\begin{array}{l}\text { So far, my employer has done an excellent job of fulfilling its } \\
\text { promises to me }(\mathrm{R})\end{array}$ & $2.23(1.12)$ \\
\hline & $\begin{array}{l}\text { *When I think about a promise not fulfilled by my employer, I } \\
\text { believe that: 1)N/A, 2) there was an honest misunderstanding } \\
\text { between me and the employer regarding what the organization } \\
\text { would provide, 3) a situation beyond my employer's control } \\
\text { made it impossible to keep a promise to me, 4) my employer } \\
\text { could have kept a promise to me, but it chose not to }\end{array}$ & $2.13(1.26)$ \\
\hline
\end{tabular}

*Attribution item to determine overall breach, then reason why 


\section{Descriptive Statistics and Scale Reliability}

After reverse coding negatively worded items (see Table 18), SPSS 26 was used to aggregate the items into five variables. The five aggregated variables were examined using Cronbach's alpha (1951) to measure scale reliability (see Table 19) which indicates the internal consistency among items comprising the scale variable. Scholars generally accept $a>.70$ as adequate. Cortina (1993) explains that, while the precision of the alpha is associated with the number of items in a scale, reliability estimates can range from questionable $(\mathrm{a}-<.70)$ to "quite good", $(\mathrm{a}>.85)$ (Cortina, 1993). Results in this study ranged from quite good, (Perceived Organizational Support, $\alpha=.90$ ), (Perceived Supervisor Support, $\alpha=.89$ ), and (Affective Commitment, $\alpha=.88$ ), to acceptable (Neuroticism, $\alpha=.76$ ) and (Psychological Contract, $\alpha=.79$ ).

Table 19.

Scale Reliability Scores, Means/SD of Scales, Skewness, and Kurtosis

\begin{tabular}{llllll}
\hline $\begin{array}{l}\text { Variable (Number of } \\
\text { Items) }\end{array}$ & $\begin{array}{l}\text { Scale } \\
\text { Reliability }\end{array}$ & Mean & SD & Skewness & Kurtosis \\
\hline POS (6 Items) & $a=.90$ & 23.74 & 5.23 & -1.13 & 1.32 \\
PSS (4 Items) & $a=.89$ & 16.96 & 3.88 & -1.52 & 1.84 \\
AC (5 Items) & $a=.88$ & 21.57 & 3.88 & -1.28 & 1.07 \\
NEU (5 Items) & $a=.76$ & 8.81 & 3.14 & 1.06 & .93 \\
PCI (6 Items) & $a=.79$ & 13.35 & 4.97 & .37 & .66 \\
\hline
\end{tabular}

Examination of Hypotheses

Correlation and regression analyses were used to examine the correlational and predictive relationships among the independent variables and dependent variable before examining path analyses. The model hypothesized that the relationship between perceived organizational support, perceived supervisor support, and affective commitment would be dampened by the personality trait neuroticism and psychological 
contract incongruence. As described in Chapter II, neuroticism is the Big Five personality trait associated with negative emotions and perceptions. Psychological contract incongruence is the form of psychological contract breach in which attribution is perceived to be an honest misunderstanding. Prior to testing the model, underlying assumptions about correlational and regression analyses were examined. The following sections discuss the four potential violations which may make inferences drawn from results of the study untrustworthy: normality, multicollinearity, linearity, and homoscedasticity (Hinkle et al., 2005).

\section{Normality}

The assumption of normality requires the frequency distribution of the variables' values to have a normal distribution or a bell-shaped curve. Some of the variables were not normally distributed, and tests of skewness and kurtosis (see Table 19) were run, and all variables were within the acceptable range of -2 to 2 (Hinkle et al., 2005).

\section{Multicollinearity}

Multicollinearity occurs when two or more of the predictor variables are highly correlated, which can make obtaining reliable estimates of individual regression coefficients more difficult, as they are essentially measuring the same phenomenon or construct (Meyers et al., 2013). To avoid multicollinearity, Green (1991) suggests removing variables with Pearson correlations greater than .90. Meyers et al. (2013) advise against proceeding with regression where correlations are in the mid $.7 \mathrm{~s}$ or higher.

Intercorrelations were checked and no correlation between predictor variables was found to be in the "red flag" levels, with the highest correlation identified $(r=.55)$ between perceived organizational support and perceived supervisor support. 


\section{Linearity}

Assumption of linearity accepts that the relationship between the independent and dependent variable is linear (Meyers et al., 2013). To assess the variables, bivariate scatterplots were used to assess the linear manner of the relationship. The bivariate scatterplots for all variables were elliptical in shape, indicating no violations of linearity (Appendix B).

\section{Homoscedasticity}

The assumption of homoscedasticity requires that variability in scores among dependent and independent variables are generally equal in value. The scatterplots for AC-POS and AC-PSS showed fewer patterns across the regression line (See Appendices $\mathrm{H}$ and I), thus supporting the homoscedasticity assumption.

Testing the Research Hypotheses

SPSS Version 26 (IBM, 2019) was used to compute correlation coefficients to examine the relationship among the two independent variables and the dependent variable as described in $H_{1}$. Additionally, the moderation analysis PROCESS v3.5 macro developed by Hayes (2013) was used to perform simple path analyses to explore $H_{2}$ and H3. The PROCESS macro, an analysis tool used within SPSS, was developed to support researchers studying effect sizes of moderators and mediators. PROCESS offers helpful features such as centering of all variables and output that facilitates generation of charts and other graphic features.

\section{Hypothesis 1}

The first hypothesis predicted that perceived organizational support, perceived supervisor support, and affective commitment are significantly related. The two 
independent variables were perceived organizational support and perceived supervisor support. The dependent variable was affective commitment.

The researcher investigated the zero-order correlations among the research variables to determine overall strength and direction of relationships. Correlation coefficients were computed among the three scales. The results of the correlational analyses presented in Table 20 show that perceived organizational support, perceived supervisor support, and affective commitment correlations were statistically significant, and their coefficients were greater than or equal to .30 (Hinkle, 2003). The correlation between perceived organizational support and affective commitment was significant with medium positive correlation $r(277)=.500, p<.01$. The correlation between perceived supervisor support and affective commitment was significant with small positive correlation, $r(277)=.305, p<.01$. Finally, the correlation between perceived organizational support and perceived supervisor support was significant, with medium positive correlation $r(277)=.557, p<.01$.

Table 20.

\begin{tabular}{|c|c|c|c|}
\hline Variables & $\mathrm{AC}$ & POS & PSS \\
\hline $\mathrm{AC}$ & 1 & $0.500^{*}$ & $0.305^{*}$ \\
\hline POS & & 1 & $0.557 *$ \\
\hline PSS & & & 1 \\
\hline
\end{tabular}

Note. $N=279 . p<.01 . A C=$ Affective Commitment; $P O S=$ Perceived Organizational Support, PSS $=$ Perceived Supervisor Support

* Correlation is significant at the .01 level (2-tailed).

In summary, perceived organizational support, perceived supervisor support, and affective commitment are significantly correlated and support Hypothesis 1. 


\section{Hypothesis 2}

The second hypothesis stated that personality trait neuroticism moderates the relationship between perceived organizational support, perceived supervisor support, and affective commitment, such that the relationship will be dampened.

A bivariate correlation analysis was conducted to examine the correlations between the variables. The indices to indicate the relative strength of the individual predictors are presented in Table 21. Two of the bivariate correlations between the moderators and affective commitment were negative, as expected. Three of the four indices were statically significant $(\mathrm{p}<.05)$.

Table 21.

The Bivariate Correlations of the Predictors with Affective Commitment Correlation between each predictor Predictors and affective commitment

\begin{tabular}{lc}
\hline Perceived Organizational Support & $.51 * *$ \\
Perceived Supervisor Support & .30 \\
Neuroticism & $-.22 *$ \\
Psychological Contract & $-.34 *$ \\
Incongruence & \\
\hline$N=279 . * p<.05, * * p<.01$. &
\end{tabular}

Multiple regression analysis was conducted to evaluate how well the four variables predicted affective commitment. The predictors were perceived organizational support, perceived supervisor support, neuroticism, and psychological contract incongruence, while the criterion was overall affective commitment. The linear combination of variables was significantly related to affective commitment, $F(4,274), R^{2}$ $=.28, p=<.01$, indicating that $28 \%$ of the variance of affective commitment can be accounted for by the four variables. Perceived organizational support was a positive, 
significant predictor of AC $(p<.001)$. It had the largest coefficient among all the predictors $(b=.33)$. Neuroticism was a negative, significant predictor of $\mathrm{AC}(b=-.13, \mathrm{p}$ $=.04)$ and psychological contract incongruence was a negative, significant predictor of $\mathrm{AC}(\mathrm{b}=-.10, \mathrm{p}=.02))$. But perceived supervisor support was not significant $(\mathrm{p}=.61)$.

Table 22.

Multiple Regression of Predictors of AC

\begin{tabular}{|l|l|l|l|l|}
\hline \multicolumn{1}{|c|}{ Predictor } & \multicolumn{1}{c|}{ b } & \multicolumn{1}{c|}{ SE } & \multicolumn{1}{c|}{$\boldsymbol{t}$} & \multicolumn{1}{c|}{$\boldsymbol{p}$} \\
\hline Constant (AC) & 16.88 & 1.67 & 10.09 & $.00^{* *}$ \\
\hline $\begin{array}{l}\text { Perceived Organizational } \\
\text { Support (POS) }\end{array}$ & .33 & .05 & 6.46 & $.00^{* *}$ \\
\hline $\begin{array}{l}\text { Perceived Supervisor } \\
\text { Support (PSS }\end{array}$ & -.03 & .06 & -511 & .61 \\
\hline Neuroticism (NEU) & -.13 & .06 & -2.05 & $.04 *$ \\
\hline $\begin{array}{l}\text { Psychological Contract } \\
\text { Incongruence (PCI) }\end{array}$ & -.10 & .04 & -2.30 & $.02^{*}$ \\
\hline$R^{2}=.28$ & & & & \\
$* p<.05 ; * p<.001$ &
\end{tabular}


Table 23.

Moderation Regression Summary

Moderation effect of neuroticism between perceived organizational support and affective commitment

\begin{tabular}{|l|l|l|l|l|l|}
\hline \multicolumn{1}{|c|}{ Predictor } & \multicolumn{1}{|c|}{ b } & b 95\% CI [LL, UL] & \multicolumn{1}{|c|}{ SE } & \multicolumn{1}{|c|}{$\boldsymbol{t}$} & \multicolumn{1}{|c|}{$\boldsymbol{p}$} \\
\hline Constant (AC) & 21.63 & $21.24-22.04$ & .20 & 106.71 & $.00^{* *}$ \\
\hline $\begin{array}{l}\text { Perceived Organizational } \\
\text { Support (POS) }\end{array}$ & .36 & $.28-.44$ & .04 & 9.21 & $.00^{* *}$ \\
\hline Neuroticism (NEU) & -.12 & $-.25-.01$ & .07 & -1.79 & .07 \\
\hline Interaction & .02 & $.00-.04$ & .01 & 1.61 & .11 \\
\hline
\end{tabular}

$R^{2}=.27$

Moderation effect of neuroticism between perceived supervisor support and affective commitment

\begin{tabular}{|l|l|l|l|l|l|}
\hline \multicolumn{1}{|c|}{ Predictor } & \multicolumn{1}{|c|}{ b } & b 95\% CI [LL, UL] & \multicolumn{1}{|c|}{ SE } & \multicolumn{1}{|c|}{$\boldsymbol{t}$} & \multicolumn{1}{|c|}{$\boldsymbol{p}$} \\
\hline Constant (AC) & 21.57 & $21.13-22.01$ & .23 & 95.78 & $.00^{* *}$ \\
\hline $\begin{array}{l}\text { Perceived Supervisor Support } \\
\text { (PSS) }\end{array}$ & .27 & $.15-.38$ & .06 & 4.61 & $.00^{* *}$ \\
\hline Neuroticism (NEU) & -.20 & $-.34--.06$ & .07 & -2.73 & $.006^{*}$ \\
\hline Interaction & -.001 & $-.04-.04$ & .02 & -.07 & .94 \\
\hline
\end{tabular}

$R^{2}=.11$

Moderation effect of psychological contract incongruence between perceived organizational support and affective commitment

\begin{tabular}{|l|l|l|l|l|l|}
\hline \multicolumn{1}{|c|}{ Predictor } & \multicolumn{1}{|c|}{ b } & b 95\% CI [LL, UL] & \multicolumn{1}{c|}{ SE } & \multicolumn{1}{c|}{$\boldsymbol{t}$} & \multicolumn{1}{c|}{$\boldsymbol{p}$} \\
\hline Constant (AC) & 21.54 & $21.12-21.98$ & .22 & 99.17 & $.00^{* *}$ \\
\hline $\begin{array}{l}\text { Perceived Organizational } \\
\text { Support (POS) }\end{array}$ & .33 & $.24-.42$ & .04 & 7.40 & $.00^{* *}$ \\
\hline $\begin{array}{l}\text { Psychological Contract } \\
\text { Incongruence (PCI) }\end{array}$ & -.11 & $--.20--.02$ & .04 & -2.37 & $.02^{*}$ \\
\hline Interaction & -.002 & $-.02-.01$ & .00 & -.29 & .77 \\
\hline$R^{2}=.27$ & & &
\end{tabular}

Moderation effect of psychological contract incongruence between perceived supervisor support and affective commitment

\begin{tabular}{|l|l|l|l|l|l|}
\hline \multicolumn{1}{|c|}{ Predictor } & \multicolumn{1}{|c|}{ b } & b 95\% CI [LL, UL] & SE & t & p \\
\hline Constant (AC) & 21.59 & $21.14-22.03$ & .23 & 95.92 & $.00^{* *}$ \\
\hline $\begin{array}{l}\text { Perceived Supervisor Support } \\
\text { (PSS) }\end{array}$ & .21 & $.08-.33$ & .06 & 3.28 & $.00^{* *}$ \\
\hline $\begin{array}{l}\text { Psychological Contract } \\
\text { Incongruence (PCI) }\end{array}$ & -.21 & $-.30--.12$ & .05 & -4.53 & $.00^{* *}$ \\
\hline Interaction & .002 & $-.02-.02$ & .01 & .24 & .81 \\
\hline$R^{2}=.15$ & & & & \\
\hline$* p .05 * * * p<.001$ &
\end{tabular}

$* p<.05 ; * * p<.001$ 
The Hypothesis 2 research question asked," Does neuroticism moderate the relationship between POS, PSS, and AC?". Two models were used to examine the moderations of NEU between POS and AC as well as between PSS and AC. The first NEU moderation analysis (see Table 22) indicated that POS is a significant, positive predictor of $\mathrm{AC}(b=.36, p<.001)$ and neuroticism is a marginally significant, negative predictor of AC $(b=-.12, p=.07)$. The interaction of POS and NEU $(\mathrm{b}=.017, p=.11)$ did not significantly predict affective commitment. The whole model explains $28 \%$ of the variance in affective commitment, with no contribution from the interaction. The regression line for the moderating effect of neuroticism on POS and AC is shown in Figure 3. The figure shows that high-end and low-end effects have a slightly different trend as AC and POS increase. The change, however, is not significant.

Figure 3.

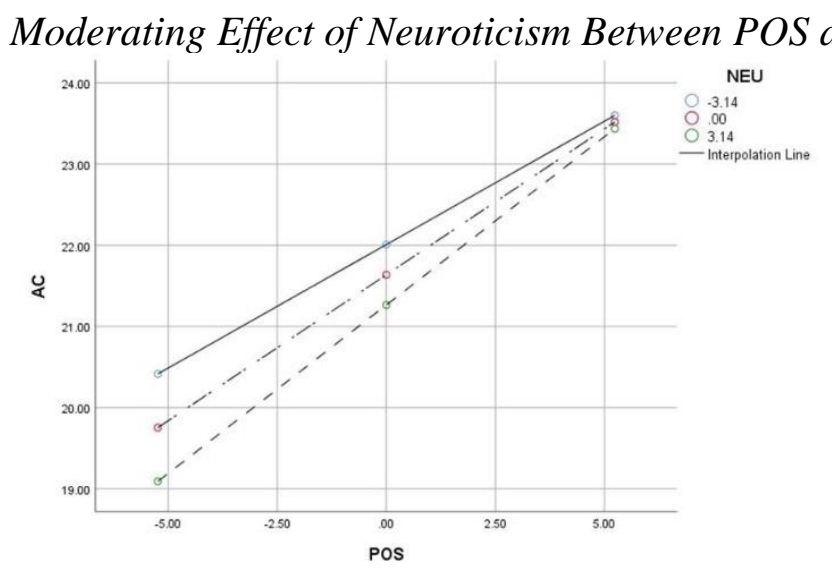

The second NEU model analysis indicated that PSS is a significant, positive predictor of $\mathrm{AC}(B=.27,(p<.001)$ and neuroticism is a significant, negative predictor of $\mathrm{AC}(B=-.20, p=.01)$. The interaction of PSS and NEU $(B=.001, p=.94)$ was not significant (see Table 22). The whole model explains $11 \%$ of the variance in affective 
commitment, with no contribution from the interaction. The regression line for the moderating effect of neuroticism on PSS and AC, shown in Figure 4, illustrates that the relationship between PSS and AC in the high and low ends are very similar, which supports no significance in moderating effect.

Figure 4.

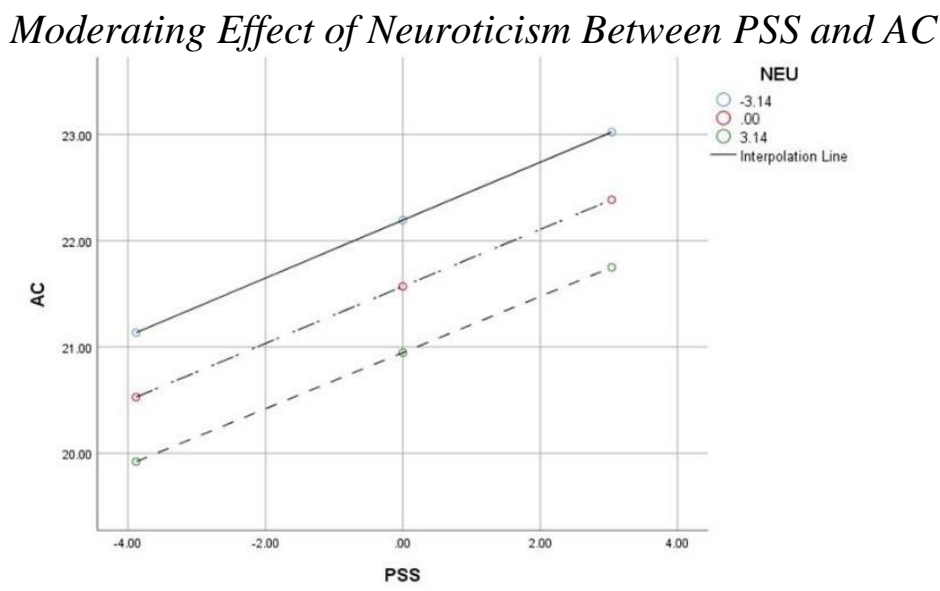

In summary of results for Hypothesis 2, the examination of the research question did not support the hypothesis that neuroticism moderated the relationship between POS, PSS, and AC. Whereas the interaction effects in this study were not significant for NEU with either POS or PSS, the research evidence rejects Hypothesis 2.

Hypothesis 3

Examining the research question for Hypothesis 3, “ Does psychological contract incongruence moderate the relationship between POS, PSS, and AC?", was also examined in two parts. Moderation analyses were used to examine the effect of PCI on POS-AC and PSS-AC. The first PCI moderation analysis (see Table 22) indicated that POS is a significant, positive predictor of $\mathrm{AC}(B=, 33, p<.001)$ and PCI is a significant, negative predictor of $\mathrm{AC}(B=-.11, p=.02)$. The interaction of POS and PCI $(B=-.002$, 
$p=.77$ ) did not significantly predict affective commitment. The whole model explains $27 \%$ of the variance in affective commitment, with no contribution from the interaction. The regression line for the moderating effect of PCI on POS and AC is shown in Figure 5, which illustrates that that high-end and low-end effects of PCI have a very slightly different trend as AC and POS increase. The change, however, is not significant.

Figure 5.

Moderating Effect of Psychological Contract Incongruence (POS and AC)

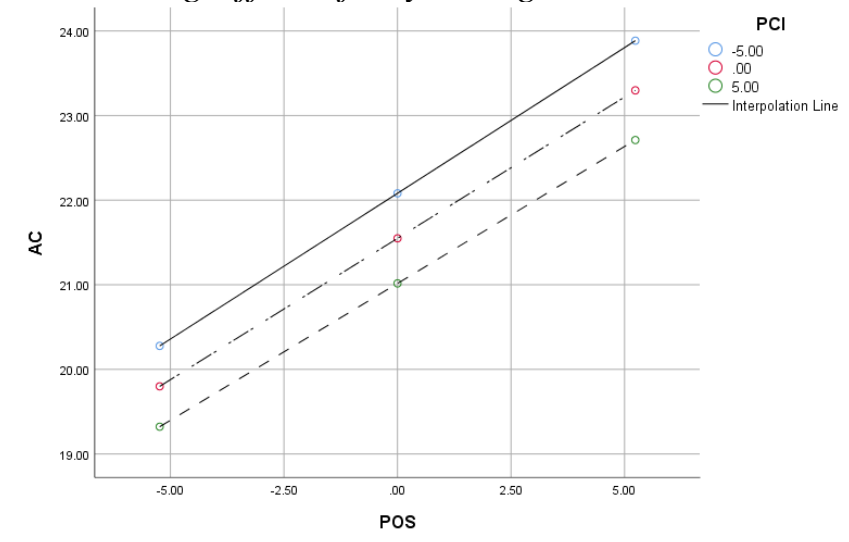

The second PCI model analysis indicated that PSS is a significant, positive predictor of $\mathrm{AC}(B=.21, p<.001)$ and $\mathrm{PCI}$ is a significant, negative predictor of $\mathrm{AC}(B$ $=-.21, p=.001)$. The interaction of PSS and PCI $(B=.001, p=.81)$ was not significant (see Table 22). The whole model explains $15 \%$ of the variance in affective commitment, with no contribution from the interaction. The regression line for the moderating effect of PCI on PSS and AC (see Figure 6) also illustrates that the relationship between PSS and $\mathrm{AC}$ in the high and low ends are very similar, which supports no significance in moderating effect. 
Figure 6.

Moderating Effect of Psychological Contract Incongruence (PSS and AC)

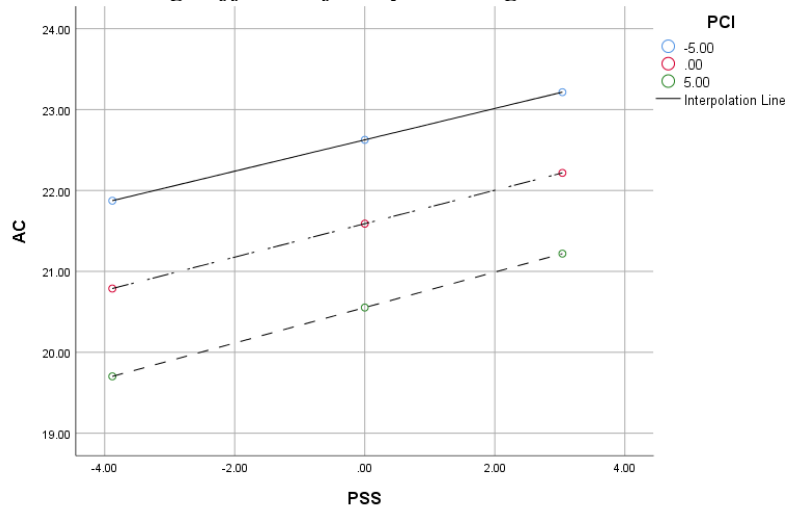

In summary of results for Hypothesis 3, the examination of the research question did not support the hypothesis that psychological contract incongrence moderated the relationship between POS, PSS, and AC.Whereas the interaction effects in this study were not significant for PCI with either POS or PSS, the research evidence rejects Hypothesis 3.

Summary

Results of this study support the first hypotheses proposed in this study. The variables perceived organizational support, perceived supervisor support, and affective commitment were significantly correlated. The results reject the second and third hypotheses which predicted the relationship between perceived organizational support, perceived supervisor support, and affective commiment would be dampened by the moderators neuroticism and psychological contract incongruence. 


\section{CHAPTER V}

\section{DISCUSSION}

This chapter provides a summary of the research and reports the conclusions and recommendations that resulted from the data. The findings of the study are discussed and interpreted. The chapter then concludes with the limitations and recommendations for future research.

\section{Summary of the Study}

Organizational commitment has engendered research interest for more than 50 years. Studies of affective commitment continue to seek better understanding of employee involvement in, identification with, and attachment to an organization (Albrecht \& Marty, 2020). Organizational support theory proposes that employees form overall and personified perceptions about their organization and their supervisor; perceived support from both is associated with the extent to which employees feel valued for their contributions and well-being (Kurtessis et al., 2017).

Organizations take note of how employee perceptions and affective commitment are associated with desirable outcomes such as job performance, retention, employee engagement, and prosocial behavior (Albrecht et al., 2020; Eisenberger et al., 2002; Kurtessis et al, 2017; Vandenberghe et al., 2002). To enhance positive workplace outcomes and behaviors, organizations increasingly turn to human resource development scholars to better understand the mechanisms underlying perceived support and feelings of affective commitment. Organizations invest in often costly development programs and interventions intended to increase employee commitment, yet employee perceptions of programs may not always be positive (Biggs et al., 2014 Vandenberghe et al., 2002). 
Panaccio et al. (2012) explored the moderating effects of Big Five personality traits and psychological contract breach on development of commitment though the literature did not specifically examine the two moderators of neuroticism and psychological contract incongruence. Those specific moderating variables may indicate hidden factors influencing how employees form perceptions and, subsequently, how those perceptions link to feelings of loyalty to the organization.

The purpose of this study was to explore a hypothesized affective commitment model by exploring the relation between perceived organizational support, perceived supervisor support, and affective commitment as moderated by neuroticism and psychological contract incongruence. Three overarching research questions guided this study: (a) What is the relationship between perceived organizational support, perceived supervisor support, neuroticism, psychological contract incongruence, organizational commitment? (b) Does neuroticism moderate the relationship between POS, PSS, and AC? and (c) Does psychological contract incongruence moderate the relationship between POS, PSS, and AC? Three hypotheses were tested to examine these questions. $\mathrm{H}_{1}$ : Perceived organizational support, perceived supervisor support, neuroticism, psychological contract incongruence, and affective commitment are significantly related.

$\mathrm{H}_{2}$ : Neuroticism will significantly moderate the relationship between POS and AC and PSS and AC, such that the relationship will be weakened.

$\mathrm{H}_{3}$ : $\quad$ Psychological contract incongruence will significantly moderate the relationship between POS and AC and PSS and AC, such that the relationship will be weakened. 
An online survey was used to investigate the relations among the variables. Existing literature was used to provide a foundation for the study and guide the research. Correlational and regression analyses were used to test the hypothesized model and examine the hypotheses.

Results supported the hypothesis that perceived organizational support, perceived supervisor support, and affective commitment are significantly related. The hidden factors of neuroticism and psychological contract incongruence were found to negatively, significantly predict POS, PSS, and AC; however, the interaction results did not yield a significant moderating effect in any of the relationships.

\section{Discussion of the Results}

The study was guided by conceptual frameworks (Figures 1 and 2) to explore the relationship between perceived organizational support, perceived supervisor support, and affective commitment as moderated by neuroticism and psychological contract. The results from this study demonstrate support for the first hypothesis and did not support the second and third. First $H_{1}$ will be discussed, followed by $H_{2}$ and $H_{3}$, and concluded with a brief summary which will close the section.

\section{Hypothesis 1}

The first hypothesis posited that there will be a relationship between perceived organizational support, perceived supervisor support, and affective commitment. Correlation coefficients were computed among the two independent variables and the dependent variable and the results are presented in Table 21 The correlations were statistically significant, greater than or equal to .30 . The correlation between perceived organizational support and affective commitment was significant with moderate positive 
correlation $r(279)=.507, p<.01$. The correlation between perceived supervisor support and affective commitment was also significant with low positive correlation, $r(279)=$ $.301, p<.01$. Finally, the correlation between perceived organizational support and perceived supervisor support was significant, with moderate positive correlation $r(279)=$ $.604, p<.01$.

The results from the analysis shown in Figure 7 indicate a significant positive relationship between perceived organizational support, perceived supervisor support, and affective commitment. Findings showed support for $H_{1}$ and the null hypothesis was rejected.

Figure 7.

Pearson Correlations among POS, PSS, and AC

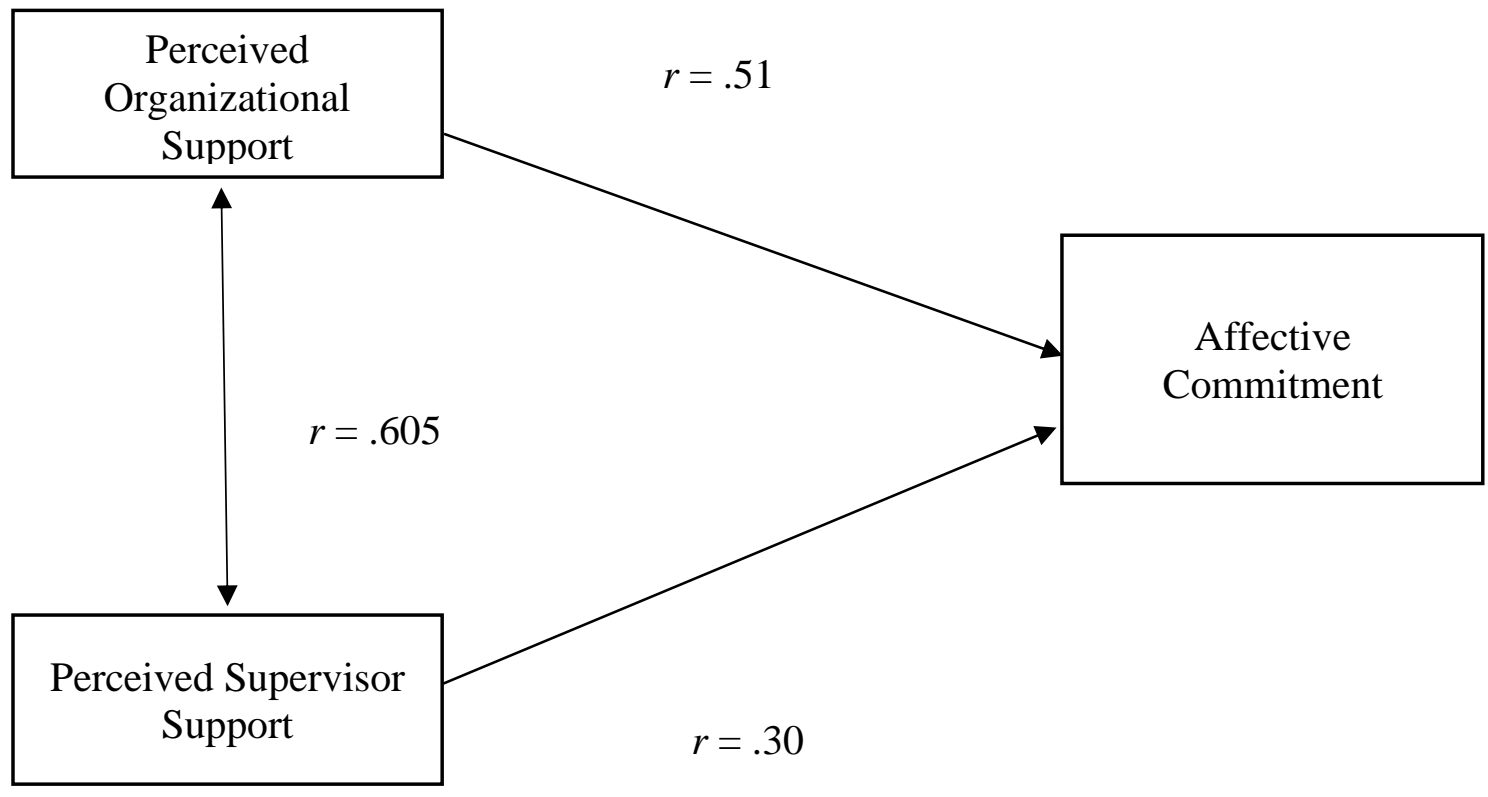




\section{Hypothesis 2}

The research question for Hypothesis 2 asked, "Does neuroticism moderate the relationship between POS, PSS, and AC?". As presented in Chapter IV, two moderation analyses were used to measure the effects, POS-AC and PSS-AC. The results found that perceived organizational support is a significant, positive predictor of $\mathrm{AC}(B=.36)(p<$ $.001)$ and neuroticism is a marginal, negative predictor of $\mathrm{AC}(B=-.12)(p<.07)$. The interaction of POS and NEU $(B=.017)(p=.11)$ did not significantly predict affective commitment. The second analysis found that PSS is a significant, positive predictor of $\mathrm{AC}(B=.27)(p<.001)$ and neuroticism is a significant, negative predictor of $\mathrm{AC}(B=-$ .20) $(p=<.01)$. The interaction of PSS and NEU $(B=.001)(p=.94)$ was also not significant) (see Table 22).

These findings confirm that neuroticism is a negative, significant predictor of AC. The results contribute to the literature by testing whether positive perceptions about the organization and the supervisor can been developed and held by employees, despite different levels in the trait neuroticism. Therefore, organizational researchers and HRD professionals should not attribute lower levels of perceived support and affective commitment to employees high in the trait neuroticism. This suggests that employees who generally tend to view experiences and relationships through a negative lens do not perceive lower support. Because neuroticism is a significant, negative predictor of AC, future studies should explore whether it has a mediating effect in the POS, PSS, AC relationship. 


\section{Neuroticism as a Negative, Significant Predictor of AC}

The results of the study did not support a moderating effect of neuroticism.

However, the empirical data in descriptive statistics may offer insights for researchers and HRD professionals regarding the potential negative hidden factor of neuroticism. The distribution of responses to neuroticism items provides perspective beyond the aggregated variables. For example, in general, the participants view themselves as emotionally stable and not easily upset. In a similar item, the word "stress" is used rather than "highly emotional" and the number of "Strongly Agree" selections is markedly decreased. This suggests employees distinguish feeling stress from having a tendency to feel easily upset. While $48.3 \%(N=132)$ strongly disagree they have a tendency for depression, none (0\%) strongly agree they have a tendency for depression, leaving $51 \%$ $(N=147)$ of the responses distributed among agree, neither agree nor disagree, and disagree. This item offers additional insight because, by directly addressing feelings of negativity, the results show a wide range of self-reported depression. Gender and ethnicity frequencies shown in Table 24 comprise the population of those reporting some level of depression.

Table 24.

Gender and Ethnicity Reporting Tendency for Depression

\begin{tabular}{llrr}
\hline Category & Variable & $f$ & \multicolumn{1}{r}{ Percent } \\
\hline Gender & Female & 116 & 78.9 \\
& Male & 30 & 20.4 \\
& Other & 1 & .7 \\
& Total & 147 & 100.0 \\
\hline Ethnicity & Asian & 3 & 2.1 \\
& Black/African American & 16 & 11.0 \\
& Latin American or Caribbean & 73 & 50.0 \\
& White & 41 & 28.1 \\
& Other & 13 & 8.8 \\
& Total & 146 & 100.0 \\
\hline
\end{tabular}




\section{Hypothesis 3}

Hypothesis 3 stated that psychological contract incongruence would moderate the relationship between POS, PSS, and AC, such that it was dampened. Moderator analyses were used to examine the effect of PCI on POS-AC and PSS-AC. The first PCI moderation analysis (see Table 23) indicated that POS is a significant, positive predictor of $\mathrm{AC}(B=.33)(p<.001)$ and $\mathrm{PCI}$ is a significant, negative predictor of $\mathrm{AC}(B=-.11)(p$ $=.02)$. The interaction of POS and PCI $(B=-.002)(p=.77)$ did not significantly predict affective commitment.

The second PCI model analysis indicated that PSS is a significant, positive predictor of $\mathrm{AC}(B=.21)(p<.001)$ and $\mathrm{PCI}$ is a significant, negative predictor of AC $(B=-.21)(p=<.001)$. The interaction of PSS and PCI $(B=.001)(p=.81)$ was not significant) (see Table 22). The whole model explains $15 \%$ of the variance in affective commitment, with no contribution from the interaction $\left(R^{2}=.15\right)$. The results of these moderation analyses do not support Hypothesis 3, and the null hypotheses was not rejected.

Psychological Contract Incongruence as a Negative, Significant Predictor of AC

As noted by Porter et al. (1998), employees expect significantly more positive considerations and incentives than employers knew were offered. The item measuring attribution within the PCI variable revealed an unexpected prevalence of contract breaches. In an analysis of only POS, PSS, and AC, the existence of broken promises would have been masked. Slightly more than half the participants $(52.2 \%)(N=142)$ indicated no psychological contract breach had occurred. To examine those with reported breaches, the remaining $47.8 \%(N=137)$ were more closely studied. Further examination 
revealed that $21.3 \%(N=58)$ believed the breach was reneged, a known promise was intentionally withheld. Approximately the same number $(22.2 \%)(N=62)$ believed the breach was due to disruption or changed circumstances making fulfilment impossible. Contrary to Hypothesis 3, the study yielded only 10 responses (3.6\%) attributing the breach to psychological contract incongruence, as defined by Morrison et al. (1998) as an honest misunderstanding. The finding is significant finding, given $21.3 \%$ of all respondents, $42 \%$ of the breaches $(N=137)$ attributed the breach to intentional reneging. The gender and ethnicity of those attributing a contact breach to be intentional are displayed in Table 25 .

Table 25.

Gender and Ethnicity Attributing Contract Breach to Reneging

\begin{tabular}{llrr}
\hline Category & Variable & $f$ & \multicolumn{1}{c}{ Percent } \\
\hline Gender & Female & 49 & 84.5 \\
& Male & 9 & 15.5 \\
& Total & 58 & 100.0 \\
\hline Ethnicity & Asian & 1 & 1.7 \\
& Black/African American & 12 & 20.7 \\
& Latin American or Caribbean & 19 & 32.8 \\
& White & 20 & 34.5 \\
& Other & 6 & 10.3 \\
& Total & 58 & 100.0 \\
\hline
\end{tabular}

To understand the implications of this finding, the literature described earlier in the study explained examples of contracts as inducements perceived to have value by employees, but which are typically not documented in employment contracts or job offers, e.g., guaranteed job security, salary increases, career growth, training, or bonuses (Porter, Pearce, Tripoli \& Lewis, 1998).

Conway et al. (2012) called for further research that enriches understanding employees' views about psychological contract incongruence. This study provides further 
insight about the attribution of breaches, and also contributes to a call for further research (Morrison et al., 1998) to examine psychological contract incongruence with the POS assessment.

The paucity of attributions to psychological contract incongruence, just a misunderstanding, contradicts the third research question, yet the empirical results contribute to a better understanding of attribution within a study of not only POS, but also with PSS and AC. The other moderator, neuroticism, was included in this study to explore whether people who had higher traits of neuroticism would perceive more psychological contract breaches and whether neuroticism influenced their attribution of a breach. The results of this study suggest that neuroticism had no interaction effect, and psychological contract breach was widely reported.

\section{Implications for Practice}

The results suggest that organizations consider whether hidden factors may affect how their employees feel about the level of support they receive from the organization and their supervisor. Although neuroticism and psychological contract incongruence did not moderate the POS, PSS, AC relationship, the study provides clear evidence that both hidden factors are negative, significant predictors of AC. Both neuroticism and psychological contract incongruence remain as hidden factors which may dampen commitment, however not through moderation effect.

The participants of this study work in a single institution of higher education and represent job functions within every academic and administrative unit of the university. The work environment offers ongoing education and professional development. For example, $75.2 \%$ of the participants held a master's degree or higher. Due to the study's 
design, fully $100 \%$ of the participants engaged in professional and leadership development programs. Additionally, it is of note that all of the study's participants also supervise other employees. The results of this study of supervisors may have implications for multiple areas of practice, e.g., organizational support practices, HRD treatments, supervisor training and resources, new employee onboarding, and development of resources and guidelines. In addition, with the emergence of the COVID-19 global pandemic, the results may have implications for enhanced support to a remote workforce.

To positively influence employee perceptions, organizations might expand the use of Human Resource Development practices and programs. Studies have shown the positive relationship between perceived organizational support and HRD practices such as policies, procedures, and programs. Employees perceive the implementation of formalized measures as indications that the organization cares enough about its people to put systems in place to support them (Eisenberger \& Stinglhamber, 2011).

Organizational commitment is defined by Kottke (1988) as bi-directional pathways in exchanges between employees and organizations and employees and supervisors. The strong response rate of the study (55\%) suggests employees valued being consulted regarding their perceptions and feelings of commitment. By seeking opinions, organizations can obtain essential feedback regarding the effectiveness of HRD programs and inform the development of new programs or enhancement of current practices.

By taking measures to elicit employee perceptions, HRD professionals might uncover hidden factors with the potential to dampen commitment to the organization. Results from this study indicate there are practical reasons to explore measures to 
mitigate negative viewpoints and prevent breaches of psychological contracts. Panaccio (2012) suggested organizations consider personality differences when designing HRD systems and processes. Organizations might enhance communication methods regarding current and new programs and treatments to provide a broader range of appeal to individuals higher in the trait neuroticism. For example, surveys can be conducted to measure levels of satisfaction with current benefits, ask for feedback and criticism, and encourage those with negative views to bring them forward to enable discussion.

In periodic organizational surveys, items asking about employee expectations of the organization might surface employee expectations, unmet needs, and identify trends. The results clearly tell us that psychological contract breaches occur far more frequently than organizations and supervisors are aware of. Further, the implication for practice is the findings show that a psychological contract breach is rarely considered to be an honest misunderstanding. Instead, unless circumstances eliminate the possibility of fulfilling a promise, an equal number of employees believe breaches were intentional. It suggests that HRD implement treatments such as goal-setting guidelines and training for employees and supervisors. The importance of two-way communication might be incorporated into training, beginning with the new employee onboarding process. Supervisor training on topics including listening, setting clear and specific expectations, and providing regular feedback can potentially prevent future breaches of unspoken psychological contracts.

Organizations can provide operational procedures to employees, and explain the organization's resources and contacts to assist in a variety of potential issues, e.g., 
appropriate ways to handle problems, how to discuss concerns with their supervisor, how to file a complaint, or report a violation of a policy.

Another implication for HRD practice is to provide training to both supervisors and employees on the performance evaluation process. Establish organizational expectations of informal, frequent communication, and a mid-year and year-end formalized discussion about performance, outcomes, and clear goals for the next performance period. Self-evaluations as a practice can also provide employees an opportunity for self-reflection and evaluation. In addition, organizations can encourage employees to describe their goals, aspirations, and expectations for discussion with their supervisors.

The literature and findings of this study discuss that supervisors are sometimes perceived as agents of the organization, even to the extent that the supervisor is seen as the other party of a psychological contract (Dysvik, 2012). Organizations can provide training for supervisors to increase self-awareness and learn to connect their actions and behaviors to how it may be received by employees. Communication resources and support materials can be provided to encourage the creation of a positive work environment. Programs and coaching can be provided on a range of specific actions supervisors can take to improve communication and allay negative concerns: listening with empathy, onboarding new employees effectively, offering opportunities for professional development, assigning special projects, and introducing informal practices such as teambuilding activities.

Finally, the results of this show that nearly half of the participants believed a promise to them had been broken by the organization or by the supervisor. These results 
suggest that HRD practices explore ways to enhance communicate about how supervisors can utilize rewards and recognition for their teams. Monetary and non-monetary recognition are effective ways for an organization and a supervisor to acknowledge and appreciate efforts such as safety, quality, special project completion, or exceeding a team goal.

In summary, the results of this study suggest implications for multiple areas of HRD practice, e.g., organizational support, HRD treatments, supervisor support, new employee onboarding, development of employee resources and guidelines, and potential considerations for support in a remote workforce.

\section{Implications for Theory}

This study tested the relationship between POS, PSS, and AC by hypothesizing that two hidden factors, neuroticism and psychological contract incongruence would moderate the relationship, such that it was dampened. The results advance understanding of organizational support theory. The findings support the literature and confirm strong positive relationships between POS, PSS, and AC. Two moderators were examined to determine whether they predict AC and whether they had a moderating effect on the core relationship model. Examining neuroticism and psychological contract incongruence together as moderators contributes to the literature in multiple areas: organizational support theory, personality trait theory, and psychological contract theory.

This study demonstrated that neuroticism had no significant effect on either the POS-AC relationship $(p=.11)$ or the PSS-AC relationship $(p=.94)$. By testing neuroticism as a moderating effect against both forms of support, the absence of 
moderation findings suggests alternative underlying mechanisms contribute to a positive POS, PSS, and AC relationship.

Empirical results for the second moderator, psychological contract incongruence, contribute to the literature by further distinguishing psychological contract theory from organizational support theory. The presence of contract breaches occurred in nearly half of a population who hold strong, positive perceptions about POS, PSS, and AC. The empirical results from this combined examination of psychological contract incongruence and neuroticism clearly show that these moderators, individually and together, did not change affective commitment. The results, on the other hand, suggest that individuals high in the trait neuroticism do not perceive more breaches of psychological contract. It is not known whether people with higher traits of neuroticism perceive breaches to be intentional. Yet, in this notably positive-perceptions population, it is clear that employees rarely attribute an unfulfilled psychological contract to a case of simple misunderstanding.

The study contributes to the field of psychological contract incongruence in that it the study's findings may interest researchers to further explore the paradox of widespread breaches, yet unwaveringly high POS, PSS, and AC.

While the results did not support the moderating effect of PCI, the breaches suggest a need for improved communication between employees and supervisors to clarify mutual expectations, both spoken and previously unspoken. In summary, this study's results expand the understanding of both organizational support theory and psychological contract theory, and present results that offer both new insights and calls for further research. 
The next section addresses the limitations of the study and recommendations for future research.

\section{Limitations and Recommendations for Future Research}

The first possible limitation of this study is the use of a purposive sampling technique, inviting supervising employees who had completed a leadership program in a single institution of higher education. The purpose of this sample selection was to concentrate the examination on a diverse population of trained supervisors relevant to the study. Although this study focused supervisors in higher education and the results are consistent with the results in prior research, the reader should be cautious in generalizing the results to other organizations. It would be interesting and useful to extend testing the models examined in this research to include different types of organizations, in different industries. Both actions would increase the generalizability of the findings. This study examined each demographic variable, including gender, ethnicity, and years with the supervisor and organization, as covariant. While the results did not yield significant results, the demographic data would be essential to understand employee perceptions feelings of commitment.

The second possible limitation is the use of self-report measures for this study. Collecting data from a single data source (survey), as employed in this study, presents potential issues with common method variance. Reio (2010) advises HRD researchers to control common method variance by careful research procedural design utilization and through use of statistical controls. First, procedurally, Dillman et al.'s (2009) Tailored Design Method was followed to reduce the likelihood of coverage, sampling, measurement and nonresponse error. Moreover, in accordance with Dillman et al.'s 
(2009) direction, a pilot study was conducted which aided in creating clear instructions and procedures. Second, statistically speaking, using Harmen's single-factor test diagnostic as a guide, an exploratory factor analysis (unrotated) was conducted on all the research variables. Using the procedure of factor analysis, results from this study revealed little evidence of common method variance bias. As more than one factor emerged, the analysis suggests results are not likely attributable to common method variance (Reio, 2010). Thus, this research demonstrates how the use of a combination of procedural and statistical procedures can limit possible common method variance issues. Further, to limit possible common method variance bias in future research, one might also use affect and acquiescence bias measures as statistical control variables. Another approach would be to collect the dependent and independent variables at different times and using other sources of the dependent variable (e.g., supervisor or coworker ratings, as appropriate) from the independent variables (Reio, 2010).

This study may be limited by response rate. The population receiving the survey link consisted of full-time, benefits earning employees of a single institution of higher education who had completed a leadership program for management. Surveys were sent by email to 573 individuals. Prior to the three-week data collection period, potential participants received emails that introduced the study, asked for their participation, and alerted them to expect the email containing the online survey link. At the closing of the survey, there were 318 responses comprising a response rate of 55\%. A preliminary examination of the results, however, revealed missing all demographic data from the last 20 surveys. The results indicate a possible systematic occurrence in the survey. The last step in the survey process required pressing "submit" to conclude. Because the responses 
reported completion, it is possible that the last twenty participants were not presented with demographic questions. Further examination of the data identified nineteen cases missing more than $50 \%$ of the data. Overall, 39 cases were removed. The 279 survey responses utilized in this study had 3\% missing data, representing a completed response rate of 49\%. Although this research closely followed Dillman et al.'s (2009) recommendations to increase response rates, it may be that a small incentive might be used to increase participation as well. Care must be taken, however, in that introducing incentives into the study might be a source of systematic in and of itself. To guard against this, the researcher could include non-incentivized participants and compare the results. If there is no evidence of systematic differences in the research variables by group, then incentives did not necessarily introduce bias into the study.

Finally, this study may be limited by nonresponse bias, which was not controlled for while collecting data. Nonresponse bias may occur if a demographic category within the sample population did not respond to the survey, indicating a bias in the study's data analysis. By comparing available demographics of all individuals invited to participate, the determination was made that the respondents' demographics are consistent with the demographics of the target population, thus indicating no bias was detectable in the data.

On the basis of these findings, additional studies are recommended to further explore how supervisors' interactions with their direct reports relate to perceptions about their own supervisor. A major research contribution would be augmenting the model to examine mediation of the variables and expanding the personality traits to the Big Five and develop additional items to tease out the otherwise 
hidden factor of psychological contract incongruence . Further research is also needed to explore psychological contract incongruence with a broader population.

This study measured length of time with the supervisor and with the organization, with the uppermost tenure of 6 or more years. The population was narrowed to that timeframe to focus exclusively supervisors who had attended the LEAP leadership program. With $80 \%$ of the population reporting length of time with the organization at 6 or more years, future research should expand the length of time variables to incorporate additional lengths, such as $6-8,9-10,10-15,15-20,21$ and over.

Further research is recommended to test a broader population of supervisors, to include all supervisors who had not attended the leadership program. Additionally, a study examining the direct reports of the supervisors who participated in this study might uncover differences in perceptions between supervisors and their direct reports.

New studies are needed to further explore organizational support theory with psychological contract theory. The connection has been established in the literature, however psychological contract breaches and attribution indicate the possibility of other hidden interactions.

New studies are called for to test the model used in this study in foreign organizations. As organizations expand and open locations in countries with different workplace ideologies, understanding how organizational support theory, psychological contract theory, and personality trait theory serve as theoretical frameworks will be increasingly important. Past research in the field of organizational support in a wide range of countries, e.g., Australia, Brazil, India, Mainland China, Hong Kong, South Korea, and the UK (Bianchi, 2004; Coyle-Shapiro, Costa, Doden \& Chang, 2019; Kwak, 
Chung, Xu, Eun-Jing, 2010; Liu, 2009). However, further studies are needed to examine employee-employer relationships in countries with emerging commerce and different cultures, such as Chile, Nigeria, and Peru.

Survey responses for this study were collected during the period immediately preceding the spread of COVID-19 in the institution's community. The empirical results from this study might serve as a baseline for a longitudinal study of changes in perceptions before and after the onset of the global pandemic. Historic economic impacts and medical benefits may have implications to all forms of organizational commitment. The employee perception about psychological contracts may have experienced significant change in the months following the requirements for employees of most institutions of higher education to close campuses and begin all work through electronic and computerbased methods. During and after a time of widespread employment uncertainty, studies are needed to detect and monitor changes in all variables measured in this and other organizational studies. New insights and empirical results may test the very structure of jobs, employment norms, supervision, communication, and workplace behaviors. Social exchange theory as it relates to organizational support might be in the process of producing new formulas for reciprocity.

\section{Conclusions}

The purpose of this study was to further explore the relationship between perceived organizational support, perceived supervisor support, and affective commitment as moderated by the personality trait neuroticism and psychological contract incongruence. The findings suggest that both neuroticism and psychological contract 
incongruence are negative, significant predictors of AC. Further the study determined that neither moderator had an interaction effect with POS or PSS.

The findings of this study provided new insights into the neuroticism scale items, suggesting that further examining depression is needed, as it was reported to some degree in more than half of the population of this study. Another finding of note is the empirical evidence that very few individuals attribute a psychological contract breach to an honest misunderstanding. Nearly half of the identified breaches were attributed to intentional reneging. This finding was unexpected from a population reporting positive, significant levels of POS, PSS, and AC. This insight suggests that supervisors and organizations should be aware that, whether known or unknown, their employees have developed unspoken psychological contracts. Providing training for supervisors to improve two-way communication may uncover unspoken expectations, allow for conversation and clarifications to take place, and mitigate future breaches.

In addition to the described insights, closing discussion should note that this study offers a snapshot of POS, PSS, and AC before the arrival of the COVID-19 pandemic. The data collection concluded two weeks prior to the complete shutdown of workplaces in the community. The university was forced to evacuate the offices and most employees worked remotely for a period of at least six months. With an unprecedented disruption immediately following data collection, the results reflect employee perceptions, expectations, and feelings of stress and negativity before the workplace and employee paradigm shifts that may emerge from the pandemic. 


\section{REFERENCES}

Alfes, K., Shantz, A., Truss, C., \& Soane, E. (2013). The link between perceived human resource management practices, engagement and employee behaviour: A moderated mediation model. The International Journal of Human Resource Management, 24, 330-351.

Allen, D. G., Shore, L. M., \& Griffeth, R. W. (2003). The role of perceived organizational support and supportive human resource practices in the turnover process. Journal of Management, 29, 99-118.

Allen, N. J., \& Meyer, J. P. (1990). The measurement and antecedents of affective, continuance and normative commitment to the organization. Journal of Occupational Psychology, 63, 1-18.

Argyris, C. (1960). Understanding organizational behavior. Oxford, England: Dorsey.

Armeli, S., Eisenberger, R., Fasolo, P., \& Lynch, P. (1998). Perceived organizational support and police performance: The moderating influence of socioemotional needs. Journal of Applied Psychology, 83, 288-297.

Aselage, J., \& Eisenberger, R. (2003). Perceived organizational support and psychological contracts: A theoretical integration. Journal of Organizational Behavior, 24, 491-509.

Barksdale, K., \& Shore, L. (1997). A typological approach to examining psychological contracts. Journal of Organizational Behavior, 19, 731-744.

Barrick, M. R., \& Mount, M. K. (1991). The big five personality dimensions and job performance: A meta-analysis. Personnel Psychology, 44, 1-26.

Barrick, M. R., Mount, M. K., \& Gupta, R. (2003). Meta-analysis of the relationship between the five-factor model of personality and holland's occupational types. Personnel Psychology, 56, 45-74.

Barrick, M. R., Parks, L., \& Mount, M. K. (2005). Self-monitoring as a moderator of the relationships between personality traits and performance. Personnel Psychology, 58, 745-767.

Barrick, M. R., \& Mount, M. K. (1993). Autonomy as a moderator of the relationships between the big five personality dimensions and job performance. Journal of Applied Psychology, 78, 111-118.

Biggs, A., Brough, P., \& Barbour, J. P. (2014). Enhancing work-related attitudes and work engagement: A quasi-experimental study of the impact of an organizational 
intervention. International Journal of Stress Management, 21, 43-68. doi: $10.1037 / \mathrm{a} 0034508$

Blau, P. M. (1964). Exchange and power in social life. New York: John Wiley \& Sons, Inc.

Bowling, N. A., \& Eschleman, K. J. (2010). Employee personality as a moderator of the relationships between work stressors and counterproductive work behavior. Journal of Occupational Health Psychology, 15, 91-103.

Brinberg, D., \& Castell, P. (1982). A resource exchange theory approach to interpersonal interactions: A test of foa's theory. Journal of Personality and Social Psychology, 43, 260-269. doi:10.1037/0022-3514.43.2.260

Buchanan, B. (1974). Building organizational commitment: The socialization of managers in work organizations. Administrative Science Quarterly, 19, 533-546.

Cable, D. M., \& Judge, T. A. (1994). Pay preferences and job search decisions: A personorganization fit perspective. Personnel Psychology, 47, 317-348.

Carrell, M. R., \& Heavrin, C. (2008). Negotiating essentials: Theory, skills, and practices Prentice Hall.

Cloutier, O., Felusiak, L., Hill, C., \& Pemberton-Jones, E. (2015). The importance of developing strategies for employee retention. Journal of Leadership, Accountability and Ethics, 12, 119-129.

Conway, N., \& Briner, R. B. (2002). A daily diary study of affective responses to psychological contract breach and exceeded promises. Journal of Organizational Behavior, 23, 287-302. doi:10.1002/job.139

Conway, N., Guest, D., \& Trenberth, L. (2011). Testing the differential effects of changes in psychological contract breach and fulfillment. Journal of Vocational Behavior, 79, 267-276. doi:10.1016/j.jvb.2011.01.003

Cook, J., \& Wall, T. (1980). New work attitude measures of trust, organizational commitment and personal need non-fulfilment. Journal of Occupational Psychology, $53,39-52$.

Cortina, J. M. (1993). What is coefficient alpha? an examination of theory and applications. Journal of Applied Psychology, 78(1), 98-104. doi:10.1037/00219010.78 .1 .98

Costa Jr, P. T., \& McCrae, R. R. (1987). Neuroticism, somatic complaints, and disease: Is the bark worse than the bite? Journal of Personality, 55, 299-316. 
Costa Jr., P. T., \& McCrae, R. R. (1995). Domains and facets: Hierarchical personality assessment using the revised NEO personality inventory. Journal of Personality Assessment, 64, 21-50.

Cotterell, N., Eisenberger, R., \& Speicher, H. (1992). Inhibiting effects of reciprocation wariness on interpersonal relationships. Journal of Personality and Social Psychology, 62, 658-668. doi:10.1037/0022-3514.62.4.658

Coyle-Shapiro, J., \& Kessler, I. (2000). Consequences of the psychological contract for the employment relationship: A large scale survey*. Journal of Management Studies, 37, 903-930. doi:10.1111/1467-6486.00210

Coyle-Shapiro, J. A., \& Conway, N. (2005). Exchange relationships: Examining psychological contracts and perceived organizational support. Journal of Applied Psychology, 90, 774-781.

Creswell, John W.,, Creswell,J.David.,. (2014). Research design : Qualitative, quantitative \& mixed methods approaches (4th ed.). Thousand Oaks: Sage Publications.

Cropanzano, R., \& Mitchell, M. S. (2005). Social exchange theory: An interdisciplinary review. Journal of Management, 31, 874-900.

Dalal, R. S. (2005). A meta-analysis of the relationship between organizational citizenship behavior and counterproductive work behavior. Journal of Applied Psychology, 90, 1241-1255. doi:10.1037/0021-9010.90.6.1241

Dansereau Jr, F., Graen, G., \& Haga, W. J. (1975). A vertical dyad linkage approach to leadership within formal organizations: A longitudinal investigation of the role making process. Organizational Behavior and Human Performance, 13, 46-78.

Dillman, D. A., Phelps, G., Tortora, R., Swift, K., Kohrell, J., Berck, J., \& Messer, B. L. (2009). Response rate and measurement differences in mixed-mode surveys using mail, telephone, interactive voice response (IVR) and the internet. Social Science Research, 38, 1-18.

Dysvik, A. A. (2012). Perceived supervisor support climate, perceived investment in employee development climate, and business-unit performance. Human Resource Management, 51, 651-664.

Eckerd, S., Hill, J., Boyer, K. K., Donohue, K., \& Ward, P. T. (2013). The relative impact of attribute, severity, and timing of psychological contract breach on behavioral and attitudinal outcomes. Journal of Operations Management, 31, 567-578. 
Eckerd, S., Hill, J., Boyer, K. K., Donohue, K., \& Ward, P. T. (2013). The relative impact of attribute, severity, and timing of psychological contract breach on behavioral and attitudinal outcomes. Journal of Operations Management; Journal of Operations Management, 31, 567-578.

Eisenberger, R., Cotterell, N., \& Marvel, J. (1987). Reciprocation ideology. Journal of Personality and Social Psychology, 53, 743-750.

Eisenberger, R., Fasolo, P., \& Davis-LaMastro, V . (1990). Perceived organizational support and employee diligence, commitment, and innovation. Journal of Applied Psychology, 75, 51-59.

Eisenberger, R., Huntington, R., Hutchison, S., \& Sowa, D. (1986). Perceived organizational support. Journal of Applied Psychology, 71, 500-507.

Eisenberger, R., Shoss, M. K., Karagonlar, G., Gonzalez-Morales, M. G., Wickham, R. E., \& Buffardi, L. C. (2014). The supervisor POS-LMX-subordinate POS chain: Moderation by reciprocation wariness and supervisor's organizational embodiment. Journal of Organizational Behavior, 35, 635-656.

Eisenberger, R., \& Stinglhamber, F. (2011). Perceived organizational support: Fostering enthusiastic and productive employees. American Psychological Association.

Eisenberger, R., Stinglhamber, F., Vandenberghe, C., Sucharski, I. L., \& Rhoades, L. (2002). Perceived supervisor support: Contributions to perceived organizational support and employee retention. Journal of Applied Psychology, 87, 565-573.

Elovainio, M., Kivimäki, M., Vahtera, J., Virtanen, M., \& Keltikangas-Järvinen, L. (2003). Personality as a moderator in the relations between perceptions of organizational justice and sickness absence. Journal of Vocational Behavior, 63, 379-395. doi:https://doi-org.ezproxy.fiu.edu/10.1016/S0001-8791(02)00058-1

Erdheim, J., Wang, M., \& Zickar, M. J. (2006). Linking the big five personality constructs to organizational commitment. Personality and Individual Differences, 41, 959-970.

Etikan, I., Musa, S. A., \& Alkassim, R. S. (2016). Comparison of convenience sampling and purposive sampling. American Journal of Theoretical and Applied Statistics, $5(1), 1-4$.

Etzioni, A. (1961). Complex organizations: A sociological reader Holt, Rinehart and Winston.

Eysenck, S. B., Eysenck, H. J., \& Barrett, P. (1985). A revised version of the psychoticism scale. Personality and Individual Differences, 6, 21-29. 
Forrest, S., Lewis, C. A., \& Shevlin, M. (2000). Examining the factor structure and differential functioning of the eysenck personality questionnaire revised-abbreviated. Personality and Individual Differences, 29, 579-588.

Francis, L. J., Brown, L. B., \& Philipchalk, R. (1992). The development of an abbreviated form of the revised eysenck personality questionnaire (EPQR-A): Its use among students in england, canada, the USA and australia. Personality and Individual Differences, 13, 443-449.

Freese, C., \& Schalk, R. (2008). How to measure the psychological contract? A critical criteria-based review of measures. South African Journal of Psychology, 38, 269286.

Freese, C., \& Schalk, R. (2008). How to measure the psychological contract? A critical criteria-based review of measures. South African Journal of Psychology, 38, 269286.

Gould, S. (1979). An equity-exchange model of organizational involvement. Academy of Management Review, 4, 53-62.

Gouldner, A. W. (1960). The norm of reciprocity: A preliminary statement. American Sociological Review, , 161-178.

Graen, G. B., \& Scandura, T. A. (1987). Toward a psychology of dyadic organizing. Research in Organizational Behavior, 9, 175-208.

Graen, G. B., Scandura, T. A., \& Graen, M. R. (1986). A field experimental test of the moderating effects of growth need strength on productivity. Journal of Applied Psychology, 71, 484-491.

Graen, G. B., \& Uhl-Bien, M. (1995). Relationship-based approach to leadership: Development of leader-member exchange (LMX) theory of leadership over 25 years: Applying a multi-level multi-domain perspective. The Leadership Quarterly, 6, 219247.

Graen, G., \& Cashman, J. F. (1975). A role-making model of leadership in formal organizations: A developmental approach. In J. G. Hunt, \& L. L. Larson (Eds.), Leadership frontiers (pp. 143-165). Kent, OH: Kent State University Press.

Graen, G., Novak, M. A., \& Sommerkamp, P. (1982). The effects of leader-member exchange and job design on productivity and satisfaction: Testing a dual attachment model. Organizational Behavior and Human Performance, 30, 109-131.

Green, S. B. (1991). How many subjects does it take to do a regression analysis? Multivariate Behavioral Research, 26, 499-510. 
Greller, M. M., \& Herold, D. M. (1975). Sources of feedback: A preliminary investigation. Organizational Behavior and Human Performance, 13, 244-256.

Guchait, P., Cho, S., \& Meurs, J. A. (2015). Psychological contracts, perceived organizational and supervisor support: Investigating the impact on intent to leave among hospitality employees in India. Journal of Human Resources in Hospitality \& Tourism, 14, 290-315.

Gunthert, K. C., Cohen, L. H., \& Armeli, S. (1999). The role of neuroticism in daily stress and coping. Journal of Personality and Social Psychology, 77, 1087-1100.

Guzzo, R., \& Berman, L. (1995). At what level of generality is psychological contract fulfilment best measured? Paper presented at the Academy of Management Meetings, Vancouver, August

Hackett, R. D., Bycio, P., \& Hausdorf, P. A. (1994). Further assessments of meyer and allen's (1991) three-component model of organizational commitment. Journal of Applied Psychology, 79, 15-23.

Hao Zhao, Wayne, S. J., \& Glibkowski, B. C. (2007). The impact of psychological contract breach on work-related outcomes: A meta-analysis. Personnel Psychology; Personnel Psychology, 60, 647-680.

Harkness, A. R., Tellegen, A., \& Waller, N. (1995). Differential convergence of selfreport and informant data for multidimensional personality questionnaire traits: Implications for the construct of negative emotionality. Journal of Personality Assessment, 64, 185-204.

Harrington, J. R., \& Lee, J. H. (2015). What drives perceived fairness of performance appraisal? exploring the effects of psychological contract fulfillment on employees' perceived fairness of performance appraisal in US federal agencies. Public Personnel Management, 44, 214-238.

Harris, T. (2014). Leader-member exchange (LMX) in context: How LMX differentiation and LMX relational separation attenuate LMX's influence on OCB and turnover intention. The Leadership Quarterly, 25, 314-328.

Hayes, A. F. (2012). . Lawrence, KS: University of Kansas.

Helena, D. C. T., \& Anderson, N. (1998). Changes in newcomers' psychological contracts during organizational socialization: A study of recruits entering the british army. Journal of Organizational Behavior, 19, 745-767. 
Hinkle, D. E., Oliver, J. D., \& Hinkle, C. A. (1985). How large should the sample be? part II-The one-sample case for survey research. Educational and Psychological Measurement, 45, 271-280.

Hom, P. W., Lee, T. W., Shaw, J. D., \& Hausknecht, J. P. (2017). One hundred years of employee turnover theory and research. Journal of Applied Psychology, 102, 530545 .

Hrebiniak, L. G. (1974). Effects of job level and participation on employee attitudes and perceptions of influence. Academy of Management Journal, 17, 649-662.

Jensen, J. M., Opland, R. A., \& Ryan, A. M. (2010). Psychological contracts and counterproductive work behaviors: Employee responses to transactional and relational breach. Journal of Business and Psychology, 25, 555-568.

John, O. P., Naumann, L. P., \& Soto, C. J. (2008). Paradigm shift to the integrative big five trait taxonomy. Handbook of Personality: Theory and Research, 3, 114-158.

Judge, T. A., \& Bono, J. E. (2001). Relationship of core self-evaluations traits-selfesteem, generalized self-efficacy, locus of control, and emotional stability - with job satisfaction and job performance: A meta-analysis. Journal of Applied Psychology, 86, 80-92.

Judge, T. A., Heller, D., \& Mount, M. K. (2002). Five-factor model of personality and job satisfaction: A meta-analysis. Journal of Applied Psychology, 87, 530-541.

Judge, T. A., \& Zapata, C. P. (2015). The person-situation debate revisited: Effect of situation strength and trait activation on the validity of the big five personality traits in predicting job performance. Academy of Management Journal, 58, 1149-1179.

Kampkötter, P. (2017). Performance appraisals and job satisfaction. The International Journal of Human Resource Management, 28, 750-774.

Karagonlar, G. G. (2016). Reciprocation wary employees discount psychological contract fulfillment psychological contract fulfillment. Journal of Organizational Behavior, $37,23-40$.

Kickul, J., Lester, S. W., \& Finkl, J. (2002). Promise breaking during radical organizational change: Do justice interventions make a difference? Journal of Organizational Behavior, 23, 469-488. doi:10.1002/job.151

Kim, K. Y., Eisenberger, R., \& Baik, K. (2016). Perceived organizational support and affective organizational commitment: Moderating influence of perceived organizational competence: Perceived organizational competence. Journal of Organizational Behavior, 37, 558-583. 
Klein, H. J., Becker, T. E., \& Meyer, J. P. (2012). Commitment in organizations: Accumulated wisdom and new directions Routledge.

Kottke, J. L., \& Sharafinski, C. E. (1988). Measuring perceived supervisory and organizational support. Educational and Psychological Measurement, 48, 10751079.

Kurtessis, J. N., Eisenberger, R., Ford, M. T., Buffardi, L. C., Stewart, K. A., \& Adis, C. S. (2017). Perceived organizational support: A meta-analytic evaluation of organizational support theory. Journal of Management, 43, 1854-1884.

Kuvaas, B., \& Dysvik, A. (2009). Perceived investment in employee development, intrinsic motivation and work performance. Human Resource Management Journal, 19, 217-236.

Lester, S. W., Turnley, W. H., Bloodgood, J. M., \& Bolino, M. C. (2002). Not seeing eye to eye: Differences in supervisor and subordinate perceptions of and attributions for psychological contract breach. Journal of Organizational Behavior, 23, 39-56.

Levinson, H. (1965). Reciprocation: The relationship between man and organization. Administrative Science Quarterly, 370-390.

Liden, R. C., \& Maslyn, J. M. (1998). Multidimensionality of leader-member exchange: An empirical assessment through scale development. Journal of Management, 24, 43-72.

Lynch, P. D., Eisenberger, R., \& Armeli, S. (1999). Perceived organizational support: Inferior versus superior performance by wary employees. Journal of Applied Psychology, 84, 467-483.

Macneil, I. R. (1985). Relational contract: What we do and do not know. Wisconsin Law Review, , 483-525. doi:10.1086/292419

March, J. G., \& Simon, H. A. (1958). Organizations. Wiley.

Mercurio, Z. A. (2015). Affective commitment as a core essence of organizational commitment : An integrative literature review. Human Resource Development Review, 14, 389-414.

Meyer, J. P., \& Allen, N. J. (1991). A three-component conceptualization of organizational commitment. Human Resource Management Review, 1, 61-89.

Meyer, J. P., Stanley, D. J., Jackson, T. A., McInnis, K. J., Maltin, E. R., \& Sheppard, L. (2012). Affective, normative, and continuance commitment levels across cultures: A meta-analysis. Journal of Vocational Behavior, 80, 225-245. 
Meyer, J. P., \& Allen, N. J. (1984). Testing the" side-bet theory" of organizational commitment: Some methodological considerations. Journal of Applied Psychology, $69,372-378$.

Meyer, J. P., \& Allen, N. J. (1997). Commitment in the workplace: Theory, research, and application, Sage.

Meyer, J. P., Allen, N. J., \& Gellatly, I. R. (1990). Affective and continuance commitment to the organization: Evaluation of measures and analysis of concurrent and time-lagged relations. Journal of Applied Psychology, 75, 710-720.

Meyer, J. P., Becker, T. E., \& Van Dick, R. (2006). Social identities and commitments at work: Toward an integrative model. Journal of Organizational Behavior: The International Journal of Industrial, Occupational and Organizational Psychology and Behavior, 27, 665-683.

Meyer, J. P., \& Parfyonova, N. M. (2010). Normative commitment in the workplace: A theoretical analysis and re-conceptualization. Human Resource Management Review, 20, 283-294.

Morrison, E. W., \& Robinson, S. L. (1997). When employees feel betrayed: A model of how psychological contract violation develops. Academy of Management Review, 22, 226-256.

Mount, M. K., Barrick, M. R., Scullen, S. M., \& Rounds, J. (2005). Higher-order dimensions of the big five personality traits and the big six vocational interest types. Personnel Psychology, 58, 447-478.

Mowday, R. T., Porter, L. W., \& Steers, R. M. (2013). Employee-organization linkages: The psychology of commitment, absenteeism, and turnover, Academic Press.

Mowday, R. T., Steers, R. M., \& Porter, L. W. (1979). The measurement of organizational commitment. Journal of Vocational Behavior, 14, 224-247.

Nasurdin, A. M., Hemdi, M. A., \& Guat, L. P. (2008). Does perceived organizational support mediate the relationship between human resource management practices and organizational commitment? Asian Academy of Management Journal of Accounting and Finance, 13, 15-36.

Ohana, M. (2016). Voice, affective commitment and citizenship behavior in teams: The moderating role of neuroticism and intrinsic motivation. British Journal of Management, 27, 97-115. doi:10.1111/1467-8551.12146 
O'Reilly, C. A., \& Chatman, J. (1986). Organizational commitment and psychological attachment: The effects of compliance, identification, and internalization on prosocial behavior. Journal of Applied Psychology, 71, 492-499.

Ozer, D. J., \& Benet-Martínez, V. (2006). Personality and the prediction of consequential outcomes. Annual Review of Psychology, 57, 401-421.

Panaccio, A., \& Vandenberghe, C. (2012). Five-factor model of personality and organizational commitment: The mediating role of positive and negative affective states. Journal of Vocational Behavior, 80, 647-658.

Porter, L. W., Steers, R. M., Mowday, R. T., \& Boulian, P. V. (1974). Organizational commitment, job satisfaction, and turnover among psychiatric technicians. Journal of Applied Psychology, 59, 603-609.

Porter, L. W., Pearce, J. L., Tripoli, A. M., \& Lewis, K. M. (1998). Differential perceptions of employers' inducements: Implications for psychological contracts. Journal of Organizational Behavior, 19, 769-782.

Rammstedt, B., Danner, D., Soto, C. J., \& John, O. P. (2018). Validation of the short and extra-short forms of the big five inventory-2 (BFI-2) and their german adaptations. European Journal of Psychological Assessment (EJPA), , 1-13. doi:10.1027/1015$5759 / \mathrm{a} 000481$

Reio Jr, T. G. (2010). The threat of common method variance bias to theory building. Human Resource Development Review, 9, 405-411.

Rhoades, L., Eisenberger, R., \& Armeli, S. (2001). Affective commitment of the organization: The contribution of perceived organizational support. Journal of Applied Psychology, 86, 825-836. doi:10.1037/0021-9010.86.5.825

Robinson, S. L., Kraatz, M. S., \& Rousseau, D. M. (1994). Changing obligations and the psychological contract: A longitudinal study. Academy of Management Journal, 37, 137-152. doi:10.2307/256773

Robinson, S. L., \& Wolfe Morrison, E. (2000). The development of psychological contract breach and violation: A longitudinal study. Journal of Organizational Behavior, 21, 525-546.

Robinson, S. L. (1996). Trust and breach of the psychological contract. Administrative Science Quarterly, 41, 574-599.

Robinson, S. L., \& Rousseau, D. M. (1994). Violating the psychological contract: Not the exception but the norm. Journal of Organizational Behavior, 15, 245-259. 
Rousseau, D. (1995). Psychological contracts in organizations: Understanding written and unwritten agreements. Thousand Oaks: Sage Publications, lnc.

Rousseau, D. M. (2000). ( No. 2).The Heinz School, Carnegie-Mellon University.

Rousseau, D. M. (1990). New hire perceptions of their own and their employer's obligations: A study of psychological contracts. Journal of Organizational Behavior, $11,389-400$.

Rousseau, D. M. (1998). The 'problem' of the psychological contract considered. Journal of Organizational Behavior, 19, 665-671.

Rousseau, D. M. (2011). The individual-organization relationship: The psychological contract in maintaining, expanding, and contracting the organization. In S. Zedeck (Ed.), APA handbook of industrial and organizational psychology, Vol. 3 (pp. 191220). Washington, D.C.: American Psychological Association. doi:Retrieved from http://dx.doi.org.ezproxy.fiu.edu/10.1037/12171-005

Rousseau, D. M., \& Tijoriwala, S. A. (1998). Assessing psychological contracts: Issues, alternatives and measures. Journal of Organizational Behavior, 19, 679-695.

Rousseau, D. D. M. (1989). Psychological and implied contracts in organizations. Employee Responsibilities and Rights Journal, 2, 121-139.

Sauermann, H., \& Roach, M. (2013). Increasing web survey response rates in innovation research: An experimental study of static and dynamic contact design features. Research Policy, 42, 273-286.

Scandura, T. A., \& Graen, G. B. (1984). Moderating effects of initial leader-member exchange status on the effects of a leadership intervention. Journal of Applied Psychology, 69, 428-436.

Schein, E. H. (2015). Organizational psychology then and now: Some observations. Annual Review of Organizational Psychology and Organizational Behavior, 2, 1-19.

Shanock, L. R., \& Eisenberger, R. (2006). When supervisors feel supported: Relationships with subordinates' perceived supervisor support, perceived organizational support, and performance. Journal of Applied Psychology, 91, 689695.

Shore, L. M., Bommer, W. H., Rao, A. N., \& Seo, J. (2009). Social and economic exchange in the employee-organization relationship: The moderating role of reciprocation wariness. Journal of Managerial Psychology, 24, 701-721. 
Shore, L. M., \& Tetrick, L. E. (1991). A construct validity study of the survey of perceived organizational support. Journal of Applied Psychology, 76, 637-643.

Shore, L. M., \& Wayne, S. J. (1993). Commitment and employee behavior: Comparison of affective commitment and continuance commitment with perceived organizational support. Journal of Applied Psychology, 78, 774-780.

Shoss, M. K., Eisenberger, R., Restubog, S. L. D., \& Zagenczyk, T. J. (2013). Blaming the organization for abusive supervision: The roles of perceived organizational support and supervisor's organizational embodiment. Journal of Applied Psychology, $98,158-168$.

Shuck, B., Reio, T. G. J., \& Rocco, T. S. (2011). Employee engagement: An examination of antecedent and outcome variables. Human Resource Development International, $14,427-445$.

Shuck, B., Twyford, D., Reio, T. G. J., \& Shuck, A. (2014). Human resource development practices and employee engagement: Examining the connection with employee turnover intentions. Human Resource Development Quarterly, 25, 239325.

Smidts, A., Pruyn, A. T. H., \& Van Riel, Cees B. M. (2001). The impact of employee communication and perceived external prestige on organizational identification. Academy of Management Journal, 44, 1051-1062.

Smith, A. (1761). The theory of moral sentiments, p. 139 (2nd ed.). London: A. Millar.

Soto, C. J., \& John, O. P. (2017). The next big five inventory (BFI-2): Developing and assessing a hierarchical model with 15 facets to enhance bandwidth, fidelity, and predictive power. Journal of Personality and Social Psychology, 113, 117-143.

Soto, C. J., \& John, O. P. (2017). Short and extra-short forms of the big five Inventory-2: The BFI-2-S and BFI-2-XS. Journal of Research in Personality, 68, 69-81.

Steers, R. M. (1977). Antecedents and outcomes of organizational commitment . Administrative Science Quarterly, 22, 46-56. doi:http://dx.doi.org.ezproxy.fiu.edu/10.2307/2391745

Stern, M. J., Bilgen, I., \& Dillman, D. A. (2014). The state of survey methodology. Field Methods: (Formerly Cultural Anthropology Methods), 26, 284-301.

Stinglhamber, F., \& Vandenberghe, C. (2003). Organizations and supervisors as sources of support and targets of commitment: A longitudinal study. Journal of Organizational Behavior, 24, 251-270. 
Suls, J., \& Martin, R. (2005). The daily life of the garden-variety neurotic: Reactivity, stressor exposure, mood spillover, and maladaptive coping. Journal of Personality, $73,1485-1510$.

Tehseen, S., Ramayah, T., \& Sajilan, S. (2017). Testing and controlling for common method variance: A review of available methods. Journal of Management Sciences, 4, 142-168.

Tekleab, A. G., \& Susan Taylor, M. (2003). Aren't there two parties in an employment relationship? antecedents and consequences of organization-employee agreement on contract obligations and violations. Journal of Organizational Behavior, 24, 585608 .

Tett, R. P., \& Meyer, J. P. (1993). Job satisfaction, organizational commitment, turnover intention, and turnover: Path analyses based on meta-analytic findings. Personnel Psychology, 46, 259-293.

Turnley, W. H., Bolino, M. C., Lester, S. W., \& Bloodgood, J. M. (2003). The impact of psychological contract fulfillment on the performance of in-role and organizational citizenship behaviors. Journal of Management, 29, 187-206.

Turnley, W. H., \& Feldman, D. C. (1999). A discrepancy model of psychological contract violations. Human Resource Management Review, 9, 367-386. doi:10.1016/S1053-4822(99)00025-X

Van Hiel, A., De Cremer, D., \& Stouten, J. (2008). The personality basis of justice: The five-factor model as an integrative model of personality and procedural fairness effects on cooperation. European Journal of Personality, 22, 519-539. doi:10.1002/per.691

Vecchio, R. P., \& Gobdel, B. C. (1984). The vertical dyad linkage model of leadership: Problems and prospects. Organizational Behavior and Human Performance, 34, 5 20 .

Watson, D., \& Clark, L. A. (1984). Negative affectivity: The disposition to experience aversive emotional states. Psychological Bulletin, 96, 465-490.

Watson, D., \& Hubbard, B. (1996). Adaptational style and dispositional structure: Coping in the context of the Five-Factor model. Journal of Personality, 64, 737-774.

Wayne, S. J., Shore, L. M., Bommer, W. H., \& Tetrick, L. E. (2002). The role of fair treatment and rewards in perceptions of organizational support and leader-member exchange. Journal of Applied Psychology, 87, 590-598. 
Wayne, S. J., Shore, L. M., \& Liden, R. C. (1997). Perceived organizational support and leader-member exchange: A social exchange perspective. Academy of Management Journal, 40, 82-111.

Worley, J. A. (2009). The survey of perceived organisational support: Which measure should we use? SA Journal of Industrial Psychology, 35, 112-116. doi:https://doi.org/10.4102/sajip.v35i1.754

Zhao, H., Wayne, S., Glibkowski, B., \& Bravo, J. (2007). The impact of psychological contract breach on work-related outcomes: A meta-analysis. Personnel Psychology, 60, 647-680. 


\section{APPENDICES}

Appendix A

\begin{tabular}{|c|c|}
\hline \multicolumn{2}{|c|}{$\begin{array}{ll}\text { STUDY QUESTIONNAIRE ITEMS } \\
\end{array}$} \\
\hline \multicolumn{2}{|l|}{ Moderator Variable 1} \\
\hline Neuroticism & I am someone who tends to feel depressed, blue \\
\hline Neuroticism & I am someone who is emotionally stable, not easily upset $(\mathrm{R})$ \\
\hline Neuroticism & I am someone who is relaxed, handles stress well $(\mathrm{R})$ \\
\hline Neuroticism & I am someone who feels secure, comfortable with self $(\mathrm{R})$ \\
\hline Neuroticism & I am someone who is temperamental, gets emotional easily \\
\hline \multicolumn{2}{|l|}{ Moderator Variable 2} \\
\hline Psychological Contract & $\begin{array}{l}\text { Almost all of the promises made by my employer during recruitment have been kept so far } \\
\text { (R) }\end{array}$ \\
\hline Psychological Contract & $\begin{array}{l}\text { I feel that my employer has come through in fulfilling the promises made to me when I } \\
\text { was hired }(\mathrm{R})\end{array}$ \\
\hline Psychological Contract & So far, my employer has done an excellent job of fulfilling its promises to me (R) \\
\hline Psychological Contract & I have not received everything promised to me in exchange for my contributions. \\
\hline Psychological Contract & $\begin{array}{l}\text { My employer has broken many of its promises to me even though I've upheld my side of } \\
\text { the deal }\end{array}$ \\
\hline Psychological Contract & $\begin{array}{l}\text { When I think about a promise not fulfilled by my employer, I believe that: 1)N/A, 2) there } \\
\text { was an honest misunderstanding between me and the employer regarding what the } \\
\text { organization would provide, 3) a situation beyond my employer's control made it } \\
\text { impossible to keep a promise to me, 4) my employer could have kept a promise to me, but } \\
\text { it chose not to }\end{array}$ \\
\hline \multicolumn{2}{|l|}{ Independent Variable 1} \\
\hline Perceived Organizational Support & My employer cares about my well-being \\
\hline Perceived Organizational Support & My employer cares about my opinions \\
\hline Perceived Organizational Support & My employer considers my goals and values \\
\hline Perceived Organizational Support & My employer cares about my general satisfaction at work \\
\hline Perceived Organizational Support & My employer is willing to help me when I need a special favor \\
\hline Perceived Organizational Support & My employer shows very little concern for me $(\mathrm{R})$ \\
\hline \multicolumn{2}{|l|}{ Independent Variable 2} \\
\hline Perceived Supervisor Support & My supervisor cares about my opinions \\
\hline Perceived Supervisor Support & My work supervisor really cares about my well-being \\
\hline Perceived Supervisor Support & My supervisor strongly considers my goals and values \\
\hline Perceived Supervisor Support & My supervisor shows very little concern for me $(\mathrm{R})$ \\
\hline \multicolumn{2}{|l|}{ Dependent Variable } \\
\hline Affective Commitment & I feel a strong sense of belonging to my organization \\
\hline Affective Commitment & I feel personally attached to my work organization \\
\hline Affective Commitment & I am proud to tell others I work at my organization. \\
\hline Affective Commitment & Working at my organization has a great deal of personal meaning to me \\
\hline Affective Commitment & I would be happy to work at my organization until I retire \\
\hline Affective Commitment & I really feel that problems faced by my organization are also my problems \\
\hline \multicolumn{2}{|l|}{ Demographic Items } \\
\hline What is your age? & $18-25,26-35,36-45,46-55,56-65,66+$ \\
\hline $\begin{array}{l}\text { With what ethnicity/race do you most } \\
\text { identify? }\end{array}$ & $\begin{array}{l}\text { Asian, Black or African American, Latin American or Caribbean, Native American, } \\
\text { White, Other }\end{array}$ \\
\hline $\begin{array}{l}\text { With what gender do you most } \\
\text { identify? }\end{array}$ & Female, Male, Other \\
\hline $\begin{array}{l}\text { What is the highest educational degree } \\
\text { achieved? }\end{array}$ & High School/GED, AA/AS, BA/BS, MA/MS, PhD/EdD, Other terminal degree \\
\hline $\begin{array}{l}\text { For how many years have you worked } \\
\text { for your present supervisor? }\end{array}$ & 1-11 months, $1-2$ years, $3-5$ years, 6 and over years \\
\hline $\begin{array}{l}\text { For how many years have you worked } \\
\text { for the organization? }\end{array}$ & 1-11 months, $1-2$ years, $3-5$ years, 6 and over years \\
\hline
\end{tabular}


Appendix B

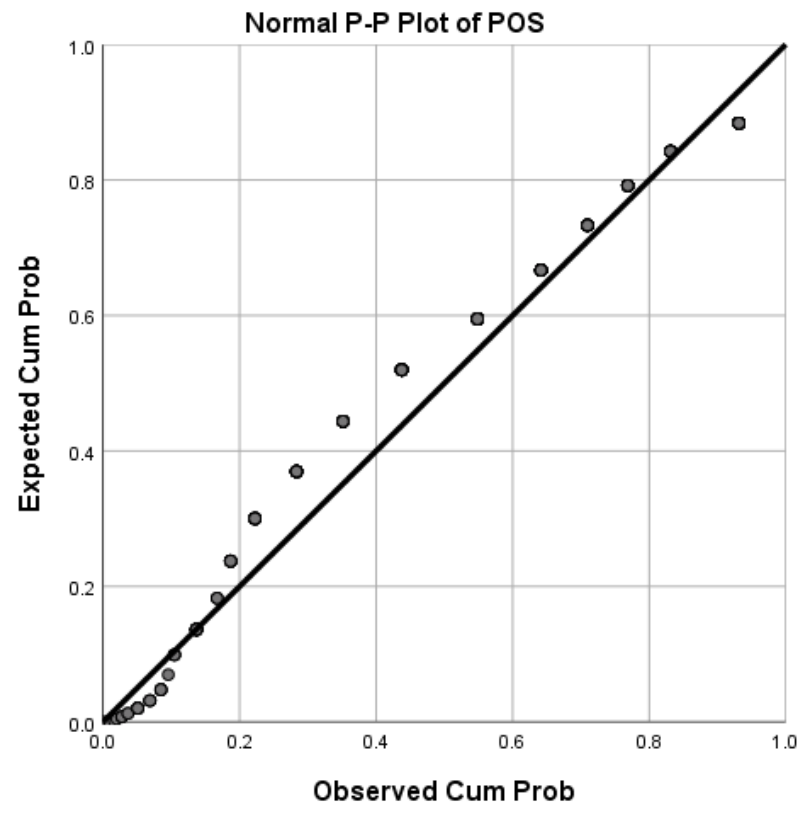


Appendix C

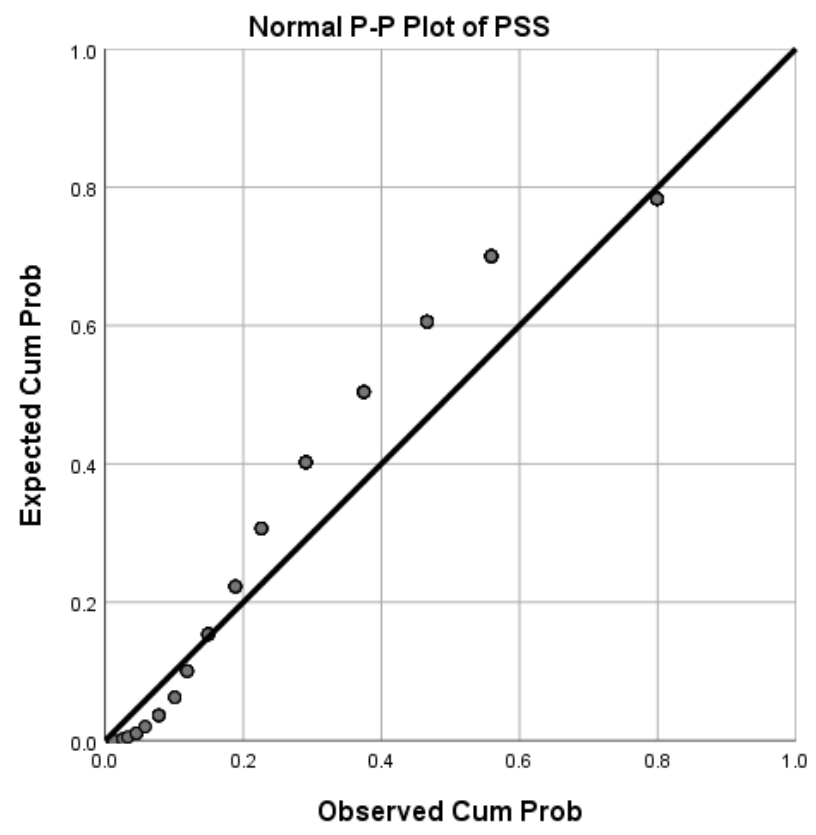


Appendix D

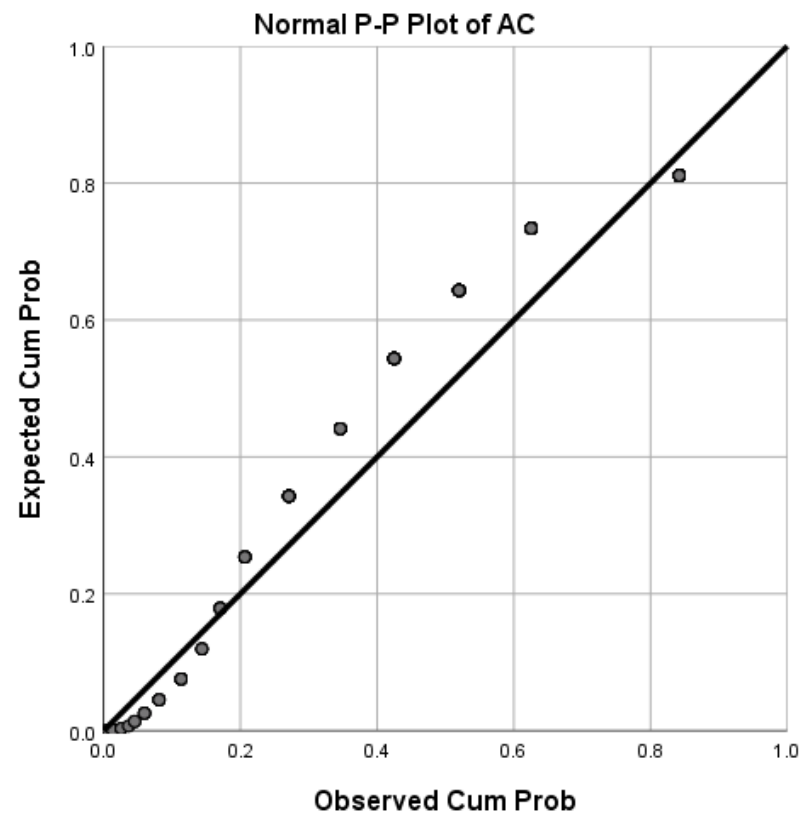


Appendix E

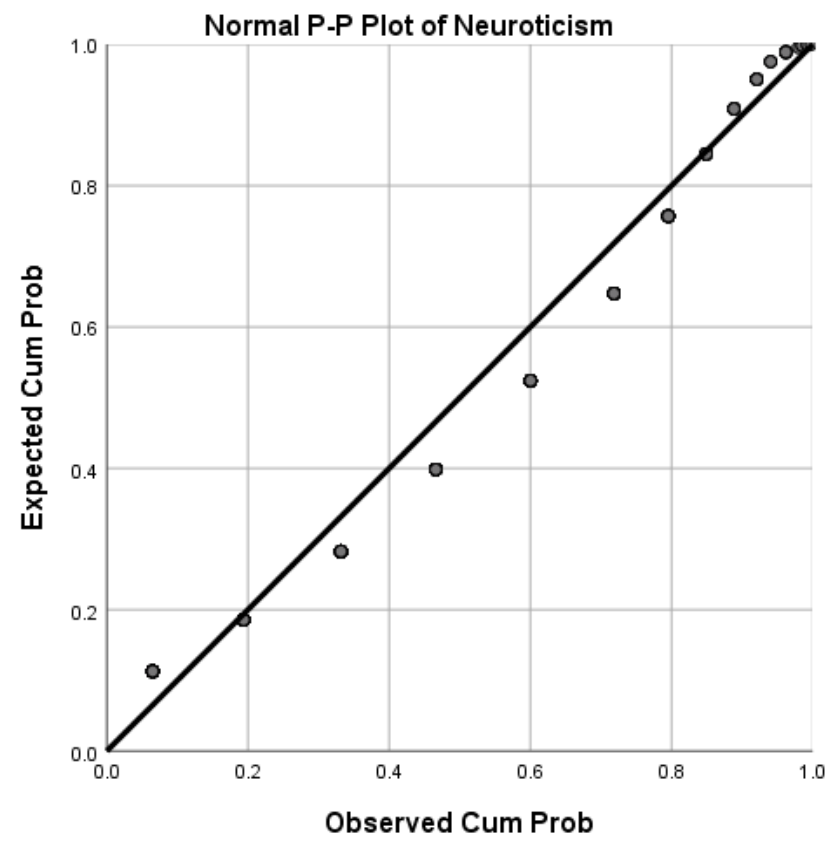


Appendix F

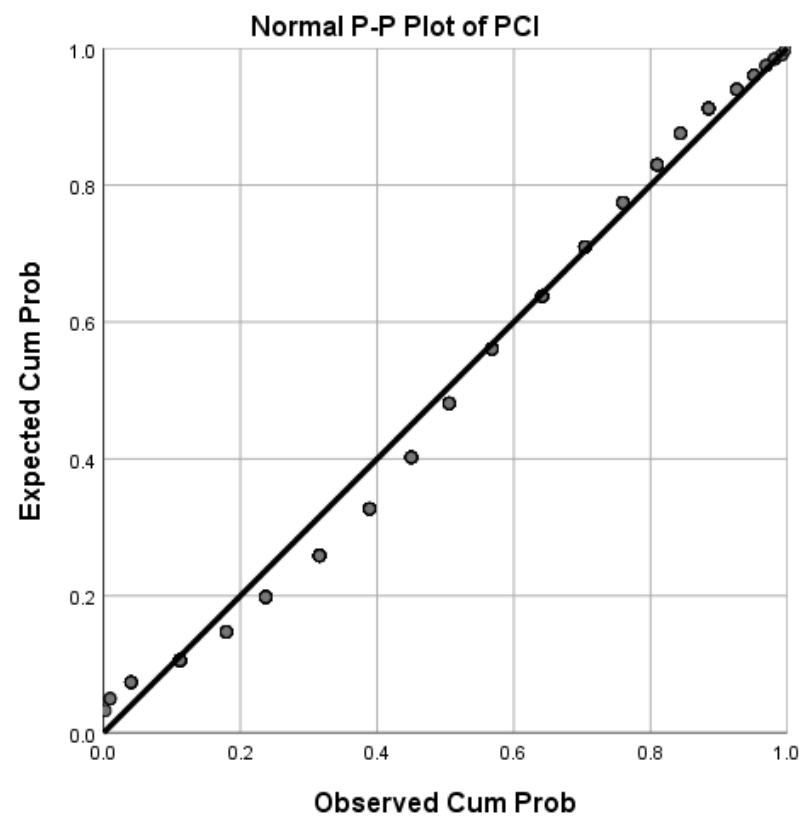




\section{Appendix G}

Multicollinearity Statistics and Scatterplot Results

\begin{tabular}{|c|c|c|c|c|c|c|c|c|}
\hline \multicolumn{9}{|c|}{ Coefficients $^{a}$} \\
\hline \multirow[b]{2}{*}{ Model } & & \multicolumn{2}{|c|}{ Unstandardized Coefficients } & \multirow{2}{*}{$\begin{array}{c}\text { Standardized } \\
\text { Coefficients } \\
\text { Beta }\end{array}$} & \multirow[b]{2}{*}{$t$} & \multirow[b]{2}{*}{ Sig. } & \multicolumn{2}{|c|}{ Collinearity Statistics } \\
\hline & & B & Std. Error & & & & Tolerance & VIF \\
\hline \multirow[t]{3}{*}{1} & (Constant) & 12.698 & 1.022 & & 12.421 & .000 & & \\
\hline & Pos & .379 & .048 & .511 & 7.857 & .000 & .636 & 1.573 \\
\hline & PSS & -.008 & .065 & -.008 & -.116 & .907 & .636 & 1.573 \\
\hline
\end{tabular}

a. Dependent Variable: $A C$

\begin{tabular}{|c|c|c|c|c|c|c|}
\hline \multirow[b]{3}{*}{ Model } & \multirow[b]{3}{*}{ Dimension } & \multicolumn{3}{|c|}{ Collinearity Diagnostics $^{a}$} & & \\
\hline & & \multirow[b]{2}{*}{ Eigenvalue } & \multirow{2}{*}{$\begin{array}{c}\text { Condition } \\
\text { Index }\end{array}$} & \multicolumn{3}{|c|}{ Variance Proportions } \\
\hline & & & & (Constant) & POS & PSS \\
\hline \multirow[t]{3}{*}{1} & 1 & 2.955 & 1.000 & .00 & .00 & .00 \\
\hline & 2 & .026 & 10.631 & .97 & .10 & .30 \\
\hline & 3 & .019 & 12.513 & .03 & .89 & .69 \\
\hline
\end{tabular}

a. Dependent Variable: $A C$

Normal P-P Plot of Regression Standardized Residual

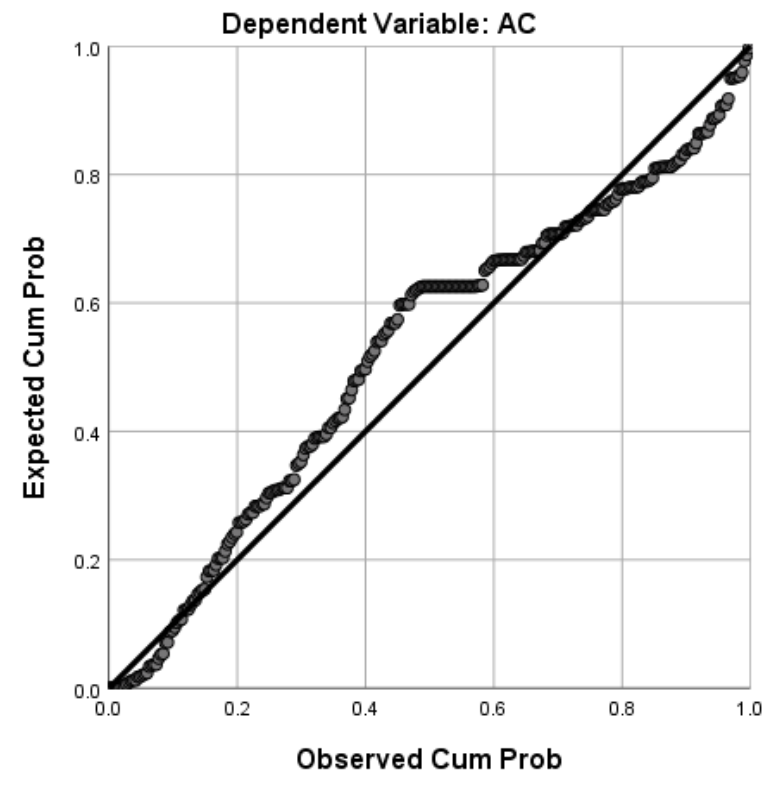




\section{Appendix $\mathrm{H}$}

Homoscedasticity Scatterplot of Standardized Residuals AC - POS

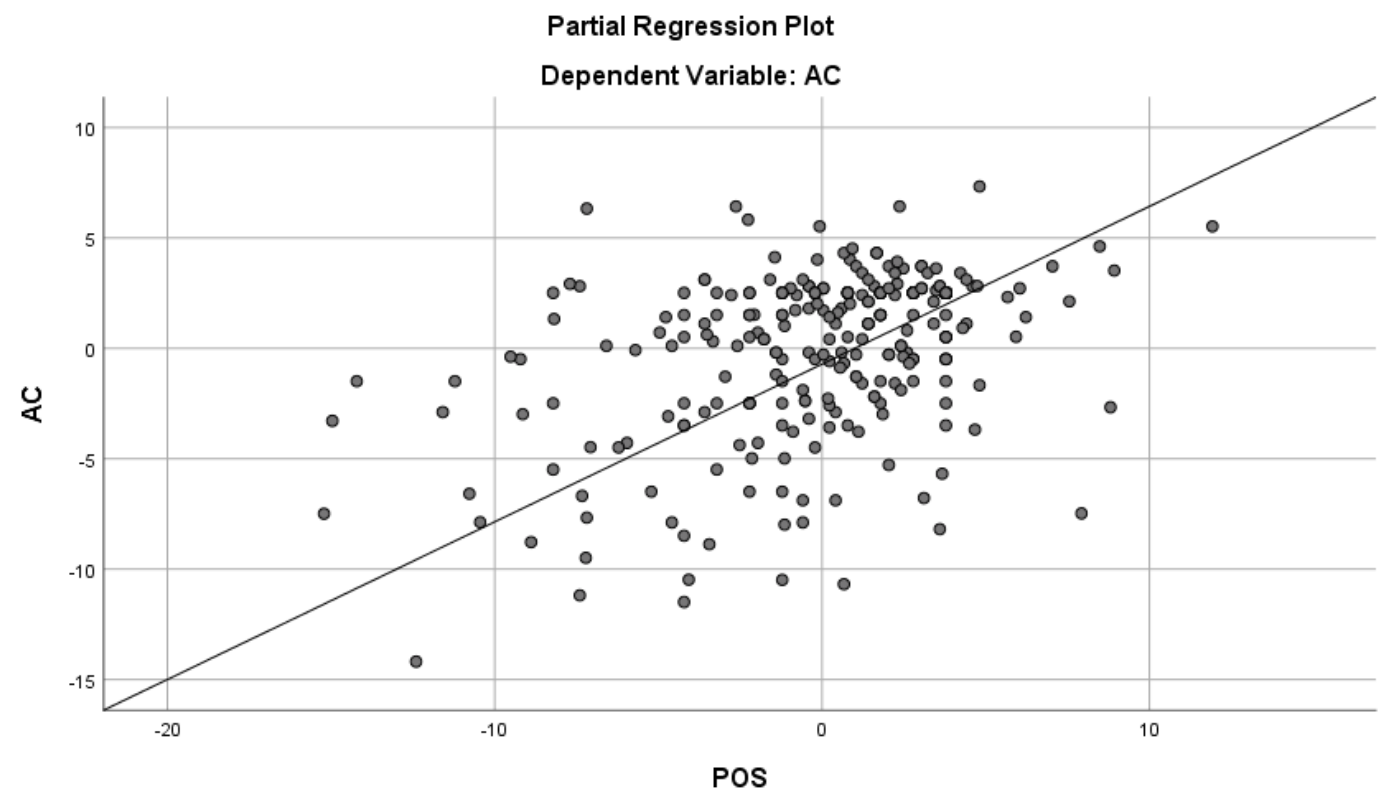


Appendix I.

Homoscedasticity Scatterplot of Standardized Residuals AC - PSS

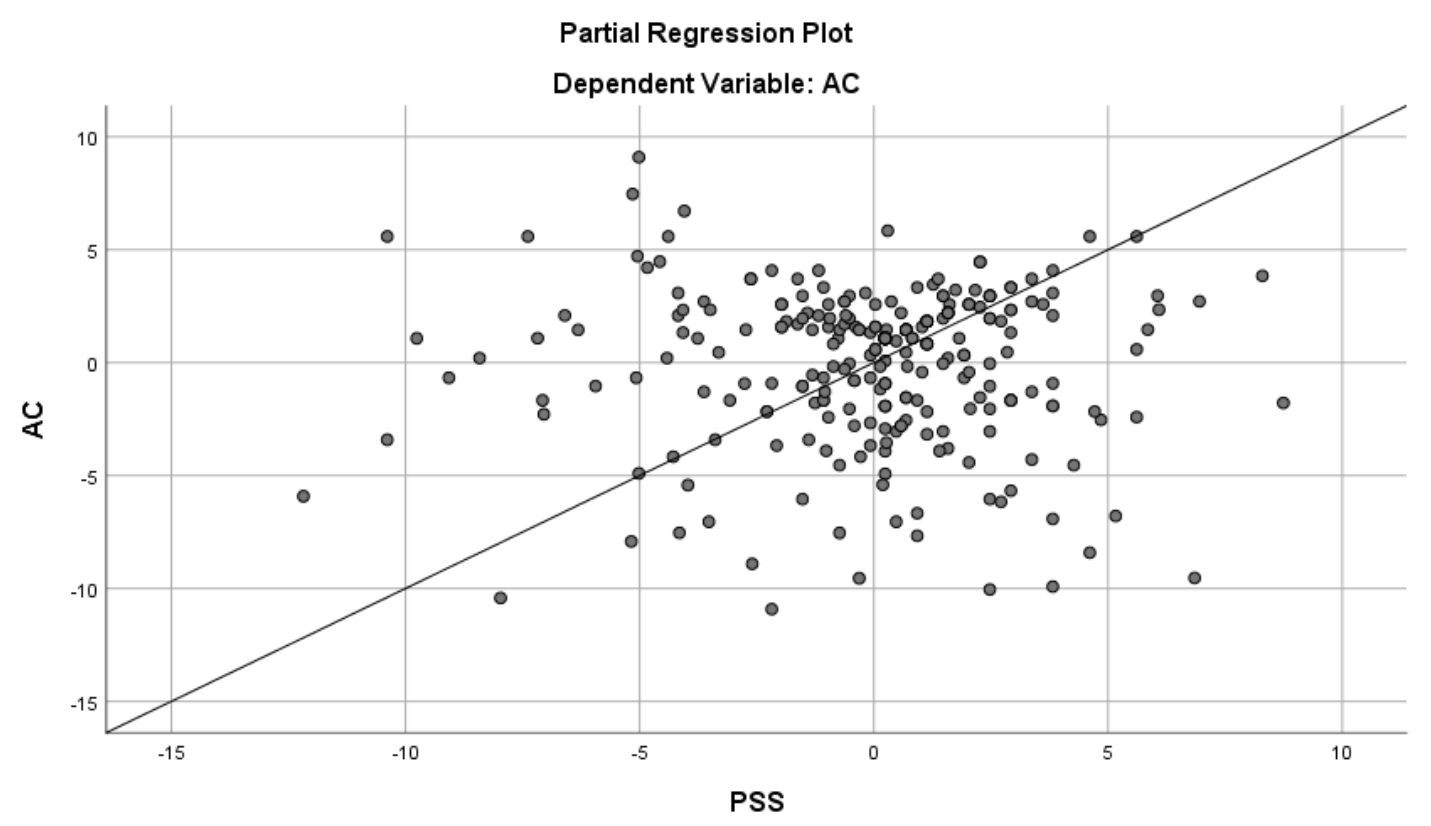


VITA

\title{
GAIL HANSEN
}

Born, Miami, Florida

\author{
1975-1978 \\ B.A., English \\ Florida International University \\ Miami, Florida \\ $1977-1984$ \\ Manager, Instructional Design \\ Ryder System, Inc. \\ Miami, Florida \\ $1978-1980$ \\ M. S., Adult Education \\ Florida International University \\ Miami, Florida \\ $1984-1987$ \\ Principal Consultant \\ Corporate Training Support Services \\ Miami, Florida \\ $1987-1990$ \\ Senior Vice President, Strategic Planning \\ City National Bank, Inc. \\ Miami, Florida \\ $1990-1995$ \\ Director of Training \\ Royal Caribbean Cruises International \\ Miami, Florida \\ $1995-1997$ \\ Director of Training \\ Sunglass Hut International \\ Miami, Florida \\ $1997-2008$ \\ Senior Vice President and Chief Learning Officer \\ SunTrust Bank, Inc. \\ Atlanta, Georgia \\ $2005-2008$ \\ $2008-2009$ \\ American Society of Training and Development \\ Public Policy Council \\ Alexandria, Virginia \\ Principal Consultant \\ Real Learning Solutions \\ Alpharetta, Georgia
}


$2009-2013$

Vice President, Learning

Fifth Third Bank, Inc.

Cincinnati, Ohio

2013 - Present

Director of Talent Acquisition and Management

Florida International University

Miami, Florida

2015 - Present

Adjunct Instructor, Global Leadership and Management

Florida International University

College of Business

Miami, Florida

$2018-2020$

Doctoral Candidate

Florida International University

Miami, Florida

\section{PUBLICATIONS AND PRESENTATIONS}

ASTD 2012 International Conference and Exposition, Keynote Speaker, International Pre-Conference Orientation, Conference Closing,

Training \& Development Magazine, June 2008 Issue, It's Branding Time at the Learning Corral.

ASTD International Conf. and Expo, June 2007, Developing a Sustainable Leadership Development Function.

IQPC Corporate University Summit Keynote: Practical Case Study of Online Leadership Development, October 2007.

Conference Founder and Chair, Managing the Business of Learning, American Bankers Association.

Consultant, Enterprise Ireland, Dublin, Ireland, Provided consultation to Irish software and services companies regarding market entry strategies for compliance e-learning in US financial services, 2005. 